\title{
Observed Evidences of Frequency-Dependent Site Spectral Amplification due to Strong Structural Control of Active Reverse Faults at Different Three Localities in Japan
}

Mostafa Thabet ( $\sim$ mostafa.thabet@aun.edu.eg )

Assiut University Faculty of Science https://orcid.org/0000-0001-5856-6064

\section{Research Article}

Keywords: Fault zone, Guided waves, Site response, Fourier spectrum, Spectral ratio, KiK-net and K-NET (Japan).

Posted Date: July 26th, 2021

DOI: https://doi.org/10.21203/rs.3.rs-606889/v1

License: (c) (1) This work is licensed under a Creative Commons Attribution 4.0 International License. Read Full License 


\section{${ }_{1}$ Observed Evidences of Frequency-Dependent Site Spectral Amplification}

\section{Due To Strong Structural Control of Active Reverse Faults at Different}

\section{Three Localities in Japan}

4

5

6

7

8

9

10

11

12

13

14

15

16

17

18
Mostafa Thabet ${ }^{1,2, *}$

${ }^{1}$ Lecturer, Geology Department, Faculty of Science, Assiut University, Assiut 71516, Egypt

${ }^{2}$ M.Sc. and Ph.D., Geoscience Division, Graduate School of Science, Osaka City University, Osaka, Japan

*Corresponding Author,

E-mail: mostafa.thabet@aun.edu.eg

Web: http://www.aun.edu.eg/membercv.php?M\%20ID=422

https://scholar.google.com/citations?user=wPsYhrMAAAAJ\&hl=en

http://www.researchgate.net/profile/Mostafa_Thabet2

ORCID ID: 0000-0001-5856-6064

Scopus Author ID: 23101743600

Tel: (002) - 01275134332 (mobile) and (002) - $088-2412223$ (work)

Fax: (002) - $088-2342223$ (work) 


\section{Abstract}

20 In the present study, observed active fault zone related site amplification is calculated based on Fourier

21 acceleration spectrum (FAS) at three different localities in Japan. For this purpose, the FASs are

22 calculated using 26432 earthquakes recorded at 126 K-NET and KiK-net seismic stations, which are

23 distributed on the fault zones and upthrown and downthrown sides. This observed amplification is

24 strongly frequency-dependent because of the presence of the near-surface low-velocity flower fault

25 structure and the deeper fault zone. Moreover, the amplification patterns at each study area are

26 tectonic-specific patterns. Sources inside the active fault zones could produce amplification at high

27 frequencies at stations on both fault zone and far away from the fault zone. This is because of the

28 impact of the near-surface fault zone. Sources outside the active fault zones could not produce

29 significant amplification at high frequencies, whereas remarkable high amplification at low

30 frequencies exhibits a gradual increase through stations on hanging walls, fault zones, and footwalls.

31 Remarkably, low-frequency amplification due to sources outside the active fault zones at stations on

32 footwalls is much higher than those observed on hanging walls. Interestingly, the peaks of the low-

33 frequency amplification are corresponding to wavelengths that approximately equalize the width of the

34 fault zone. Diffuse field theory inversion using earthquake horizontal-to-vertical spectral ratio

35 (EHVSR) could successfully detect the presence of fault zone low-velocity layers. However, analyzing

36 the fault zone related site effects using HVSR is not effective because of the strong amplification

37 related structural control of the active fault zones on the ground motions.

Keywords: Fault zone, Guided waves, Site response, Fourier spectrum, Spectral ratio, KiK-net and KNET (Japan). 
42

43 Because many industrial and/or metropolitan areas are built on alluvial fans or basins, a correct

44 quantification of the local site effects is necessary for a systematic and robust assessment of seismic

45 hazards due to the direct relation with significant seismic damage and consequent loss of life. The

46 amplification of an earthquake signal at a site plays a significant role in increasing seismic damage.

47 The seismic site response due to fault zones has important implications on earthquake hazard on a

48 local scale causing amplified motions near faults due to guided waves. Valuable research works by Li

49 et al. (1994) and Li and Leary (1990) on fault zone guided waves due to the San Andreas Fault zone

50 grow attention to this issue. Constructive interference between reflected seismic waves is responsible

51 for generating highly amplified fault zone guided waves and later arrivals of dispersive energy after

52 S-waves (Igel et al. 1997; Ben-Zion and Aki 1990). Fault gouge, clay-rich fault gouge, fracturing,

53 increased porosity, remineralization, crack dilatation, and pore-fluid concentration near fault zones

54 are the possible causes for this low-velocity zone (Thurber 1983; Cormier and Spudich 1984;

55 Mooney and Ginzburg 1986; Li and Leary 1990; Ben-Zion 1998; Ben-Zion and Sammis 2003;

56 Hickman et al. 2005).

57

58 Recently, studies by Peruzza et al. (2017) and Tortorici et al. (2019) were focused on analyzing the 59 site effects due to the presence of fault zones. Ground motion amplification of directional effects 60 along polarized horizontal component could be observed because of active faults and extended 61 fractures (e.g. Spudich et al., 1996). These directional effects are observed on horizontal amplitude 62 variations versus azimuth of fault zones (Rigano et al., 2008; Pischiutta et al., 2015; Panzera et al., 63 2017a) indicating S-wave velocity anisotropy (i.e. fast $S$-waves are parallel to fault zone, whereas the 64 slow $S$-waves are normal causing high amplification). 
66 Many researchers such as Rigano et al. (2008), Di Giulio et al. (2009), Pischiutta et al. (2012, 2013,

67 2015, 2017), Panzera et al. (2014, 2016a, 2016b, 2017a, 2017b), Burjánek et al. (2012), Panzera et al.

68 (2019), Tortorici et al. (2019), and Kakhki et al. (2020) used the horizontal-to-vertical spectral ratios

69 (HVSR) of earthquake and ambient vibration data to reveal the site effects related to fault zones.

70 They observed systematic directional amplification normal to the dominant fault strike. Panzera et al.

71 (2020) studied the site effects considering tectono-stratigraphic setting of the Santa Caterina area in

72 Italy and observed maximum directional HVSR amplification of 8 in the perpendicular azimuth of the

73 dominant N-S fracture zone. In contradict to these studies, Villani et al. (2018) did not observe any

74 significant directional effects through their geophysical investigation at the Victoria fault in Malta.

75 They interpreted their results because of the present inactivity in the fault zone, which is expressed in

76 terms of $\sim 0.6 \mathrm{Myr}$ ago. Pischiutta et al. (2017) found a predominant high horizontal amplification in

77 the NE-SW to NNE-SSW direction (i.e. fault perpendicular direction) across the Vado di Corno fault

78 in Italy, which is considered as active normal faults during the L'Aquila 2009 earthquake. Di Giulio et

79 al. (2009) conducted dense microtremor measurements along and across the intensely fractured zones

80 of the Pernicana fault, Mount Etna, Italy. They observed strong directional horizontal amplification at

$811 \mathrm{~Hz}$ close to the highly fractured zone.

82

83 The existence of seismic stations across the fault provides a good opportunity in identifying these 84 guided waves. According to studies by Igel et al. (2002), Jahnke et al. (2002), and Fohrmann et al. 85 (2004), moderate variations of fault zone properties could produce guided waves. Seismogenic depths

$86>10 \mathrm{~km}$ could act as fault zone waveguide according to studies by Li et al. (1997, 2000, and 2004),

87 Li and Vernon (2001), Korneev et al. (2003), Mizuno et al. (2004), and Mizuno and Nishigami 
89 Rovelli et al. (2002), Peng et al. (2003), and Lewis et al. (2005) proved significant trade-offs between

90 propagation distance along the fault zone, fault zone width, impedance contrasts between massive and

91 damaged rock, and source location. Fault zone-related site effects are extensively studied by many

92 researchers in fault zone stations due to sources not necessarily in the fault zone. Li and Leary (1990)

93 and Li et al. $(1990,1997)$ used a small number of selected waveforms to study the fault zone guided

94 waves due to $100 \mathrm{~m}$ wide of low-velocity fault zone extending to the seismogenic depth. In

95 California, 1500 weak ground motions on fault zone arrays were studied by Li and Vernon (2001).

96 Shallow fault zone could behave as a waveguide due to very deep ground motions and far from the

97 fault zone (Jahnke et al. 2002; Igel et al. 2002; Fohrmann et al. 2004). Roux et al. (2016) and Ben-

98 Zion et al. (2015) used spatially high dense seismic array (i.e. 1108 vertical geophones, with

99 instrument spacing of $10 \mathrm{~m}$ to $30 \mathrm{~m}$ and sampling interval of $200 \mathrm{~Hz}$ ) to study the structural image of

100 the subsurface material in the damage zone of the San Jacinto fault in California.

101

102 The role of active fault zones in affecting the earthquake hazard estimation is playing an important 103 role in evaluating the seismic risk analyses. In Japan, a comprehensive database of active faults is 104 provided by the National Institute of Advanced Industrial Science and Technology (AIST: 105 https://gbank.gsj.jp/activefault/index_e_gmap.html, last accessed January 2021). These active faults 106 are subdivided into several strands and characterized by their surface trace geometry, rupture history, 107 slip per event, slip rate, calculated future rupture probability, and recurrence interval. These 108 characteristics are evaluated based on paleoseismic and geologic studies. To improve the database 109 system, all these characteristics are compiled based on previous studies, such as, Matsubara and 110 Obara (2011), Nishida et al. (2008), Matsubara et al. (2008), Nakamura et al. (2008), Abdelwahed 
111 and Zhao (2007), Nakajima and Hasegawa (2007a, b, and c), Kato et al. (2006), Nakajima et al.

112 (2001), Zhao et al. (1996), to cite few among many others. Therefore, the present research work is

113 originated based on the AIST database of active faults in Japan.

115 Motivated by these aforementioned valuable previous studies and the valuable AIST database of

116 active faults, the present research work is established taking into account that strong variation in

117 amplitude and frequency content of surface ground motions are strongly related to fault zone's

118 geometry and seismic properties at depth. The present study is reported observed evidence of active

119 reverse fault zone-related site spectral characteristics at three different localities in Japan using 26432

120 earthquakes recorded at $126 \mathrm{~K}-\mathrm{NET}$ and KiK-net seismic stations. The spectral characteristics of the

121 ground motions on the footwall (i.e. downthrown wall), fault zone, and the hanging wall (i.e.

122 upthrown wall) are investigated by the Fourier acceleration spectrum of the surface orthogonal

123 components, the HVSR, and the surface-to-borehole spectral ratio. Comparisons among these

124 techniques are also implemented as a procedure for identifying and analyzing site spectral

125 amplifications. Considering that reverse faults at those three different localities in Japan have similar

126 main fault strike, the resulted site spectral amplifications could be possibly inferred to the dominant

127 fault dip, the dominant frequency caused by the fault zone width, and the different fracture patterns

128 due to the existence of a dense network of minor and major active faults, and the seismic properties of

129 the fault zone ( $P$-wave and $S$-wave velocities, Poisson's ratio, and perturbation velocities). 


\section{Tectonic Patterns and Subsurface Tomography}

134 In this study, active reverse faults with a predominant strike of north-south are studied. The study areas of this work (Figure 1) are located in East Hokkaido, Akita-Iwate, and Fukushima in Japan.

137 The East Hokkaido active reverse faults, which are showing arc-shaped alignment, are composed of

138 four major behavioral segments, including Shihoro, Otofuke, Tobetsugawa, and Kochien segments 139 (Figure 2). The first three behavioral segments (i.e. Shihoro, Otofuke, and Tobetsugawa) are trending 140 eastwards dipping reverse faults (dip azimuth/dip angle $=\mathrm{N} 10 / 30^{\circ}, \mathrm{N} 0 / 30^{\circ}$, and $\mathrm{N} 0 / 30^{\circ}$, respectively) 141 along the eastern side of the Tokachi Plain in central Hokkaido. The fourth behavioral segment (i.e.

142 Tobetsugawa) is trending northeastwards dipping reverse fault (dip azimuth/dip angle $=\mathrm{N} 330 / 45^{\circ}$ ) 143 along the eastern side of the Hidaka Mountains in central Hokkaido. The maximum slip rate is 144 belonging to Shihoro behavioral segment, is estimated based on the vertical displacement of dated 145 terrace surfaces (Togo 2000) at $0.4 \mathrm{~m}$ over about 1000 years with $7.2 \mathrm{~m}$ slip per event. Table 1 is 146 showing detailed characteristics of these behavioral segments as obtained from AIST (2012, 2013).

148 The active reverse fault system in the Akita-Iwate study area is composed of a set of several en149 echelon behavioral segments (Figure 3). Those behavioral segments of this active reverse fault 150 system have their footwall blocks (i.e. downthrown sides) located on the right and left sides of the 151 study area, whereas their hanging wall blocks (i.e. upthrown sides or the main fault zone) located in 152 the center of the study area. As a result, the reverse fault system in the Akita-Iwate study area could 153 be considered as a horst fault system. However, this active reverse fault system in the Akita-Iwate 154 study area could be accommodated in three major parallel active reverse fault stands. The first major 
155 fault stand is composed of Ukai, Hanamaki, and Kitakami-nishi behavioral segments and are trending 156 westwards dipping reverse fault (dip azimuth/dip angle $=\mathrm{N} 10 / 45^{\circ}, \mathrm{N} 10 / 45^{\circ}$, and $\mathrm{N} 350 / 45^{\circ}$, 157 respectively) along the western margin of the Kitakami Basin in northern Honshu. The second is 158 composed of Shizukuishibonchi-seien, Kawafune, and Warikurayama behavioral segments. 159 Shizukuishibonchi-seien reverse fault is trending westwards dipping (dip azimuth/dip angle = $160 \mathrm{~N} 10 / 45^{\circ}$ ) along the western margin of the Shizukuishi Basin in northern Honshu. Kawafune has NNE161 SSW trending westwards dipping reverse fault (dip azimuth/dip angle $=\mathrm{N} 20 / 45^{\circ}$ ) along the eastern 162 margin of the Mahiru Mountains in northern Honshu. This fault is ruptured because of the 1896 163 Rikuu earthquake. Warikurayama is trending westwards dipping reverse fault (dip azimuth/dip angle $164=\mathrm{N} 0 / 45^{\circ}$ ) along the eastern margin of the Mahiru Mountains in northern Honshu. The third is 165 composed of Tazawako-toho, Senya, Kanazawa, and Omoriyama behavioral segments and are 166 trending eastwards dipping reverse fault (dip azimuth/dip angle $=\mathrm{N} 0 / 45^{\circ}, \mathrm{N} 10 / 30^{\circ}, \mathrm{N} 0 / 45^{\circ}$, and $167 \mathrm{~N} 350 / 45^{\circ}$, respectively). Tazawako-toho segment extends along the eastern shore of Lake Tazawa in 168 northern Honshu, whereas Senya, Kanazawa, and Omoriyama segments are extending along the 169 eastern margin of the Yokote Basin in northern Honshu. Tazawako-toho and Senya segments are also 170 ruptured because of the 1896 Rikuu earthquake. Senya and Hanamaki behavioral segments exhibit 171 the highest slip rate at $0.8 \mathrm{~m}$ over about 1000 years and the highest slip per event of $4.9 \mathrm{~m}$, 172 respectively. Table 2 is summarizing the characteristics of these behavioral segments as obtained 173 from AIST $(2012,2013)$. Moreover, sub-parallel active reverse faults stands are located westwards in 174 the Akita-Iwate study area. They are composed of Takinosawa and Nakacho segments and are 175 trending westwards dipping reverse fault (dip azimuth $/$ dip angle $=\mathrm{N} 0 / 45^{\circ}$ and $\mathrm{N} 20 / 45^{\circ}$, respectively), 176 whereas Toridame and Kitayuri segments and are trending eastwards dipping reverse fault with dip 177 azimuth/dip angle $=\mathrm{N} 0 / 45^{\circ}$. 
179 Fukushima's active fault system is composed of two sets of behavioral segments (Figure 4). Along 180 the eastern margin of the Abukuma Mountains in northern Honshu, Watari and Namie segments are 181 trending westwards dipping reverse fault with dip azimuth/dip angle $=\mathrm{N} 350 / 80^{\circ}$, while Haramachi 182 and Sangunmori segments are trending left-lateral strike-slip faults with vertical displacement of 183 west-side-up and east-side-up, respectively. Table 3 is showing detailed characteristics of these 184 behavioral segments as obtained from AIST $(2012,2013)$.

Understanding the physical properties of the subsurface structure of these large active reverse faults is 187 an important step towards the understanding of the related site effects on those faults. AIST provides 188 physical property in two dimension subsurface structures, such as velocities of $P$-wave and $S$-wave, 189 Poisson's ratio, and perturbation velocities of $P$-wave and $S$-wave, through their subsurface structures 190 visualization system. In this research work, these physical property structures beneath the 191 aforementioned active reverse faults are created and viewed for the profiles, which are selected 192 beforehand in each study area. In the present paper, the velocities of $P$-wave and $S$-wave beneath the 193 selected profiles are depending on the valuable study by Nakamura et al. (2008).

195 Profile AB in the East Hokkaido study area is shown in Figure 5. The active reverse fault, which is 196 dipping eastwards, extends to $30 \mathrm{~km}$ depth with Poisson's ratio of 2.2 , and $P$-wave and $S$-wave 197 velocities of 5.5 and $3 \mathrm{~km} / \mathrm{s}$, respectively. The intensely damaged and fractured fault material 198 compared with the high velocities of massive surrounding rocks (footwall and hanging wall blocks) 
are indicated by lower velocity perturbations of $P$-wave and $S$-wave $(\sim 8 \%$ lower than the initial

200 velocity structures).

201

202 In the Akita-Iwate study area, CD and EF profiles are created and viewed using AIST's visualization 203 system for subsurface structures based on Nakamura et al. (2008). The subsurface structures at CD 204 and EF profiles are shown in Figure 6 and Figure 7, respectively. In profile CD, the reverse faults 205 dipping eastwards, which are represented in reduced physical property, are seen particularly in the 206 subsurface structures of $P$-wave velocity perturbations, whereas westwards dipping reverse faults are 207 losing their reduced physical property evidence. Conversely, the reverse faults dipping westwards are 208 seen in profile EF when compared with reverse faults dipping eastwards that are losing their reduced 209 physical property evidence. This lateral discontinuity reveals that Akita-Iwate's fault system is 210 undergoing a significant activity.

212 At profile $\mathrm{GH}$ in the Fukushima study area, the subsurface structures of $P$-wave and $S$-wave 213 velocities, Poisson's ratio, and perturbation of $P$-wave and $S$-wave velocities are created and viewed 214 in Figure 8 and Figure 9 based on Nakamura et al. (2008) and Nakajima et al. (2001), respectively. 215 The reduced physical property in this active fault system could not be exhibited as seen in the East 216 Hokkaido active fault system. This could be related to two reasons. First, the currently active fault 217 trace could accommodate a maximum slip rate that is estimated at $0.1 \mathrm{~m}$ over about 1000 years with $218 \quad 2.4 \mathrm{~m}$ slip per event. Second, Fukushima active fault system might be young. Consequently, this lack 219 of reduced physical properties has occurred clearly across the entire fault zone in the Fukushima 220 study area. 


\section{3. Data and Methods}

222 To study site spectral amplification across and along active reverse faults at the aforementioned three 223 different localities in Japan, K-NET and KiK-net database (https://www.kyoshin.bosai.go.jp, last 224 accessed, January 2020) is used. Dense seismic stations of K-NET and KiK-net are present at those 225 three different localities of the present study, which are the East Hokkaido, Akita-Iwate, and 226 Fukushima study areas (Figure 1).

227

228 Location maps of K-NET and KiK-net seismic stations in the East Hokkaido, Akita-Iwate, and 229 Fukushima study areas are shown in Figure 2, Figure 3, and Figure 4, respectively. Those stations 230 located on the footwall (FW) block are differentiated from those located on the hanging wall (HW) 231 block. Few stations are distributed on the surface of the fault zone (FZ) at the East Hokkaido and 232 Akita-Iwate study areas, whereas no stations at all are distributed on the FZ in the Fukushima study 233 area. Accordingly, earthquakes recorded at these stations are also classified based on the locations of 234 their hypocenters. They are earthquakes having their hypocenters beneath footwall (EFWs), fault 235 zone (EFZs), hanging wall (EHWs) blocks.

237 A total of manually selected 126 seismic stations, which are maintained by K-NET and KiK-net, are 238 distributed on FW, FZ, and HW blocks at the three study areas. Additionally, a total of automatically 239 selected 26432 earthquakes were recorded at those $126 \mathrm{~K}-\mathrm{NET}$ and KiK-net seismic stations from 240 May 1996 to January 2020. The selection of earthquakes depends on two criteria. First, only 241 earthquakes with PGAs (i.e. Peak Ground Accelerations) of $\leq 10 \mathrm{~cm} / \mathrm{s}^{2}$ are used in the present study

242 to characterize the linear response at each seismic station and avoid later modification due to 243 nonlinear response (Thabet 2008a, b, 2021). Figure 10 is showing correlations between surface and 
244 borehole PGAs using KiK-net stations. Second, the hypocenters of these earthquakes must not exceed 245 the predefined areas that are shown in Figures 2, 3, and 4. Table 4 is summarizing the detailed 246 numbers of seismic stations with their corresponding recorded earthquakes at the three study areas.

248 Ben-Zion et al. (2003) noted that stations located on the fault zone have motion amplification not 249 only in the $S$-wave trains but also in the $P$-wave and other portions of the seismograms. Moreover, 250 they observed that differences between waveforms recorded on fault zone and far from it are 251 generated by nearly all events (i.e. on fault zone and far from it) and they exist not only in fault252 parallel seismograms but also in the other components. Therefore, three orthogonal continuous time 253 series are prepared at each seismic station in the present study based on the multiple-earthquakes 254 approach of Thabet (2019), which are representing EFWs, EFZs, and EHWs. Consequently, the 255 structural control due to the presence of active reverse faults could be observed and interpreted at 256 each seismic station. Figure 11 is showing an example of three continuous time series of east-west 257 components (EW) at the TKCH05 KiK-net seismic station, including 111, 26, and 140 recorded 258 EFWs, EFZs, and EHWs, respectively. Adopting this multiple-earthquakes approach enables us to 259 study only the structural control of active reverse faults excluding effects of different earthquake 260 sources with different propagation paths.

262 In engineering seismology, the site effects are usually studied in the frequency domain as variations 263 of seismic wave's amplitude. There are various spectral ratio methods, which effectively reveal how 264 active reverse fault zones modify the seismic waves. Since pioneering studies by Nogoshi and 265 Igarashi $(1970,1971)$ and Nakamura (1989, 2000), horizontal-to-vertical spectral ratio is the usual 266 technique for realistically estimate the predominant and fundamental frequencies at a site (Lermo and 
267 Chavez-Garcia 1993; Seekins et al. 1996; Thabet 2019). The applicability of horizontal-to-vertical

268 spectral ratio (HVSR) is tested by Rigano et al. (2008) concluding good results on the surface of

269 faults. Moreover, surface-to-borehole spectral ratio (SBSR) is early introduced by Borcherdt (1970,

270 1994), which is considered as the base of other later studies. The resulted in resonant frequencies are

271 only characteristic of the soil column between the surface and borehole sensors.

272

273 Using Geopsy software (Wathelet 2005; http://www.geopsy.org), the Fourier acceleration spectrum

274 (FAS) of the three orthogonal continuous time series and their HVSRs are calculated. During 275 calculations, and following the SESAME (2004) guidelines, the reliability and quality of these FAS 276 and HVSR calculations are checked to yield an acceptable level of scattering (i.e. acceptable low 277 standard deviation values) that may significantly influence the physical meaning of the FAS and 278 HVSR curves. At KiK-net seismic stations only, the SBSRs are calculated using the orthogonal FAS.

279

280 To estimate the site spectral amplification (SSA) at each seismic station, equations 1 through 4 are 281 used.

$$
\begin{aligned}
& S S A_{O H}=\frac{S_{O}}{S_{H}} \quad ; \quad S S A_{O / l . F}=\frac{S_{O}}{S_{l . F}} \\
& S S A_{O F}=\frac{S_{O}}{S_{F}} \quad ; \quad S S A_{O / r . F}=\frac{S_{O}}{S_{r . F}} \\
& S S A_{H F}=\frac{S_{H}}{S_{F}} \quad ; \quad S S A_{l . F / r . F}=\frac{S_{l . F}}{S_{r . F}} \\
& S S A_{F H}=\frac{S_{F}}{S_{H}} \quad ; \quad S S A_{r . F / l . F}=\frac{S_{r . F}}{S_{l . F}}
\end{aligned}
$$


282 where $S$ could be FAS, HVSR, or SBSR curves (Note: left side equations are applied on the East

283 Hokkaido and Fukushima study areas, whereas right side equations are applied on the Akita-Iwate

284 study area). $F, H$, and $O$ terms are referring to earthquakes located beneath footwall block, hanging 285 wall block, and fault zone (i.e. hanging wall blocks in the Akita-Iwate study area), respectively. $r . F$ 286 and $l . F$ terms are referring to earthquakes located beneath the right and left footwall blocks (Er.FWs 287 and El.FWs), respectively, in the Akita-Iwate study area.

289 For the purpose of measuring how the active reverse faults modify the amplification spectrum, 290 equations 3 and 4 are used at stations on FW in East Hokkaido and Fukushima study areas or right 291 footwall (r.FW) block in Akita-Iwate study area, and HW in East Hokkaido and Fukushima study 292 areas or left footwall (l.FW) block in Akita-Iwate study area, respectively. To quantify the behavior 293 of the site spectral amplifications at seismic stations located on different fault blocks, the average site 294 spectral amplifications are calculated and bounded with their minimum and maximum amplification.

To examine the velocity structures beneath the fault zones, earthquake HVSR (EHVSR) inversions 297 are carried out using inversion code program developed by Nagashima et al. (2014, 2017), which is 298 specifically designed for calculating the theoretical EHVSR based on the diffuse field concept. As a result, it would be possible to confirm the presence of the low-velocity fault zone. The link between the fault zone and the spectral analyses of earthquakes has been a long-standing fundamental problem. It is important for acquiring insight into the physical characteristics of fault zone guided waves and predicting future ground motions for engineering purposes. The resulted site 
effects of the present analyses consist of (1) FASs of seismic stations located on FW, FZ, and HW blocks, independently, and (2) calculations of the averaged SSAs at each independent zone. In the following sections, results are presented with discussions to interpret the resulted amplification patterns at the three study areas in the present research work.

\subsection{East Hokkaido Study Area}

311 In the East Hokkaido study area, Figures 12, 13, and 14 are showing FASs results for stations on FW, 312 FZ, and HW blocks, respectively. Obviously, the recorded EFZs yield maximum Fourier amplitude in 313 the high-frequency band (i.e. approximately $>3 \mathrm{~Hz}$ ) at all stations. Moreover, recorded EHWs yield 314 maximum Fourier amplitude in the low-frequency band (i.e. approximately $<3 \mathrm{~Hz}$ ), particularly at 315 stations located on FW block and FZ (Figure 12 and Figure 13, respectively). These frequency316 dependent maximum Fourier amplitudes are strongly related to the presence of the active reverse fault 317 system. For example, the example of continuous-time series of TKCH05 KiK-net station (Figure 11) 318 is showing very low PGAs for recorded EFZs when compared with those recorded EFWs and EHWs. 319 However, the FASs of recorded EFZs at TKCH05 (Figure 14) are showing maximum Fourier amplitude in the high-frequency band (i.e. approximately $>3 \mathrm{~Hz}$ ) in all orthogonal components. For seismic stations located on HW block, the FASs due to recorded EFWs are clearly exhibiting 322 maximum amplitudes higher than FASs due to recorded EHWs. For seismic stations located on the 323 FW block, slightly higher amplitudes of the FASs in the high-frequency band (i.e. approximately $>3$ $324 \mathrm{~Hz}$ ) due to recorded EHWs are observed when compared with FASs due to recorded EFWs. For 325 seismic stations located on FZ, higher amplitudes of the FASs in the high-frequency band (i.e. 326 approximately $>3 \mathrm{~Hz}$ ) due to recorded EFWs are observed when compared with FASs due to 327 recorded EHWs. 
329 The generalized site spectral amplification patterns in the East Hokkaido study area are independently 330 exhibited for seismic stations on FW (Figure 15), FZ (Figure 16), and HW (Figure 17) blocks. The 331 behaviors of $S S A_{O H}$ and $S S A_{O F}$ are showing overall similar amplification patterns. This consistency 332 in amplification patterns is obviously exhibited in Figures 15, 16, and 17 as a transition from high 333 amplification at high frequencies to low amplification at low frequencies. This indicates that 334 amplification due to earthquakes outside the fault zone (EFWs and EHWs) is larger than 335 amplifications due to earthquakes inside the fault zone (EFZs) in the low-frequency band (the 336 maximum amplifications at $0.5 \mathrm{~Hz}$ in the vertical components and $0.3 \mathrm{~Hz}$ in the EW and NS 337 components). Conversely, at seismic stations located on FW and FZ, both behaviors of $S S A_{H F}$ and $338 S S A_{F H}$ are showing a transition from high amplification at low frequencies to low amplification at 339 high frequencies. It is noteworthy that frequencies at transition points between high amplifications 340 and low amplifications are $3 \mathrm{~Hz}, 2 \mathrm{~Hz}$, and $<1 \mathrm{~Hz}$ at seismic stations on FW, FZ, and $\mathrm{HW}$ blocks, 341 respectively. In this paper, these frequencies would be called pivoted frequencies (i.e. PF). The $342 S S A_{F H}$ at seismic stations on the hanging wall is consistent without exhibiting PF. Table 5 is 343 summarizing the highs and lows of the average of $S S A_{O H}, S S A_{O F}, S S A_{H F}$, and $S S A_{F H}$ values 344 considering the orthogonal components observed at FW, FZ, and HW blocks at the East Hokkaido 345 study area. The high amplifications in the high-frequency bands $\left(S S A_{O H}\right.$ and $\left.S S A_{O F}\right)$ reveal the strong 346 role of the deep FZ effects. The low amplification in the low-frequency $\left(S S A_{O H}\right.$ and $\left.S S A_{O F}\right)$ could be 347 inferred to the strong role of the near- surface impedance effects of the FZ, which are obviously 348 shown in $S S A_{H F}$ and $S S A_{F H}$. The gradual increase of the low amplification through $S S A_{O H}, S S A_{O F}$, 349 and $S S A_{H F}$ (shown in Table 5) is reflecting the strong structural control of the HW compared with the 350 weak role of the FW in amplifying the ground motions. For stations on the FW, the $S S A_{O H}$ indicates 
351 that the effect of EFZs in the high-frequency is similar to the effect of EHWs in the low-frequency.

352 However, it could be concluded from the amplification factors that the influence of sources inside the 353 fault zone (EFZs) are higher than those outside the fault zone (EFWs and EHWs) in amplifying the 354 ground motions.

Guided waves of fault zone could be produced due to earthquakes very close to or in the fault zone 357 (Igel et al. 2002; Fohrmann et al., 2004; Li and Vidale, 1996; Jahnke et al., 2002). In the light of 358 these studies, the FASs of the recorded EFZs favour the highest amplifications at stations on FW, FZ, 359 and HW blocks in East Hokkaido study area (Figures 12, 13, and 14). Their amplification patterns $360\left(S S A_{O H}, S S A_{O F}, S S A_{H F}\right.$, and $\left.S S A_{F H}\right)$ shown in Figures 15, 16, and 17 are compatible with the 361 recent study by Wu et al. (2008). They observed that earthquakes inside (i.e. EFZs) and outside (i.e. 362 EFWs and EHWs) the fault zone could produce high amplification (i.e. guided waves) in the near363 surface fault zone. This near-surface fault zone could guide waves at low-frequency, whereas the 364 deep part of the fault zone could guide high-frequency waves (Wu et al., 2008). This frequency365 dependent feature makes the guided waves dominant in the earthquake seismogram after travelling 366 far distances. The shallow layers of the fault system in the East Hokkaido study area resemble the top 367 part of 'flower' structure (Figure 5). The significance of these shallow layers (i.e. low-frequency 368 waveguide) for seismic shaking hazard is considerably higher than that associated with the deep fault 369 zone layers (i.e. high-frequency waveguide), because of the ability to generate motion amplification 370 from a much broader spatial distribution of earthquakes (i.e. EFZs, EFWs, and EHWs in the present 371 study) as previously concluded by Seeber et al. 2000. This consideration is already mentioned and 372 indicated as the amplification due to earthquakes outside the fault zone (EFWs and EHWs) are larger 373 than amplifications due to earthquakes inside the fault zone (EFZs) in the low-frequency band (the 
374 maximum amplification at $0.5 \mathrm{~Hz}$ in the vertical components and $0.3 \mathrm{~Hz}$ in the EW and NS 375 components). Additionally, the peculiar feature of the PF could be interpreted as the transition from 376 PF of $3 \mathrm{~Hz}$ (at stations on FW correspond to high-frequency waveguide due to deep fault zone) 377 through $2 \mathrm{~Hz}$ (at stations on FZ), and $<1 \mathrm{~Hz}$ (at stations on $\mathrm{HW}$ correspond to low-frequency 378 waveguide due to shallow flower fault structure). The wavelengths matching or close to the width of 379 the fault are corresponding to these dominant frequencies. Interestingly, the peaks of the low380 frequency amplification of $S S A_{O H}$ and $S S A_{O F}$, particularly for seismic stations on FZ, are 381 corresponding to frequencies of $0.5 \mathrm{~Hz}$ (vertical components) and $0.3 \mathrm{~Hz}$ (EW and NS components). 382 Moreover, the $P$-wave and $S$-wave velocities in the $\mathrm{FZ}$ are approximately 5 and $3 \mathrm{~km} / \mathrm{s}$, respectively 383 (Figure 5). Consequently, the estimated wavelengths are $10 \mathrm{~km}$ that approximately equalize the FZ 384 width in the East Hokkaido study area.

385

\section{4.2 Akita-Iwate Study Area}

387 In the Akita-Iwate study area, Figures 18, 19, and 20 are showing the results of FASs for stations on 388 1.FW, FZ (i.e. hanging wall blocks or upthrown sides), and r.FW blocks, respectively. The FASs of 389 stations on 1.FW and FZ, which are calculated using recorded earthquakes having their hypocenters 390 beneath the right footwall block (Er.FWs), have the highest Fourier amplitudes in the low-frequency 391 band (i.e. approximately $<5 \mathrm{~Hz}$ ). Conversely, the highest Fourier amplitudes in the high-frequency 392 band (i.e. approximately $>5 \mathrm{~Hz}$ ) are prevailing in the FASs that are calculated using recorded 393 earthquakes having their hypocenters beneath the left footwall block (El.FWs), as shown in Figures 39418 and 19. Seismic stations on the r.FW are exhibiting the highest Fourier amplitudes for FASs due to 395 recorded El.FWs (Figure 20). Spectacular behavior of FASs, which are calculated using recorded 
396 EFZs, could be clearly seen in all seismic stations with approximately intermediate Fourier 397 amplitudes.

399 Figure 21, Figure 22, and Figure 23 are exhibiting the site spectral amplification patterns in the Akita400 Iwate study area for seismic stations on r.FW, FZ (i.e. hanging wall blocks), and 1.FW blocks, 401 respectively. The behavior of $S S A_{O / l . F}$ is remarkably variant.

403 At seismic stations located on r.FW, the effect of the recoded El.FWs (i.e. sources outside the fault 404 zone) is higher than the recorded EFZs at all frequency bands, as depicted from $S S A_{O / l . F}$ in Figure 405 21. At low frequencies (i.e. $0.3 \sim 0.5 \mathrm{~Hz}$ ), the behavior of $S S A_{O / l . F}$ is showing maximum 406 amplification factors of 2.08 and 9.37 for seismic stations on FZ and 1.FW, respectively. These 407 maximum amplification factors are reflecting the high influence of the active reverse fault system on 408 amplifying the ground motions, particularly due to those recorded EFZs (i.e. sources inside the fault 409 zone) at low frequencies (i.e. $0.3 \sim 0.5 \mathrm{~Hz}$ ). Comparable maximum amplification factors from $410 S S A_{O / r . F}$ are 2.14, 3.28, and 2.91 at seismic stations on 1.FW, FZ, r.FW blocks, respectively. The 411 amplification pattern resulted from $S S A_{l . F / r . F}$ at seismic stations on r.FW resembles their 412 corresponding amplification patterns resulted from $S S A_{O / r . F}$. The comparison between maximum 413 amplification factors, particularly at low-frequency of $0.25 \mathrm{~Hz}$, for $S S A_{O / r . F}$ and $S S A_{l . F / r . F}$ is

414 indicating the higher influence of recorded El.FWs (i.e. sources outside the fault zone) than those 415 recorded EFZs (i.e. sources inside the fault zone) in amplifying the ground motions at all frequency 416 bands, as depicted from Figure 21. 
418 At seismic stations on FZ (Figure 22), the behavior of $S S A_{O / r . F}$ is showing maximum amplification 419 factors at frequencies $>10 \mathrm{~Hz}$, whereas amplification due to recorded EFZs equalizes those Er.FWs 420 at frequencies lower than $10 \mathrm{~Hz}$. The maximum amplification factors depicted by $S S A_{O / l . F}$ at low421 frequency between 0.4 and $0.5 \mathrm{~Hz}$ are indicating the higher influence of recorded EFZs (i.e. sources 422 or earthquakes inside the fault zone) than those recorded El.FWs (i.e. sources or earthquakes outside 423 the fault zone) in amplifying the ground motions. This could be related to the effect of the shallow 424 fault zone 'flower' structure (Figures 6 and 7). The behavior of $S S A_{r . F / l . F}$ resembles $S S A_{O / r . F}$ 425 behavior, indicating the higher impact of Er.FWs than those of El.FWs in amplifying the ground 426 motions at frequencies $>10 \mathrm{~Hz}$, whereas the comparable response is observed at frequencies $<10 \mathrm{~Hz}$.

428 At seismic stations located on 1.FW (Figure 23), $S S A_{O / r . F}$ is showing a transition from high 429 amplification of high-frequency to low amplification of low-frequency and vice versa is shown by $430 S S A_{O / l . F}$. This feature is reflecting the strong influence of the near-surface fault zone (flower 431 structure) at the low frequencies, whereas higher amplification at higher frequencies is related to the 432 deep fault zone impact. These aforementioned transitions could be exhibited at PF of $5 \mathrm{~Hz}$ for EW 433 and NS components and $7 \mathrm{~Hz}$ for UD component. The amplification patterns resulted from $S S A_{r . F / l . F}$ 434 resemble their corresponding amplification patterns resulted from $S S A_{O / l . F}$, but exhibiting PF at 6 $435 \mathrm{~Hz}$ for EW and NS components and $8 \mathrm{~Hz}$ for UD component. The comparison between maximum 436 amplification factors, particularly at low frequencies between 0.3 and $0.5 \mathrm{~Hz}$, for $S S A_{O / l . F}$ and $437 S S A_{r . F / l . F}$ is indicating the higher influence of recorded Er.FWs than those recorded EFZs in 438 amplifying the ground motions at all frequency bands, as depicted from Figure 23. 
440 Table 6 is summarizing the highs and lows of the averages of $S S A_{O / \text { l.F }}, S S A_{O / r . F}, S S A_{\text {r.F } / l . F}$, and $441 S S A_{l . F / r . F}$ values considering the orthogonal components observed at r.FW, FZ, and 1.FW blocks at 442 Akita-Iwate study area. It could be concluded from the amplification factors that the influence of 443 sources or earthquakes far away from the fault zone (El.FWs and Er.FWs) are higher than those in the 444 fault zone (EFZs) in amplifying the ground motions.

445

446 4.3 Fukushima Study Area

447 In the Fukushima study area, Figures 24 and 25 are showing the results of FASs for stations located 448 on footwall and hanging wall blocks, respectively. Two observations are prevailing in this study area. 449 First, FASs that are calculated using recorded EFZs have the highest Fourier amplitudes. Second, the 450 amplitudes of FASs, which are calculated using recorded EHWs, are higher than those calculated 451 using recorded EFWs.

452

453 Similar generalized site spectral amplification patterns in the Fukushima study area (Figure 26 and 454 Figure 27) as previously seen in the East Hokkaido study area. At both FW and HW blocks, a 455 transition from high amplification at high frequencies to low amplification at low frequencies is 456 observed in the behaviors of $S S A_{O H}$ and $S S A_{O F}$. The PFs are $\sim 2 \mathrm{~Hz}$ and $\sim 1 \mathrm{~Hz}$ at seismic stations 457 located on FW and HW blocks, respectively. As previously discussed in the East Hokkaido and 458 Akita-Iwate study areas, these high amplification in the high-frequency bands $(>2 \mathrm{~Hz}) \mathrm{reveal}$ the 459 strong role of the deep FZ effects, whereas the low amplification in the low-frequency bands $(0.4 \sim$ $460 \quad 0.6 \mathrm{~Hz}$ ) reveal the strong role of the near-surface impedance effects of the FZ. These low 461 amplification factors are seen in both $S S A_{O H}$ and $S S A_{O F}$ indicates that the effect of EHWs and EFWs 
462 (sources outside the fault zone) is higher than the effect of the EFZs (sources inside the fault zone) in 463 amplifying the ground motions.

465 At seismic stations on FW, the behavior of $S S A_{H F}$ is showing general high amplification, particularly 466 at frequencies of $0.3 \sim 0.4 \mathrm{~Hz}$. The behavior of $S S A_{F H}$ for stations on the $\mathrm{HW}$ is exhibiting overall 467 low amplification with unusual high amplification seen around $1 \mathrm{~Hz}$. This feature is reflecting the 468 strong structural control of the HW compared with the weak role of the FW in amplifying the ground 469 motions.

470

471 Table 7 is summarizing the highs and lows of the averages of $S S A_{O H}, S S A_{O F}, S S A_{H F}$, and $S S A_{F H}$ 472 values considering the orthogonal components observed at FW and HW blocks at the Fukushima 473 study area. Both high and low amplifications are reflecting the strong structural role of the HW in 474 amplifying the ground motions at the expense of the FW block. This feature is similar to the study 475 case in the East Hokkaido area. Moreover, the effect due to the recorded EHWs and EFWs is higher 476 than those of the recorded EFZs in amplifying the ground motions at low frequencies and vice versa 477 at high frequencies.

478

479 Although the non-presence of clear and well-developed low-velocity fault zone as depicted in Figures 4808 and 9, the amplification patterns are comparable to those observed in the East Hokkaido study area.

\section{4.4 HVSR and SBSR}

483 Figure 28 is showing examples of HVSRs at different K-NET and KiK-net seismic stations in the 484 three present study areas. Figure 29 is showing examples of SBSRs at different KiK-net seismic 
stations. These examples are generalizing the overall results from those HVSRs and SBSRs in the

486 three present study areas. It is obvious that there are no significant responses that could be interpreted

487 as the effect of strong structural control due to active reserve faults, which is contradicted to previous

488 work by Rigano et al. (2008) who concluded good HVSR results on the surface of faults through

489 testing the reliability of HVSR.

490

491 The effect of the fault zone in the three study areas could not be captured in the SBSRs. This is

492 because the SBSRs eliminate the source and the propagation path effects completely. As a result, 493 variation in amplitude or frequency due to the presence of fault zone would not be exhibited in the 494 processed SBSRs.

495

496 Pischiutta et al. (2015) concluded that fault zone could cause high amplification normal to this fault 497 zone, which is called directional amplification. In the afore depicted Figures 15, 16, 17, 21, 22, 23, 49826 , and 27, comparable behaviors of SSAs of the horizontal components is concluded, which conflict 499 with previous study of Pischiutta et al. (2015). The behaviors of SSAs in the EW components are 500 similar to those in the NS components, through the active fault system in the present study areas are 501 trending NS. This questionable feature could be inferred to the strong structural prevalence 502 amplification due to active fault zone guided waves on both the horizontal and vertical components. 503 Another reason for this feature could be related to the negligible horizontal heterogeneities in the 504 subsurface.

505

506

507 


\subsection{EHVSR Inversion}

509 In each study area, two seismic stations on each block (FW, FZ, and HW) are selected to run EHVSR

510 inversion. However, the different three tectonic patterns in the present study are summarized in

511 Figure 30 accompanying the resulted maximum averages of SSAs at high and low frequencies 512 deduced from stations on each block.

514 Figure 31 is showing three examples of inverted EHVSR curves superimposed with their 515 corresponding observed HVSR curves. Reasonable fitting between the observed and the inverted 516 EHVSR curves could be achieved. Smoothing technique is not applied; instead the EHVSR curves 517 are used without smoothing in order to capture all the available information in the HVSR curves. 518 Consequently, the resulted velocity structures are well recognized for the subsurface structure.

520 Reduced $P$-wave and $S$-wave velocity structures with respect to the surrounding fault blocks (i.e. FW, 521 HW, r.FW, or 1.FW) are concluded as inverted from stations on the fault zone system in the East 522 Hokkaido study area (Figure 32). This reduction extends to $\sim 8 \mathrm{~km}$ depth, which indicates the fault 523 depth existence. Similar velocity reduction is concluded in the Akita-Iwate study area (Figure 33), but 524 this reduction extends to $\sim 2.5 \mathrm{~km}$ depth, which indicates shallow fault system. In the Fukushima 525 study area, there is no station lying on the fault zone, but FKS007 K-NET station is the closest station 526 to the fault system in this study area. Remarkably, deep fault system of $\sim 8 \mathrm{~km}$ depth is concluded in 527 the Fukushima study area (Figure 34).

529 It is hoped that the present inversion could link these concluded inverted velocity structures with the 530 frequency-dependent behavior of the different amplification patterns in the three present study areas. 
531 As a result, these different amplification patterns reflect the efficiency of the variation of guided

532 waves with fault system depth. Clarifying the important role of this low-velocity fault zone in the

533 interpretation of the resulted amplification patterns will require multidisciplinary research works

534 joining microtremor field studies across these fault systems, two- and three-dimension calculations -

535 taking into account basins, sedimentary covers, and other topographic effects associated with fault

536 zones in the near-surface -, measurements in deep boreholes inside and outside fault zones, and other

537 geophysical studies. Although they are essential, these fuller treatment studies are highly likely

538 beyond the scope of the present conclusions.

539

540 5. Conclusion

541 This study has originated from the observation of systematic larger amplitudes of ground motion 542 spectra at K-NET and KiK-net seismic stations at three different localities in Japan because of the 543 presence of active faults (AIST, 2012 and 2013). Those north-south active faults have different 544 degrees of complexity for characterizing fault zones. They could be categorized as 1) low-velocity 545 active reverse faults (East Hokkaido area), 2) system of active reverse faults (set of several en546 echelon fault traces) composing horst fault system (Akita-Iwate area), and 3) complex active fault 547 zone that includes vertical strike-slip and reverse faults (Fukushima area). These active reverse fault 548 zones could produce local amplification not only on these active faults but also far away from these 549 faults (i.e. footwall and hanging wall blocks). Analyzing site response related to these fault zones 550 using FAS is most effective than using HVSR or SBSR at the present study areas.

551

552 Comparable SSAs at seismic stations on fault zone and far away from the fault zone are resulted at 553 high frequencies due to sources or earthquakes inside the active fault zones. At low frequencies, 
554 sources inside the active fault zones could favor higher SSAs at stations on FW and 1.FW in

555 Fukushima and Akita-Iwate study areas, respectively, than at stations on HW, FZ, and r.FW in both

556 study areas. In the study area of East Hokkaido, observed amplification could not be produced due to

557 sources inside the active fault zones at low frequencies. In East Hokkaido and Fukushima study areas,

558 sources outside the fault zone could not produce significant SSAs at high frequencies, whereas

559 remarkable high SSAs at low frequencies with a gradual increase from stations on HWs through FZs

560 and FWs. The stations on r.FW and 1.FW in Akita-Iwate study area exhibit similar SSAs due to

561 sources outside the fault zone at low frequencies, whereas stations on the FZ (i.e. HWs) are exhibiting

562 high SSAs at high frequencies.

563

564 The observed amplification patterns on FW, FZ, and HW are strongly related to the corresponding 565 tectonic pattern (i.e. tectonic-specific pattern) and the frequency bands. The near-surface (i.e. low566 velocity layers forming flower structure) fault zone could produce low-frequency amplification, 567 whereas high-frequency amplification is inferred to the fault zone in depth. Interestingly, the peaks of 568 the low-frequency amplification are corresponding to wavelengths approximately equalize fault 569 zone's width, particularly in the East Hokkaido and Akita-Iwate study areas.

570

571 Using HVSR is not effective in the present study areas, which is contradicted to previous work by 572 Rigano et al. (2008) who concluded good HVSR results on the surface of faults through testing the 573 reliability of HVSR. Additionally, the observed horizontal components are showing comparable 574 amplification patterns. This peculiar feature indicates the strong structural prevalence amplification 575 due to active fault zone guided waves as exhibited in all motion components (horizontal and vertical). 576 
578 The author is highly appreciated and grateful to the National Research Institute for Earth Science and Disaster 579 prevention (NIED) for making the valuable KiK-net and K-NET data available (DOI : 10.17598/NIED.0004).

580 The author would appreciate and acknowledge providing the EHVSR inversion code by Prof. Fumiaki 581 Nagashima (DPRI, Kyoto University). The author would appreciate and acknowledge the generous, valuable, 582 and constructive comments and suggestions from the Editor and the reviewers.

$584 \quad$ DECLARATIONS

$585 \quad$ Funding

586 The author states that this research work is not supported by any fund and no fund is received.

587 Conflicts of interest/Competing interests

588 The author states that there are no any conflicts of interests or competing interests

$589 \quad$ Availability of data and material

590 Any data in this research work would be available upon request immediately.

$591 \quad$ Code availability

592 Any software application or custom code in this research work would be available upon request immediately.

$593 \quad$ Authors' contributions

594 The submitting author confirm that he is a single author named in the manuscript is aware of the submission 595 and has agreed for the paper to be submitted to Natural Hazards. I am acknowledging the consent 596 requirements. I am very appreciated for your careful consideration. 


\section{$597 \quad$ References}

598 Abdelwahed M F, Zhao D (2007) Deep structure of the Japan subduction zone. Phys. Earth Planet. Inter. 162: 32-52.

599 AIST (National Institute of Advanced Industrial Science and Technology. Active Fault Database of Japan), February 28, 6002012 version. Research Information Database DB095, National Institute of Advanced Industrial Science and Technology.

601 Geological Survey of Japan https://gbank.gsj.jp/activefault/index_e_gmap.html

602 AIST (National Institute of Advanced Industrial Science and Technology, Active Fault Database of Japan), July 23, 2013

603 Version. Research Information Database DB095, National Institute of Advanced Industrial Science and Technology

604 https://gbank.gsj.jp/activefault/index_e_gmap.html

605 Ben-Zion Y (1998) Properties of seismic fault zone waves and their utility for imaging low-velocity structure. J. geophys. 606 Res. 103(12): 567-585.

607 Ben-Zion Y, Aki K (1990) Seismic radiation from an SH line source in a laterally heterogeneous planar fault zone. Bull. 608 seism. Soc. Am. 80: 971-994.

609 Ben-Zion Y,Sammis C G (2003) Characterization of fault zones. Pure appl. Geophys. 160: 677-715.

610 Ben-Zion Y, Peng Z, Okaya D, Seeber L, Armbruster J G, Ozer N, Michael A J, Baris S, Aktar M (2003) A shallow fault611 zone structure illuminated by trapped waves in the Karadere-Duzce branch of the North Anatolian Fault, western Turkey. 612 Geophys. J. Int.152: 699-717.

613 Ben-Zion, Y. et al., 2015. Basic data features and results from a spatially dense seismic array on the San Jacinto fault 614 zone, Geophys. J. Int., 202, 370-380.

615 Borcherdt RD, (1970) Effects of local geology on ground motion near San Francisco Bay. Bull. seism. Soc. Am. 60(1): $616 \quad 29-61$.

617 Borcherdt RD (1994) Estimates of site-dependent response spectra for design (methodology and justification). Earthq 618 Spectra 10(4): 617-653. 
619 Burjánek, J., Moore, J.R., Yugsi-Molina, F.X., Fäh, D., 2012. Instrumental evidence of normal mode rock slope vibration. 620 Geophys. J. Int. 188 (2), 559-569. https://doi.org/10.1111/j.1365-246X.2011.05272.x.

621 Cormier V F, Spudich P (1984) Amplification of ground motion and waveform complexity in fault zones: Examples from 622 the San Andreas and Calaveras faults. Geophys. J. R. astron. Soc. 79: 135-152.

623 Di Giulio, G., F. Cara, A. Rovelli, G. Lombardo, and R. Rigano (2009), Evidences for strong directional resonances in 624 intensely deformed zones of the Pernicana fault, Mount Etna, Italy, J. Geophys. Res., 114, B10308, 625 doi:10.1029/2009JB006393

626 Fohrmann M, Igel H, Jahnke G, Ben-Zion Y (2004) Guided waves from sources outside faults: an indication for shallow 627 fault zone structure?. Pure Appl. Geophys. 161: 2125-2137.

628 Hickman S H, Zoback M D, Ellsworth W L (2005) Structure and composition of the San Andreas Fault zone at Parkfield: 629 Initial results from SAFOD Phase 1 and 2. EOS, Trans. Am. geophys. Un. 83(47): 237.

630 Igel H, Ben-Zion Y, Leary P (1997) Simulation of SH and P-SV wave propagation in fault zones. Geophys. J. Int. 128: $631 \quad 533-546$ Igel H, Jahnke G, Ben-Zion Y (2002) Numerical simulation of fault zone guided waves: accuracy and 3-D effects. Pure 633 Appl. Geophys. 159: 2067-2083.

634 Jahnke G, Igel H, Ben-Zion Y (2002) Three-dimensional calculations of fault zone guided waves in various irregular 635 structures. Geophys. J. Int. 151: 416-426.

636 Kakhki, M.K., Peters, F.C., Mansur, W.J., SadidKhoii, A., Rezaei, S., 2020. Deciphering site response directivity in 637 landslide-prone slopes from ambient noise spectral analysis. Eng. Geol. 269, 105542 638 https://doi.org/10.1016/j.enggeo.2020.105542.

639 Kato A, Sakai S, Hirata N, Kurashimo E, Iidaka T, Iwasaki T, Kanazawa T (2006) Imaging the seismic structure and 640 stress field in the source region of the 2004 mid-Niigata prefecture earthquake: Structural zones of weakness and 641 seismogenic stress concentration by ductile flow. J. Geophys. Res. 111: B08308. doi:10.1029/2005JB004016. 
642 Korneev V A, Nadeau R M, McEvilly T V (2003) Seismological studies at Parkfield IX: fault-zone imaging using guided 643 wave attenuation. Bull. seism. Soc. Am. 93: 1415-1426.

644 Lermo J, Chavez-Garcia FJ (1993) Site effect evaluation using spectral ratios with only one station. Bull. seism. Soc. Am. 645 83(5):1574-94.

646 Lewis M A, Peng Z, Ben-Zion Y, Vernon F L (2005) Shallow seismic trapping structure in the San Jacinto fault zone near 647 Anza, California. Geophys. J. Int. 162: 867-881. doi:10.1111/j.1365-246X.2005. 02684.x.

648 Li Y G, Leary P C (1990) Fault-zone trapped seismic waves. Bull. seism. Soc. Am. 80: 1245-1271.

649 Li Y G, Leary P C, Aki K, Malin P (1990) Seismic trapped modes in the Orville and San Andreas Fault zones. Science $650 \quad 249: 763-766$.

651 Li Y G, Aki K, Adams D, Hasemi A, Lee W H K (1994) Seismic guided waves trapped in the fault zone of the Landers, 652 California, earthquake of 1992. J. geophys. Res. 99: 11705-11722.

653 Li Y G, Ellsworth W L, Thurber C H, Malin P E, Aki K (1997) Fault zone guided waves from explosions in the San 654 Andreas fault at Parkfield and Cienega Valley, California. Bull. seism. Soc. Am. 87: 210-221.

655 Li Y G, Vernon F L (2001) Characterization of the San Jacinto fault zone near Anza, California, by fault zone trapped 656 waves. J. geophys. Res.-Solid Earth 106(30): 671-688.

657 Li Y G, Vidale J E, Aki K, Xu F (2000) Depth-dependent structure of the Landers fault zone from trapped waves 658 generated by aftershocks. J. geophys. Res.-Solid Earth 105: 6237-6254.

659 Li Y G, Vidale J E (1996) Low-velocity fault-zone guided waves: numerical investigations of trapping efficiency. Bull. 660 seism. Soc. Am. 86: 371-378.

661 Li Y G, Vidale J E, Cochran E S (2004) Low-velocity damaged structure of the San Andreas fault at Parkfield from fault 662 zone trapped waves. Geophys. Res. Lett. 31: 2165, doi:10.1029/2001JB001456. 
663 Matsubara M, Obara K, Kasahara K (2008) Three-dimensional P- and S-velocity structures beneath the Japan Islands

664 obtained by high-density seismic stations by seismic tomography. Tectonophysics 454: 86-103.

665 doi:10.1016/j.tecto.2008.04.016

666 Matsubara M, Obara K (2011) The 2011 Off the Pacific coast of Tohoku earthquake related to a strong velocity gradient 667 with the Pacific plate. Earth Planets Space 63: 663-667. doi:10.5047/eps.2011.05.018.

668 Michael A J, Ben-Zion Y (1998) Inverting fault zone trapped waves with genetic algorithm. EOS, Trans. Am. geophys. 669 Un. 79: F584.

670 Mizuno T, Nishigami K, Ito H, Kuwahara Y (2004) Deep structure of the Mozumi-Sukenobu fault, Central Japan, 671 estimated from the subsurface array observation of fault zone trapped waves. Geophys. J. Int. 159: $622-642$.

672 Mizuno T, Nishigami K (2006) Deep structure of the Nojima Fault, southwest Japan, estimated from borehole 673 observations of fault-zone trapped waves. Tectonophysics 417: 231-247.

674 Mooney W D, Ginzburg A (1986) Seismic measurements of the internal property of fault zone. Pure appl. Geophys. 124: $675 \quad 141-157$.

676 Nagashima F, Matsushima S, Kawase H, Sánchez-Sesma FJ, Hayakawa T, Satoh T, Oshima M (2014) Application of 677 horizontal-to-vertical (H/V) spectral ratios of earthquake ground motions to identify subsurface structures at and around 678 the K-NET site in Tohoku, Japan. Bull. seism. Soc. Am. 104: 2288-2302. https://doi.org/10.1785/0120130219

679 Nagashima F, Kawase H, Matsushima S (2017) Estimation of horizontal seismic bedrock motion from vertical surface 680 motion based on horizontal-to-vertical spectral ratios of earthquake motions. In: 16th world conference on earthquake 681 engineering, No. 3685, 9-13 Jan 2017, Santiago

682 Nakajima J, Hasegawa A (2007a) Deep crustal structure along the Niigata-Kobe Tectonic Zone, Japan: Its origin and 683 segmentation. Earth, Planets and Space 59: e5-e8.

684 Nakajima J, Hasegawa A (2007b) Tomographic evidence for the mantle upwelling beneath southwestern Japan and its 685 implications for arc magmatism. Earth and Planetary Science Letters 254: 90-105. 

its relationship to arc magmatism. J. Geophys. Res. 112: B08306. doi:10.1029/2006JB004770 northeastern Japan: Implications for arc magmatism and fluids. J. Geophys. Res. 106(21); 843-857. surface. Q Rep RTRI Jpn 30: 25-33. the XII World Conf. Earthq. Engrg., Auckland, New Zeeland, 8 pp. dimensional P- and S-wave velocity structures beneath Japan. Phys. Earth Planet. Inter. 168: 49-70. doi:10.1016/j.pepi.2008.04.017. microseismic data recorded by Hi-net tiltmeters. J. Geophys. Res. 113: B10302. doi:10.1029/2007JB005395. ground surface. J Seismol Soc Jpn 23: 264-280. western flank of Mt. Etna: observations and fracture orientation modelling. Pure Appl. Geophys. 171, 3083-3097. https://doi.org/10.1007/s00024-014-0831-x. 
Panzera, F., Lombardo, G., Sicali, S., D’Amico, S., 2016b. Surface geology and morphologic effects on seismic site response: the study case of Lampedusa, Italy. Phys. Chem. Earth Parts A/B/C 98, 62-72. 710 https://doi.org/10.1016/j.pce.2016.08.006.

711 Panzera, F., Halldorsson, B., Vogfjörð, K., 2017a. Directional effects of tectonic fractures on ground motion site 712 amplification from earthquake and ambient noise data: a case study in South Iceland. Soil Dyn. Earthq. Eng. 97, 143-154. 713 https://doi.org/10.1016/j.soildyn.2017.03.024.

714 Panzera, F., Lombardo, G., Longo, E., Langer, H., Branca, S., Azzaro, R., Cicala, V., Trimarchi, F., 2017b. Exploratory 715 seismic site response surveys in a complex geologic area: a case study from Mt. Etna volcano (southern Italy). Nat. 716 Hazards 86, 385-399. https://doi.org/10.1007/s11069-016-2517-4.

717 Panzera, F., D’Amico, S., Colica, E., Viccaro, M., 2019. Ambient vibration measurements to support morphometric 718 analysis of a pyroclastic cone. Bull. Volcanol. 81 (12), 74. https://doi.org/10.1007/s00445-019-1338-1.

719 Panzera F, Tortorici G, Romagnoli G, Marletta G, Catalano S (2020) Empirical evidence of orthogonal relationship 720 721 Engineering Geology 279 (2020) 105900, https://doi.org/10.1016/j.enggeo.2020.105900

722 Peng Z, Ben-Zion Y, Zhu L, Michael A J (2003) Inference of a shallow fault zone layer in the rupture zone of the 1992. 723 Landers, California earthquake fro locations of events generating trapped waves and travel time analysis. Geophys. J. Int. 724 155: 1021-1041.

725 Peruzza, L., Azzaro, R., Gee, R., D’Amico, S., Langer, H., Lombardo, G., Pace, B., Pagani, M., Panzera, F., Ordaz, M., 726 Suarez, M.L., Tusa, G., 2017. When probabilistic seismic hazard climbs volcanoes: the Mt. Etna case, Italy - part 2: 727 Computational implementation and first results. Nat. Hazards Earth Syst. Sci. 17, $1999-2015$. 728 https://doi.org/10.5194/nhess-17-1999-2017.

729 Pischiutta, M., Salvini, F., Fletcher, J.B., Rovelli, A., Ben-Zion, Y., 2012. Horizontal polarization of ground motion in the 730 Hayward fault zone at Fremont, California: dominant fault-high-angle polarization and fault-induced cracks. Geophys. J. 731 Int. 188 (3), 1255-1272. https://doi.org/10.1111/j.1365-246X.2011.05319.x. 
732 Pischiutta, M., Rovelli, A., Salvini, F., Di Giulio, G., Ben-Zion, Y., 2013. Directional resonance variations across the 733 Pernicana fault, Mt. Etna, in relation to brittle deformation fields. Geophys. J. Int. 193 (2), $986-996$. 734 https://doi.org/10.1093/gji/ggt031.

735 Pischiutta M, Savage M K, Holt R A, Salvini F (2015) Fracture-related wavefield polarization and seismic anisotropy 736 across the Greendale Fault. J. Geophys. Res. Solid Earth 120: 7048-7067. doi:10.1002/2014JB011560.

737 Pischiutta, M., Fondriest, M., Demurtas, M., Magnoni, F., Di Toro, G., Rovelli, A., 2017. Structural control on the 738 directional amplification of seismic noise (Campo Imperatore, Central Italy). Earth Planet. Sci. Lett. 471, 10-18. 739 https://doi.org/10.1016/j.epsl.2017.04.017.

740 Rigano R, Cara F, Lombardo G, Rovelli A (2008) Evidence of ground motion polarization on fault zones of Mount Etna 741 volcano. J Geophys Res. 113: B10306. http:// dx.doi.org/10.1029/2007JB005574.

742 Rovelli A, Caserta A, Marra F, Ruggiero V (2002) Can seismic waves be trapped inside an inactive fault zone? The case 743 study of Nocera Umbra, central Italy. Bull. seism. Soc. Am. 92: 2217-2232.

744 Roux, P., Moreau, L., Lecointre, A., Hillers, G., Campillo, M., Ben-Zion, Y., Zigone, D., Vernon, F., 2016. A 745 methodological approach toward high-resolution surface wave imaging of the San Jacinto Fault Zone using ambient-noise 746 recordings at a spatially dense array. Geophys. J. Int. 206 (2), 980-992. http://dx.doi.org/10.1093/gji/ggw193.

747 Seeber L, Armbruster J G, Ozer N, Aktar M, Baris S, Okaya D, Ben-Zion Y, Field E (2000) The 1999 Earthquake 748 Sequence along the North Anatolia Transform at the Juncture between the Two Main Ruptures, in The 1999 Izmit \& 749 Duzce Earthquakes: preliminary results. edit. Barka A., O. Kazaci, S. Akyuz \& E. Altunel, Istanbul technical university, $750 \quad 209-223$.

751 Seekins LC, Wennerberg L, Marghereti L, Liu HP (1996) Site amplification at five locations in San Fransico, California: 752 a comparison of S waves, codas, and microtremors. Bull. seism. Soc. Am. 86(3): 627-35.

SESAME (2004) Guidelines for the implementation of the $\mathrm{H} / \mathrm{V}$ spectral ratio technique on ambient vibrations: 754 Measurements, processing and interpretation, SESAME (Site Effects Assessment Using Ambient Excitations. EC-RGD, 755 Project No. EVG1-CT-2000-00026 SESAME), European Research Project WP12, deliverable D23.12, at http://sesame756 fp5.obs.ujfgrenoble.fr/Deliverables 2004 
757 Spudich, P., Hellweg, M., Lee, H.K., 1996. Directional topographic site response at Tarzana observed in aftershocks of 758 the 1994 North-ridge, California, earthquake: implications for mainshock motions. Bull. Seismol. Soc. Am. 86, S193759 S208.

760 Thabet M, Nemoto H, Nakagawa K (2008a) Variation process in stiffness inferred by nonlinear inversion during 761 mainshocks at Kushiro Port vertical array site. Earth Planet Sp 60: 581-589. https://doi.org/10.1186/BF03353121

762 Thabet M (June, 2008b) Variation Process in Stiffness of Liquefiable Subsurface Layer Caused by Large Earthquake 763 Application to Vertical Array Sites of Port Island in Kobe and Kushiro Port in Hokkaido, Japan-. Doctor Dissertation. $764 \quad$ Osaka City University. (PDF, researchgate.net) Thabet M (2019) Site-Specific Relationships between Bedrock Depth and HVSR Fundamental Resonance Frequency Using KiK-NET Data from Japan. Pure Appl. Geophys. 176: 4809-4831. https://doi.org/10.1007/s00024-019-02256-7

Thabet M (2021) Nonlinearity evaluation considering the uncertainty of $S$-wave velocity based on total stress analyses and diffuse field assumption: the $M_{w} 9.1$ great Tohoku Taiheiyo-Oki earthquake at 05:46 UTC on 11 March $2011 . J$ Seismol. https://doi.org/10.1007/s10950-020-09974-9 Thurber C H (1983) Earthquake locations and three-dimensional crustal structure in the Coyote Lake area, central California. J. geophys. Res. 88: 8226-8236.

772 Togo M (2000) Geomorphological Analysis on Surface Ruptures by Reverse Faulting. 206 pp. Kokon. Tokyo.

773 Villani, F., D’Amico, S., Panzera, F., Vassallo, M., Bozionelos, G., Farrugia, D., Galea, P., 2018. Shallow high-resolution 774 geophysical investigation along the western segment of the Victoria Lines Fault (island of Malta). Tectonophysics 724$775725,220-233$. https://doi.org/10.1016/j.tecto.2018.01.010.

776 Tortorici, G., Romagnoli, G., Grassi, S., Imposa, S., Lombardo, G., Panzera, F., Catalano, S., 2019. Quaternary negative 777 tectonic inversion along the Sibillini Mts. Thrust zone: the Arquata del Tronto case history (Central Italy). Environ. Earth 778 Sci. 78 (1), 37. https://doi.org/10.1007/s12665-018-8021-2.

779 Wathelet M (2005) Array Recordings of Ambient Vibrations: Surface-Wave Inversion. Ph.D. thesis, Liège University, 780 Belgium. 


\begin{tabular}{|c|c|c|c|c|}
\hline Symbol & $\mathbf{a}$ & b & c & d \\
\hline Name & Shihoro & Otofuke & Tobetsugawa & Kochien \\
\hline Description & $\begin{array}{l}\text { N-S trending east- } \\
\text { dipping reverse fault } \\
\text { along the eastern } \\
\text { margin of the Tokachi } \\
\text { Plain in central } \\
\text { Hokkaido }\end{array}$ & $\begin{array}{l}\mathrm{N}-\mathrm{S} \text { trending east- } \\
\text { dipping reverse fault } \\
\text { along the eastern } \\
\text { margin of the } \\
\text { Tokachi Plain in } \\
\text { central Hokkaido }\end{array}$ & $\begin{array}{l}\text { N-S trending east- } \\
\text { dipping reverse fault } \\
\text { along the eastern } \\
\text { margin of the } \\
\text { Tokachi Plain in } \\
\text { central Hokkaido }\end{array}$ & $\begin{array}{l}\text { NW-SE trending } \\
\text { northeast-dipping } \\
\text { reverse fault along } \\
\text { the eastern margin of } \\
\text { the Hidaka mountains } \\
\text { in central Hokkaido }\end{array}$ \\
\hline Trend & $10^{\circ}$ & $0^{\circ}$ & $0^{\circ}$ & $330^{\circ}$ \\
\hline Dip & $30^{\circ} \mathrm{E}$ & $30^{\circ} \mathrm{E}$ & $30^{\circ} \mathrm{E}$ & $45^{\circ} \mathrm{E}$ \\
\hline Length & $62 \mathrm{Km}$ & $18 \mathrm{Km}$ & $40 \mathrm{Km}$ & $26 \mathrm{Km}$ \\
\hline Sense of faulting & Reverse & Reverse & Reverse & Reverse \\
\hline Upthrown side & East & East & East & East \\
\hline Slip rate & $0.4 \mathrm{~m} / \mathrm{K}$ years & $0.0 \mathrm{~m} / \mathrm{K}$ years & $0.3 \mathrm{~m} / \mathrm{K}$ years & $0.1 \mathrm{~m} / \mathrm{K}$ years \\
\hline Slip per Event & $7.2 \mathrm{~m}$ & & $4.7 \mathrm{~m}$ & $3.0 \mathrm{~m}$ \\
\hline $\begin{array}{l}\text { Recurrence } \\
\text { Interval }\end{array}$ & 18000 years & ----- & 16000 years & 24000 years \\
\hline Elapsed time rate & ----- & ----- & ----- & 0.68 \\
\hline $\begin{array}{c}\text { Rupture } \\
\text { Probability in next } \\
30 \text { years }\end{array}$ & $0.2 \%$ & ----- & $0.2 \%$ & $0.1 \%$ \\
\hline
\end{tabular}


Table 2: Characteristics of the behavioral segments of the Akita-Iwate active reverse faults (AIST 2012, 2013).

\begin{tabular}{|c|c|c|c|c|c|c|c|c|c|c|}
\hline Symbol & $\mathbf{a}$ & $\mathbf{b}$ & c & d & $\mathbf{e}$ & $\mathbf{f}$ & $\mathrm{g}$ & $\mathbf{h}$ & $\mathbf{i}$ & $\mathbf{j}$ \\
\hline Name & Ukai & Hanamaki & $\begin{array}{c}\text { Kitakami- } \\
\text { nishi }\end{array}$ & $\begin{array}{c}\text { Shizukuishibonc } \\
\text { hi-seien }\end{array}$ & Kawafune & $\begin{array}{c}\text { Warikuraya } \\
\text { ma }\end{array}$ & $\begin{array}{l}\text { Tazawako- } \\
\text { toho }\end{array}$ & Senya & Kanazawa & Omoriyama \\
\hline Description & $\begin{array}{l}\text { N-S trending } \\
\text { west- } \\
\text { dipping } \\
\text { reverse fault } \\
\text { along the } \\
\text { western } \\
\text { margin of } \\
\text { the Kitakami } \\
\text { Basin in } \\
\text { northern } \\
\text { Honshu }\end{array}$ & $\begin{array}{l}\mathrm{N}-\mathrm{S} \text { trending } \\
\text { west-dipping } \\
\text { reverse fault } \\
\text { along the } \\
\text { western } \\
\text { margin of } \\
\text { the Kitakami } \\
\text { Basin in } \\
\text { northern } \\
\text { Honshu }\end{array}$ & $\begin{array}{l}\text { N-S trending } \\
\text { west-dipping } \\
\text { reverse fault } \\
\text { along the } \\
\text { western } \\
\text { margin of } \\
\text { the Kitakami } \\
\text { Basin in } \\
\text { northern } \\
\text { Honshu }\end{array}$ & $\begin{array}{l}\mathrm{N}-\mathrm{S} \text { trending } \\
\text { west-dipping } \\
\text { reverse fault } \\
\text { along the } \\
\text { western margin } \\
\text { of the } \\
\text { Shizukuishi } \\
\text { Basin in } \\
\text { northern Honshu }\end{array}$ & $\begin{array}{l}\text { NNE-SSW } \\
\text { trending } \\
\text { west-dipping } \\
\text { reverse fault } \\
\text { along the } \\
\text { eastern } \\
\text { margin of } \\
\text { the Mahiru } \\
\text { Mountains } \\
\text { in northern } \\
\text { Honshu, } \\
\text { ruptured } \\
\text { during the } \\
\text { 1896 Rikuu } \\
\text { earthquake }\end{array}$ & $\begin{array}{l}\text { N-S trending } \\
\text { west-dipping } \\
\text { reverse fault } \\
\text { along the } \\
\text { eastern } \\
\text { margin of } \\
\text { the Mahiru } \\
\text { Mountains } \\
\text { in northern } \\
\text { Honshu }\end{array}$ & $\begin{array}{l}\text { N-S trending } \\
\text { east-dipping } \\
\text { reverse fault } \\
\text { along the } \\
\text { eastern shore } \\
\text { of Lake } \\
\text { Tazawa in } \\
\text { northern } \\
\text { Honshu, } \\
\text { partly } \\
\text { ruptured } \\
\text { during } 1896 \\
\text { Rikuu } \\
\text { earthquake }\end{array}$ & $\begin{array}{l}\text { N-S trending } \\
\text { east-dipping } \\
\text { reverse fault } \\
\text { along the } \\
\text { eastern } \\
\text { margin of } \\
\text { the Yokote } \\
\text { Basin in } \\
\text { northern } \\
\text { Honshu, } \\
\text { ruptured } \\
\text { during the } \\
\text { 1896 Rikuu } \\
\text { earthquake }\end{array}$ & $\begin{array}{l}\mathrm{N}-\mathrm{S} \text { trending } \\
\text { east-dipping } \\
\text { reverse fault } \\
\text { along the } \\
\text { eastern } \\
\text { margin of } \\
\text { the Yokote } \\
\text { Basin in } \\
\text { northern } \\
\text { Honshu }\end{array}$ & $\begin{array}{c}\mathrm{N}-\mathrm{S} \text { trending } \\
\text { east-dipping } \\
\text { reverse fault } \\
\text { along the } \\
\text { eastern } \\
\text { margin of the } \\
\text { Yokote Basin } \\
\text { in northern } \\
\text { Honshu }\end{array}$ \\
\hline Trend & $10^{\circ}$ & $10^{\circ}$ & $350^{\circ}$ & $10^{\circ}$ & $20^{\circ}$ & $0^{\circ}$ & $0^{\circ}$ & $10^{\circ}$ & $0^{\circ}$ & $350^{\circ}$ \\
\hline Dip & $45^{\circ} \mathrm{W}$ & $45^{\circ} \mathrm{W}$ & $45^{\circ} \mathrm{W}$ & $45^{\circ} \mathrm{W}$ & $45^{\circ} \mathrm{W}$ & $45^{\circ} \mathrm{W}$ & $45^{\circ} \mathrm{E}$ & $30^{\circ} \mathrm{E}$ & $45^{\circ} \mathrm{E}$ & $45^{\circ} \mathrm{E}$ \\
\hline Length & $11 \mathrm{Km}$ & $42 \mathrm{Km}$ & $27 \mathrm{Km}$ & $21 \mathrm{Km}$ & $24 \mathrm{Km}$ & $17 \mathrm{Km}$ & $10 \mathrm{Km}$ & $24 \mathrm{Km}$ & $17 \mathrm{Km}$ & $23 \mathrm{Km}$ \\
\hline $\begin{array}{l}\text { Sense of } \\
\text { faulting }\end{array}$ & Reverse & Reverse & Reverse & Reverse & Reverse & Reverse & Reverse & Reverse & Reverse & Reverse \\
\hline Upthrown side & West & West & West & West & West & West & East & East & East & East \\
\hline Slip rate & $\begin{array}{c}0.0 \mathrm{~m} / \mathrm{K} \\
\text { years }\end{array}$ & $\begin{array}{c}0.6 \mathrm{~m} / \mathrm{K} \\
\text { years }\end{array}$ & $\begin{array}{c}0.2 \mathrm{~m} / \mathrm{K} \\
\text { years }\end{array}$ & $0.6 \mathrm{~m} / \mathrm{K}$ years & $\begin{array}{c}0.1 \mathrm{~m} / \mathrm{K} \\
\text { years }\end{array}$ & $\begin{array}{c}0.0 \mathrm{~m} / \mathrm{K} \\
\text { years }\end{array}$ & $0.3 \mathrm{~m} / \mathrm{K}$ years & $\begin{array}{c}0.8 \mathrm{~m} / \mathrm{K} \\
\text { years }\end{array}$ & $\begin{array}{c}0.3 \mathrm{~m} / \mathrm{K} \\
\text { years }\end{array}$ & $\begin{array}{c}0.2 \mathrm{~m} / \mathrm{K} \\
\text { years }\end{array}$ \\
\hline Slip per Event & ----- & $4.9 \mathrm{~m}$ & $3.1 \mathrm{~m}$ & $2.4 \mathrm{~m}$ & $2.2 \mathrm{~m}$ & ---- & $1.2 \mathrm{~m}$ & $2.9 \mathrm{~m}$ & $2.0 \mathrm{~m}$ & $2.7 \mathrm{~m}$ \\
\hline $\begin{array}{c}\text { Recurrence } \\
\text { Interval }\end{array}$ & ----- & 8200 years & 13000 years & 4300 years & 22000 years & ----- & 3900 years & 3700 years & 6700 years & 16000 years \\
\hline $\begin{array}{l}\text { Elapsed time } \\
\text { rate }\end{array}$ & ---- & 0.51 & ----- & 0.41 & 0.0 & ----- & ----- & 0.03 & ----- & ----- \\
\hline $\begin{array}{c}\text { Rupture } \\
\text { Probability in } \\
\text { next } 30 \text { years }\end{array}$ & ----- & $0.4 \%$ & $0.2 \%$ & $0.7 \%$ & $0.1 \%$ & ----- & $0.8 \%$ & $0.8 \%$ & $0.5 \%$ & $0.2 \%$ \\
\hline
\end{tabular}




\begin{tabular}{|c|c|c|c|c|}
\hline Symbol & $\mathbf{k}$ & 1 & $\mathbf{m}$ & n \\
\hline Name & Takinosawa & Nakacho & Toridame & Kitayuri \\
\hline Description & $\begin{array}{l}\mathrm{N}-\mathrm{S} \text { trending } \\
\text { west-dipping } \\
\text { reverse fault in } \\
\text { northern } \\
\text { Honshu }\end{array}$ & $\begin{array}{l}\text { NNE-SSW } \\
\text { trending west- } \\
\text { dipping } \\
\text { reverse fault } \\
\text { in northern } \\
\text { Honshu }\end{array}$ & $\begin{array}{l}\mathrm{N}-\mathrm{S} \text { trending } \\
\text { east-dipping } \\
\text { reverse fault in } \\
\text { northern } \\
\text { Honshu }\end{array}$ & $\begin{array}{l}\text { N-S trending east- } \\
\text { dipping reverse } \\
\text { fault along the } \\
\text { western offshore of } \\
\text { northern Honshu }\end{array}$ \\
\hline Trend & $0^{\circ}$ & $20^{\circ}$ & $0^{\circ}$ & $0^{\circ}$ \\
\hline Dip & $45^{\circ} \mathrm{W}$ & $45^{\circ} \mathrm{W}$ & $45^{\circ} \mathrm{E}$ & $45^{\circ} \mathrm{E}$ \\
\hline Length & $18 \mathrm{Km}$ & $9 \mathrm{Km}$ & $11 \mathrm{Km}$ & $29 \mathrm{Km}$ \\
\hline $\begin{array}{l}\text { Sense of } \\
\text { faulting }\end{array}$ & Reverse & Reverse & Reverse & Reverse \\
\hline Upthrown side & West & West & East & East \\
\hline Slip rate & $0.0 \mathrm{~m} / \mathrm{K}$ years & $0.1 \mathrm{~m} / \mathrm{K}$ years & $0.0 \mathrm{~m} / \mathrm{K}$ years & $0.9 \mathrm{~m} / \mathrm{K}$ years \\
\hline Slip per Event & ----- & ----- & ----- & $3.4 \mathrm{~m}$ \\
\hline $\begin{array}{l}\text { Recurrence } \\
\text { Interval }\end{array}$ & ----- & ----- & ----- & 3600 years \\
\hline $\begin{array}{c}\text { Elapsed time } \\
\text { rate }\end{array}$ & ----- & ----- & ----- & 0.41 \\
\hline $\begin{array}{c}\text { Rupture } \\
\text { Probability in } \\
\text { next } 30 \text { years }\end{array}$ & ----- & ----- & ----- & $0.8 \%$ \\
\hline
\end{tabular}




\begin{tabular}{|c|c|c|c|c|}
\hline Symbol & $\mathbf{a}$ & b & c & d \\
\hline Name & Watari & Haramachi & Namie & Sangunmori \\
\hline Description & $\begin{array}{l}\text { N-S trending west- } \\
\text { dipping reverse } \\
\text { fault along the } \\
\text { eastern margin of } \\
\text { the Abukuma } \\
\text { Mountains in } \\
\text { northern Honshu }\end{array}$ & $\begin{array}{l}\text { N-S trending left- } \\
\text { lateral strike-slip } \\
\text { fault with west- } \\
\text { side-up vertical } \\
\text { displacement along } \\
\text { the eastern margin } \\
\text { of the Abukuma } \\
\text { Mountains in } \\
\text { northern Honshu }\end{array}$ & $\begin{array}{l}\text { N-S trending west- } \\
\text { dipping reverse } \\
\text { fault along the } \\
\text { eastern margin of } \\
\text { the Abukuma } \\
\text { Mountains in } \\
\text { northern Honshu }\end{array}$ & $\begin{array}{l}\text { N-S trending left- } \\
\text { lateral strike-slip } \\
\text { fault with east- } \\
\text { side-up vertical } \\
\text { displacement in the } \\
\text { Abukuma } \\
\text { Mountains, } \\
\text { northern Honshu }\end{array}$ \\
\hline Trend & $350^{\circ}$ & $350^{\circ}$ & $350^{\circ}$ & $0^{\circ}$ \\
\hline Dip & $80^{\circ} \mathrm{W}$ & $90^{\circ} \mathrm{V}$ & $80^{\circ} \mathrm{W}$ & $90^{\circ} \mathrm{V}$ \\
\hline Length & $21 \mathrm{Km}$ & $21 \mathrm{Km}$ & $53 \mathrm{Km}$ & $15 \mathrm{Km}$ \\
\hline Sense of faulting & Reverse & L-lateral & Reverse & L-lateral \\
\hline Upthrown side & West & West & West & East \\
\hline Slip rate & $0.1 \mathrm{~m} / \mathrm{K}$ years & $0.1 \mathrm{~m} / \mathrm{K}$ years & $0.0 \mathrm{~m} / \mathrm{K}$ years & $0.1 \mathrm{~m} / \mathrm{K}$ years \\
\hline Slip per Event & $2.4 \mathrm{~m}$ & $1.5 \mathrm{~m}$ & ----- & $1.7 \mathrm{~m}$ \\
\hline $\begin{array}{c}\text { Recurrence } \\
\text { Interval }\end{array}$ & 24000 years & 10000 years & ---- & 17000 years \\
\hline $\begin{array}{c}\text { Elapsed time } \\
\text { rate }\end{array}$ & ----- & 0.20 & ----- & ----- \\
\hline $\begin{array}{c}\text { Rupture } \\
\text { Probability in } \\
\text { next } 30 \text { years }\end{array}$ & $0.1 \%$ & $0.3 \%$ & ----- & $0.2 \%$ \\
\hline
\end{tabular}


Table 4: Detailed numbers of seismic stations and recorded earthquakes at the three study areas.

\begin{tabular}{|c|c|c|c|c|c|c|c|c|}
\hline & \multicolumn{2}{|c|}{ East Hokkaido } & \multicolumn{2}{|c|}{ Fukushima } & & \multicolumn{2}{|c|}{ Akita-Iwate } \\
\hline & & K-NET & KiK-net & K-NET & KiK-net & & K-NET & KiK-net \\
\hline \multirow{2}{*}{ FW } & Sta. & 5 & 5 & 4 & 2 & \multirow{2}{*}{ r.FW } & 16 & 11 \\
\hline & Eq. & \multicolumn{2}{|c|}{2925} & \multicolumn{2}{|c|}{6618} & & \multicolumn{2}{|c|}{6081} \\
\hline \multirow{2}{*}{ FZ } & Sta. & 3 & 2 & --- & --- & \multirow{2}{*}{$\begin{array}{c}\text { FZ } \\
\text { (Upthrown side) }\end{array}$} & 5 & 6 \\
\hline & Eq. & & & & 2 & & \multicolumn{2}{|c|}{3114} \\
\hline \multirow{2}{*}{ HW } & Sta. & 17 & 10 & 14 & 8 & \multirow{2}{*}{ 1.FW } & 10 & 8 \\
\hline & Eq. & & & & & & \multicolumn{2}{|c|}{573} \\
\hline
\end{tabular}

830 (Note: Sta. is station, Eq. is earthquake, FW is footwall block, FZ is fault zone, HW is hanging wall block, and r.FW

831 and l.FW are right and left footwall blocks, respectively) area deduced from Figures 22, 23, and 24.

\begin{tabular}{|c|c|c|c|c|c|c|}
\hline & $\mathrm{SSA}_{\mathrm{OH}}$ & $\mathrm{SSA}_{\mathrm{OF}}$ & $\mathrm{SSA}_{\mathrm{HF}}$ & $\mathrm{SSA}_{\mathrm{FH}}$ \\
\hline \multirow{6}{*}{$\begin{array}{l}=\bar{J} \\
3 \\
0 \\
0 \\
0\end{array}$} & \multirow[t]{2}{*}{ EW } & $\mathrm{H}$. & 2.98 & 2.68 & 5.39 & --. \\
\hline & & L. & 0.29 & 0.45 & 0.86 & --- \\
\hline & \multirow[t]{2}{*}{ NS } & H. & 3.15 & 3.15 & 4.05 & --- \\
\hline & & L. & 0.35 & 0.57 & 0.89 & --- \\
\hline & \multirow[t]{2}{*}{ UD } & H. & 3.17 & 2.90 & 4.59 & --- \\
\hline & & L. & 0.25 & 0.52 & 0.87 & -- \\
\hline \multirow{6}{*}{ 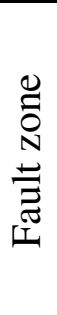 } & \multirow[t]{2}{*}{ EW } & H. & 3.25 & 2.28 & -- & 3.73 \\
\hline & & L. & 0.15 & 0.50 & --- & 0.69 \\
\hline & \multirow[t]{2}{*}{ NS } & H. & 3.35 & 2.39 & --- & 3.53 \\
\hline & & L. & 0.18 & 0.49 & --- & 0.65 \\
\hline & \multirow[t]{2}{*}{$\mathrm{UI}$} & $\mathrm{H}$. & 3.51 & 2.37 & --- & 3.39 \\
\hline & & L. & 0.22 & 0.52 & -- & 0.59 \\
\hline \multirow{6}{*}{$\begin{array}{l}\overline{\bar{\sigma}} \\
3 \\
00 \\
.00 \\
.00 \\
\bar{\Xi} \\
\text { I }\end{array}$} & \multirow[t]{2}{*}{ EW } & H. & 3.14 & 2.46 & --- & 1.61 \\
\hline & & L. & 0.69 & 0.74 & --- & 1.10 \\
\hline & \multirow[t]{2}{*}{$\mathrm{NS}$} & $\mathrm{H}$. & 2.97 & 2.25 & -- & 1.73 \\
\hline & & L. & 0.86 & 0.72 & -- & 1.22 \\
\hline & \multirow[t]{2}{*}{ UD } & H. & 2.98 & 2.66 & --- & 1.77 \\
\hline & & L. & 0.71 & 0.71 & --- & 1.09 \\
\hline
\end{tabular}


849 Table 6: Summary of highs and lows of site spectral amplifications in the Akita-Iwate study area 850 deduced from Figures 25, 26, and 27.

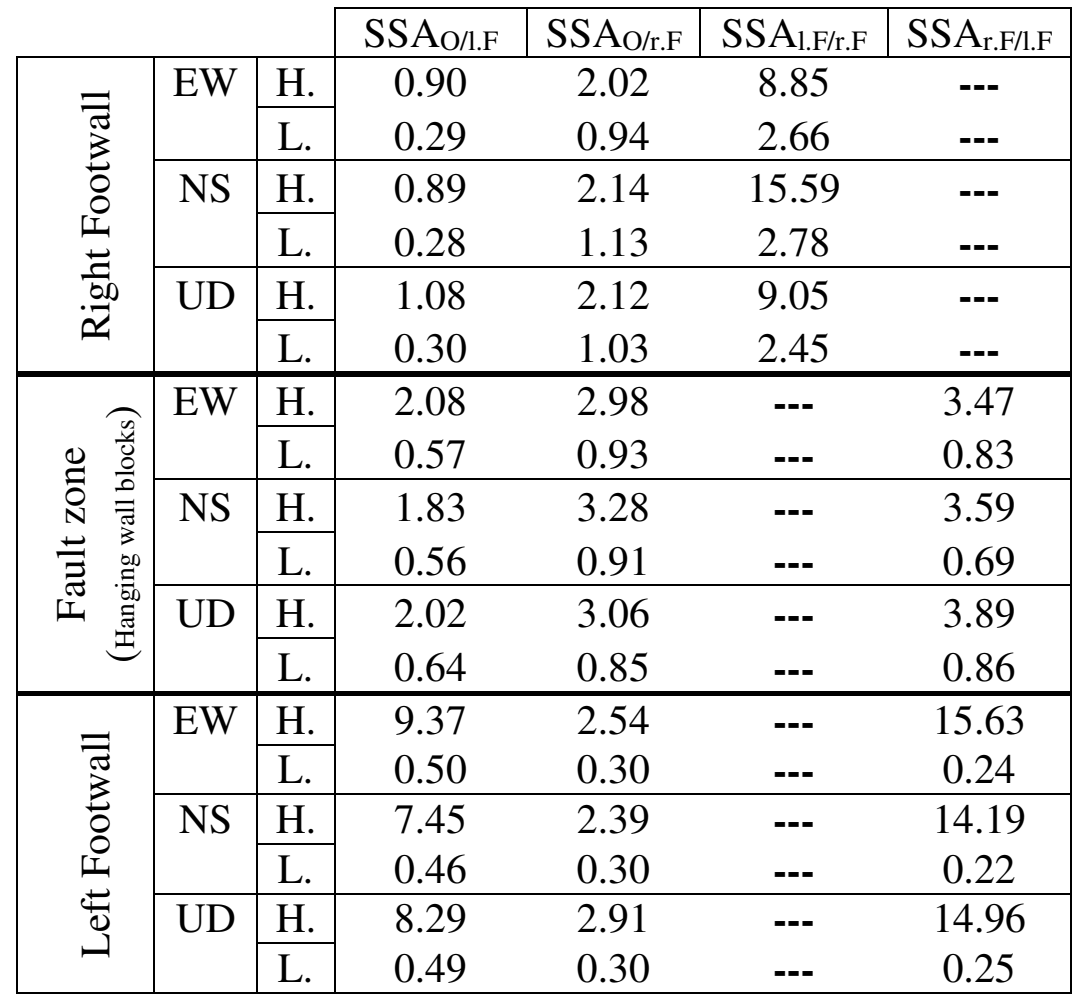

851 
859

860 Table 7: Summary of highs and lows of site spectral amplifications in the Fukushima study area 861 deduced from Figures 28 and 29.

862

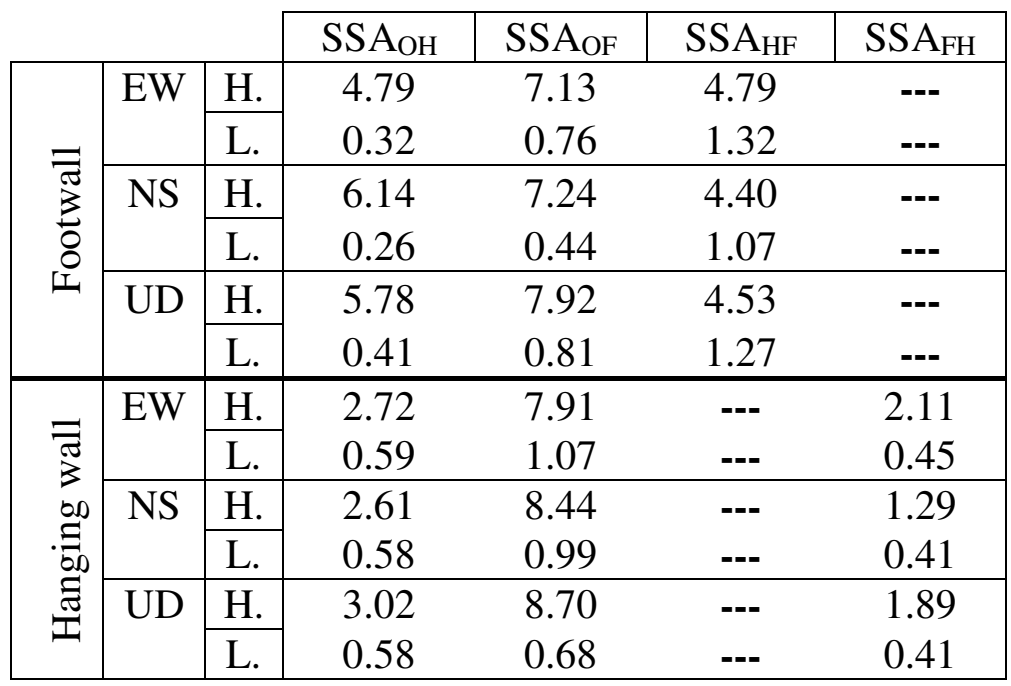


Figures

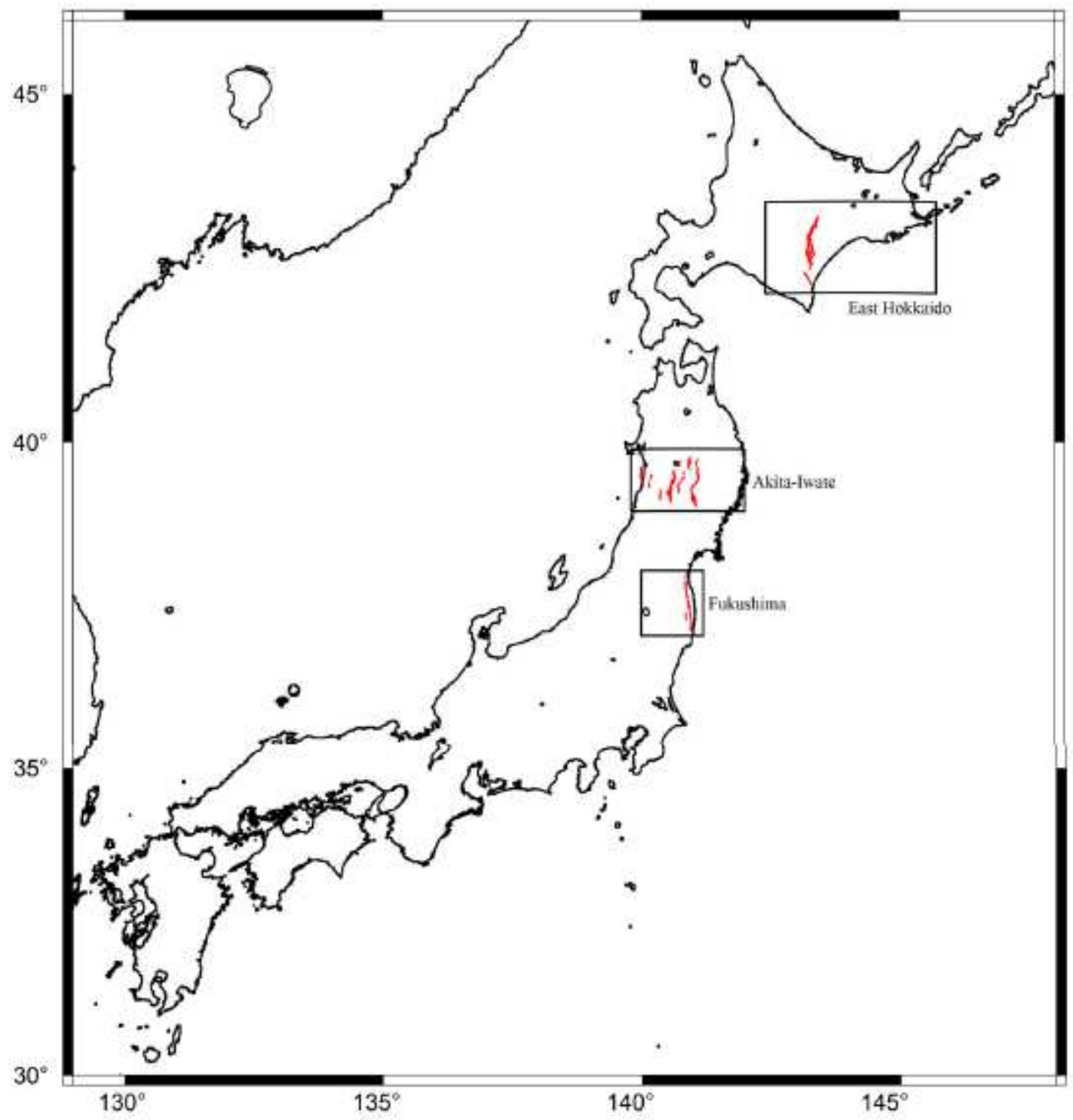

Figure 1

Location map for the three different study areas of East Hokkaido, Akita-Iwate, and Fukushima in Japan that are used in the present study. (Note: red lines are representing the active reverse fault traces) 

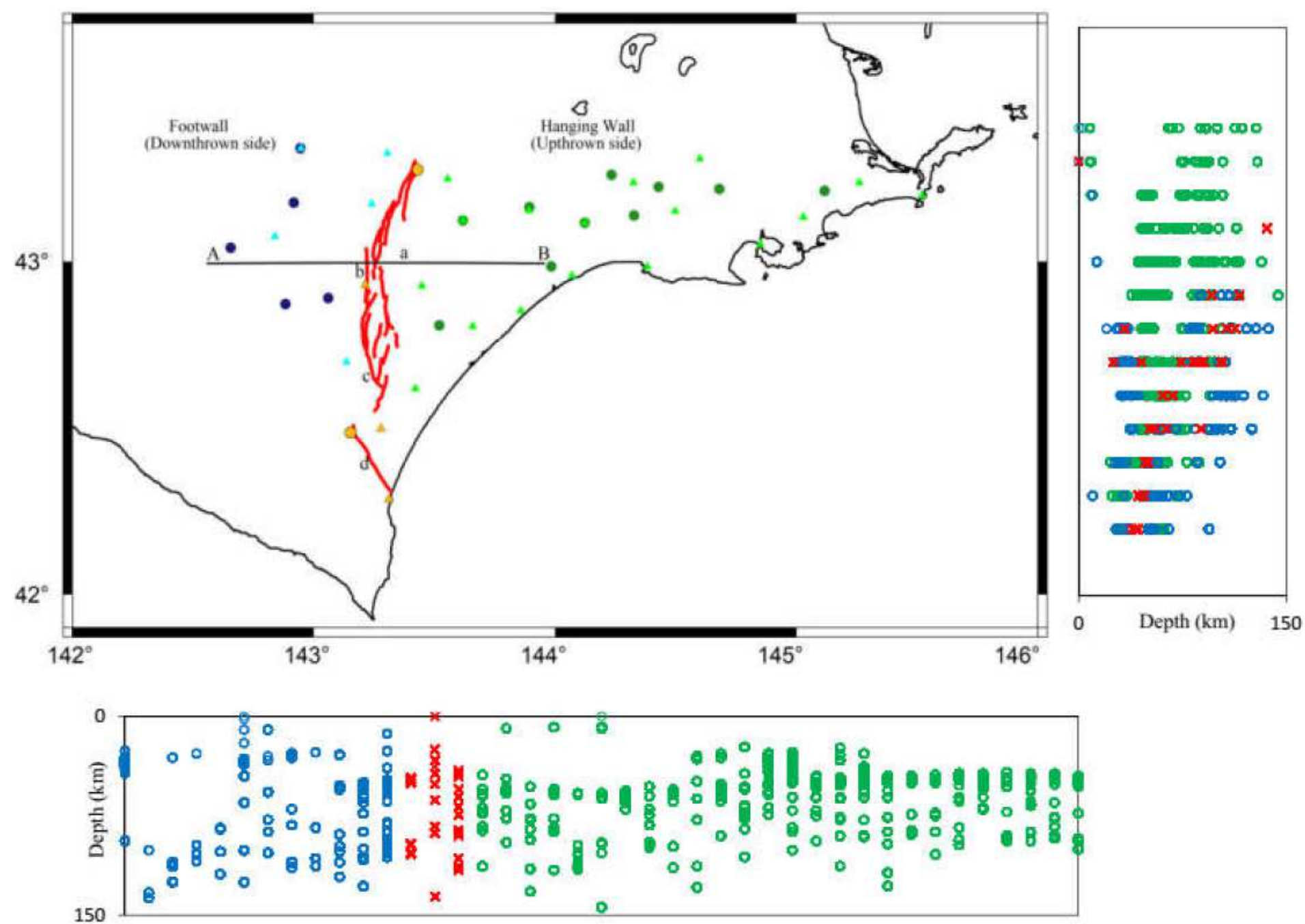

Figure 2

Distribution of K-NET (triangles) and KiK-net (circles) seismic stations and the recorded earthquakes with their focal depths in East Hokkaido study area. (Note: The station's color of blue, yellow, or green on map, and the focal depth's color of blue, red, or green are used to discriminate locations on and beneath FW, FZ, or $\mathrm{HW}$, respectively. Red lines on map are representing active reverse fault traces. $A B$ is profile across fault zones.) 

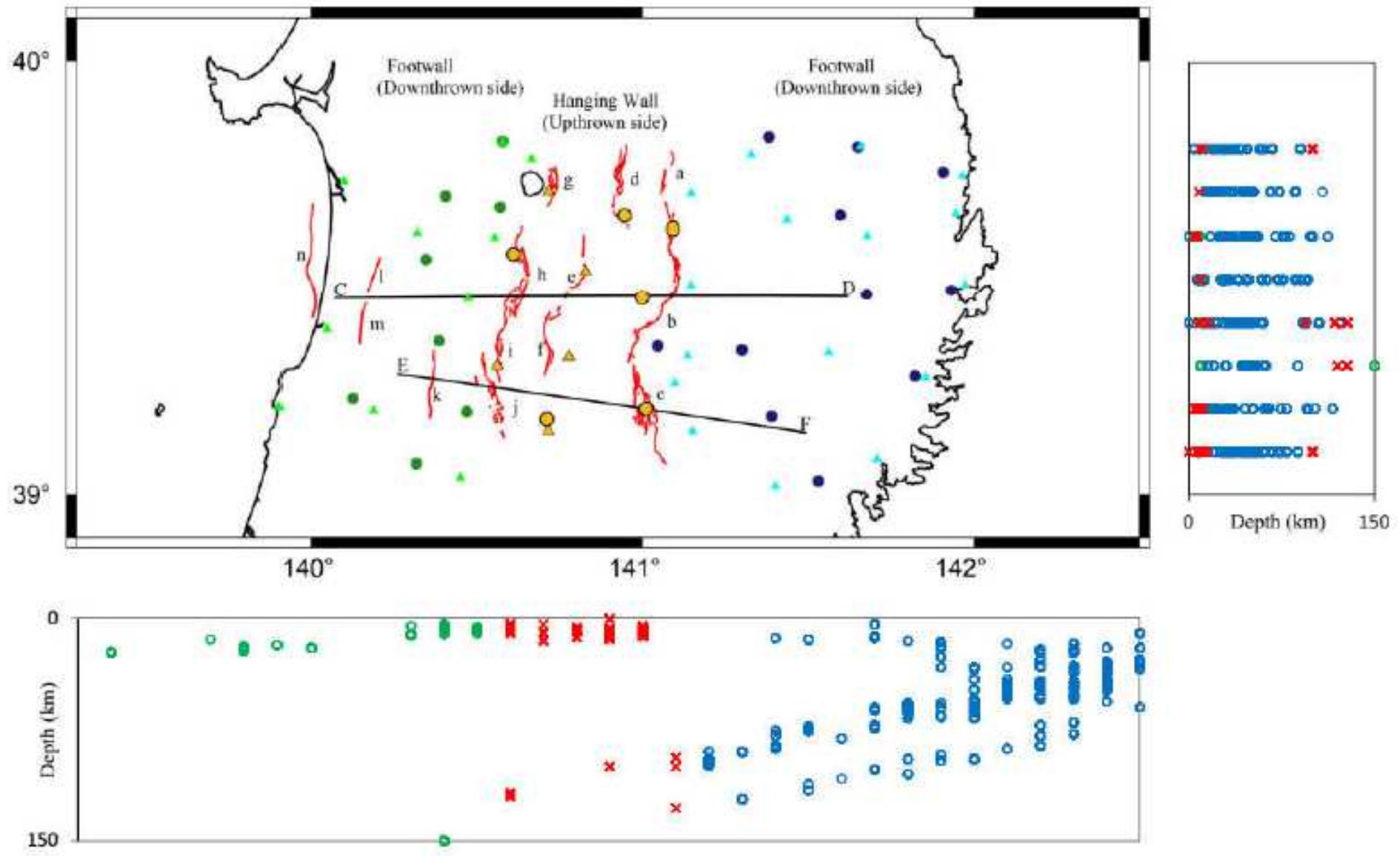

Figure 3

Distribution of K-NET (triangles) and KiK-net (circles) seismic stations and the recorded earthquakes with their focal depths in Akita-Iwate study area. (Note: On map, the colors of green, blue, and yellow are used to discriminate seismic stations located on left and right footwall blocks, and fault zone, respectively. For events, the colors of green, blue, and red are used to discriminate focal depths beneath left and right FW, and FZ, respectively. Red lines on map are representing active reverse fault traces. CD and EF are profiles across fault zones.) 

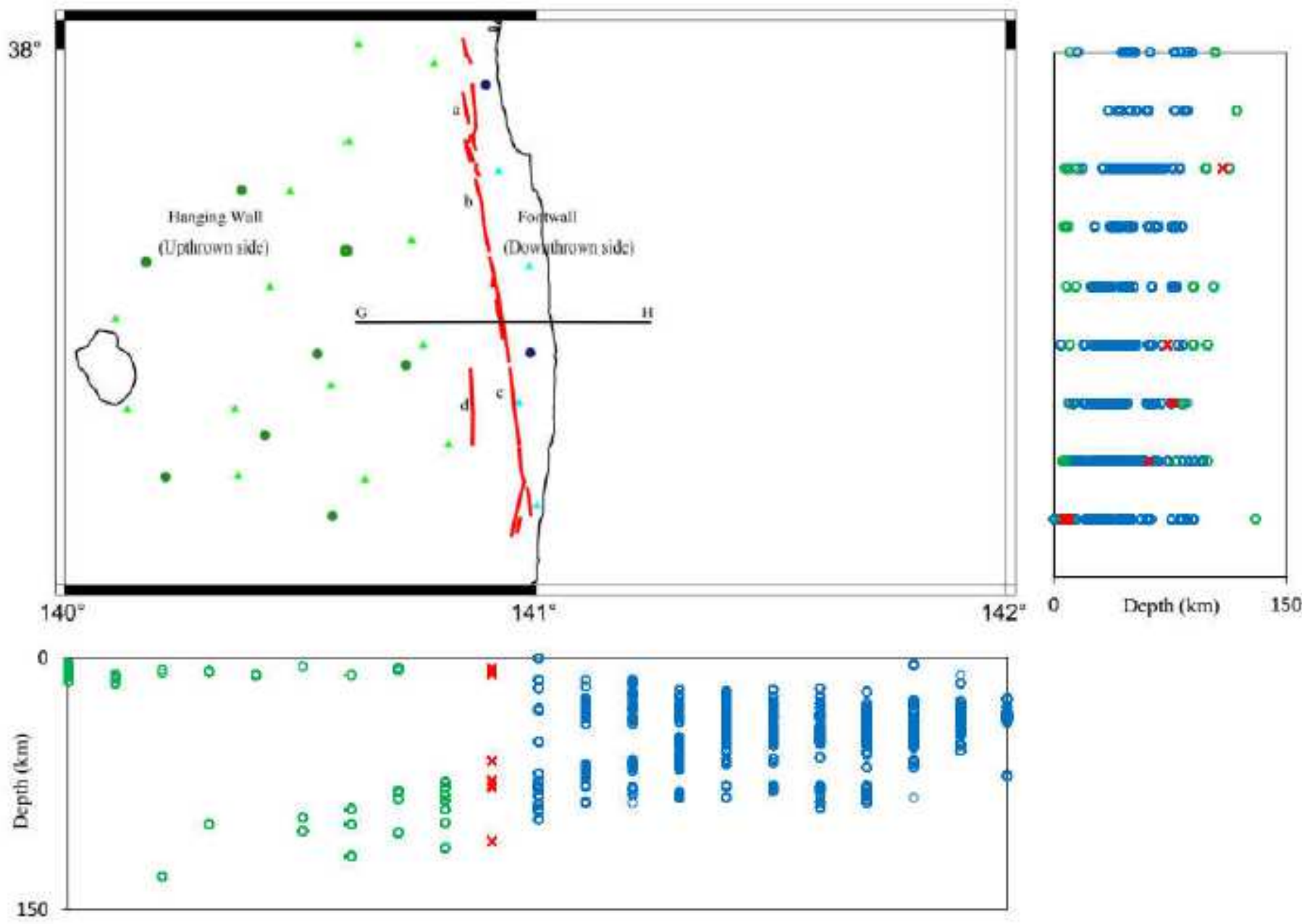

\section{Figure 4}

Distribution of K-NET (triangles) and KiK-net (circles) seismic stations and the recorded earthquakes with their focal depths in Fukushima study area. (Note: On map, the colors of green and blue are used to discriminate seismic stations located on hanging wall block and footwall blocks, respectively. For events, the colors of green, red, and blue are used to discriminate focal depths beneath HW, FZ, and FW, respectively. Red lines on map are representing active reverse fault traces. $\mathrm{GH}$ is profile across fault zones.) 

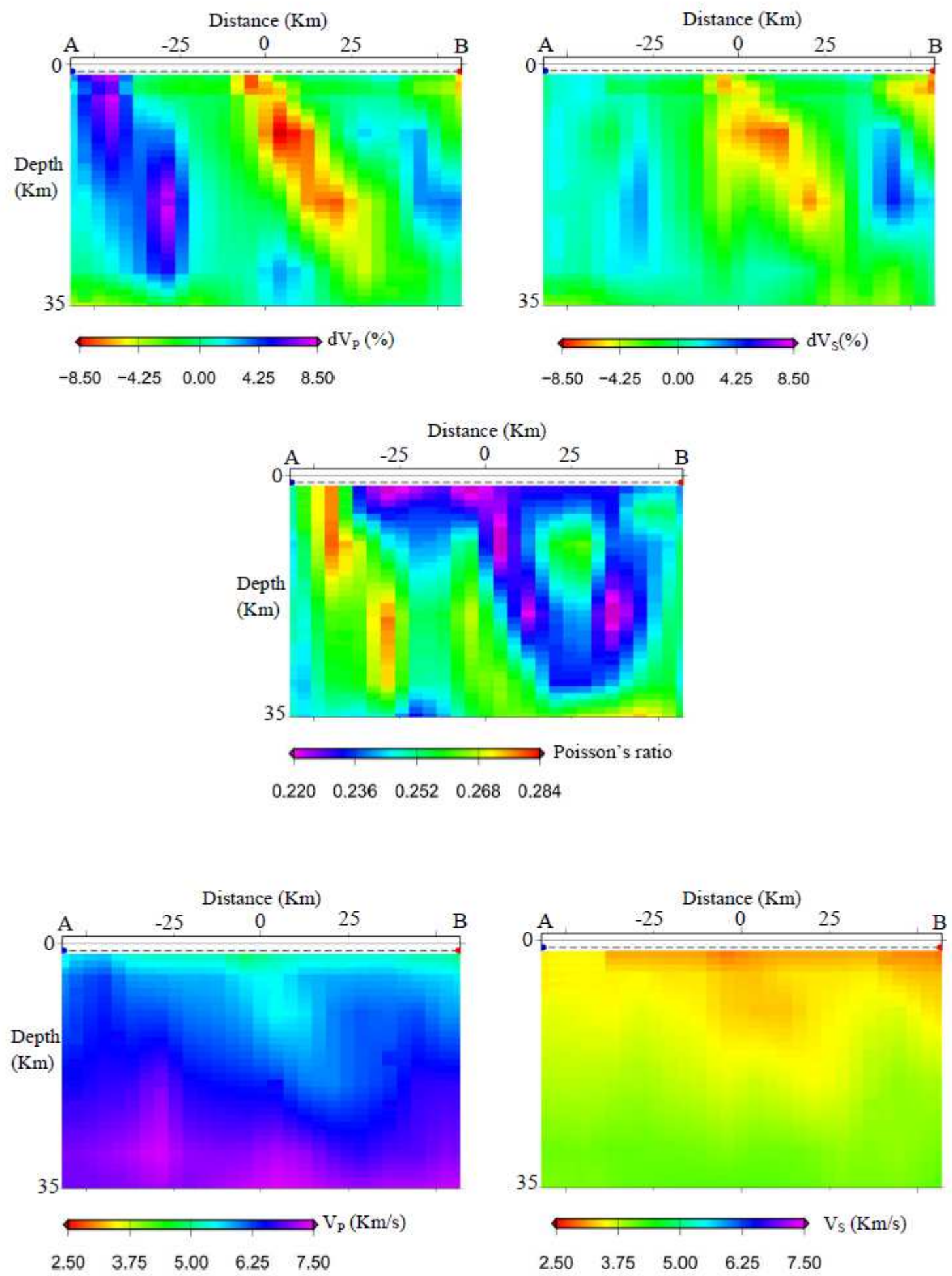

\section{Figure 5}

Subsurface tomography structures along profile $A B$ in East Hokkaido study area. 

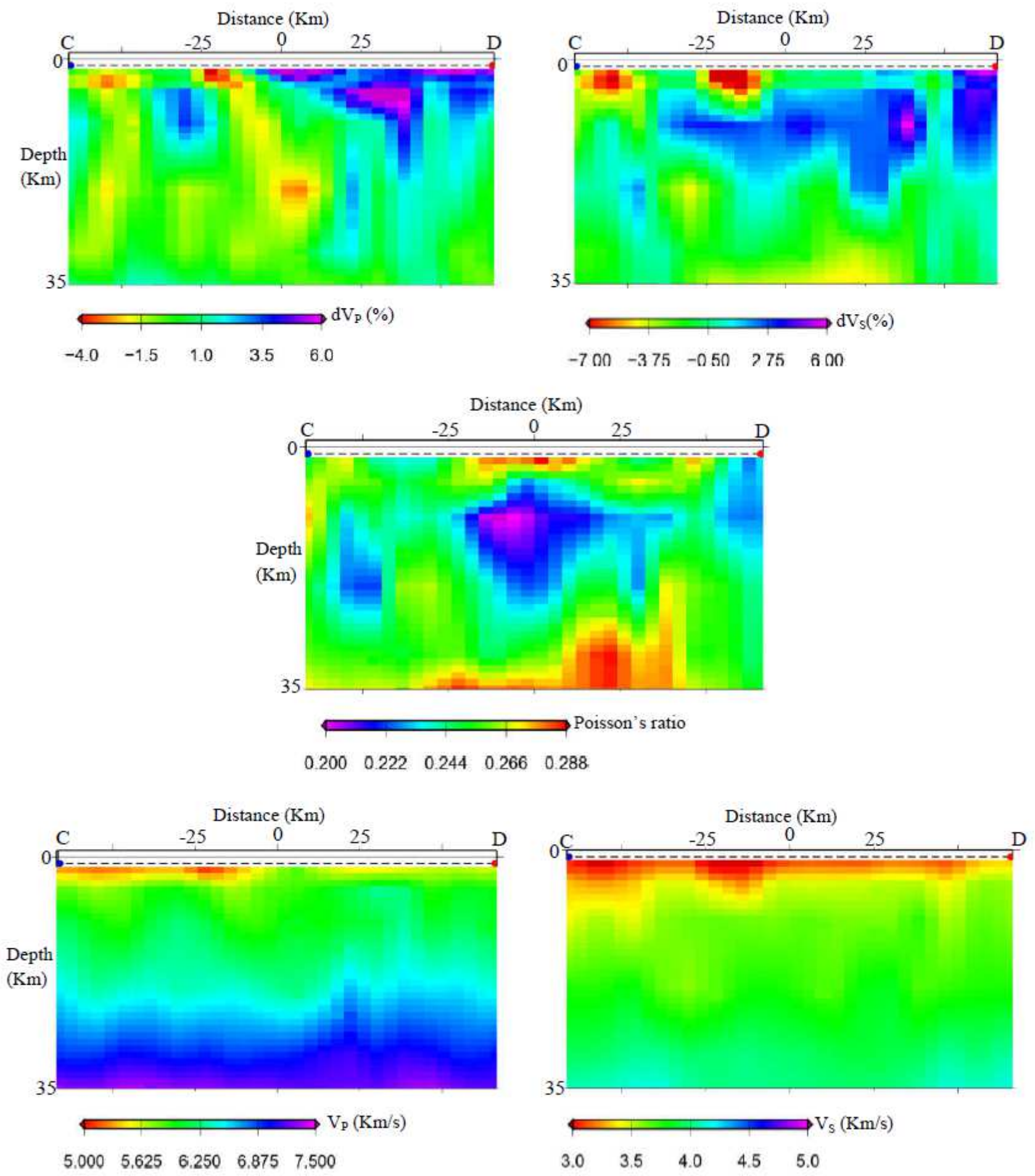

\section{Figure 6}

Subsurface tomography structures along profile CD in Akita-Iwate study area. 

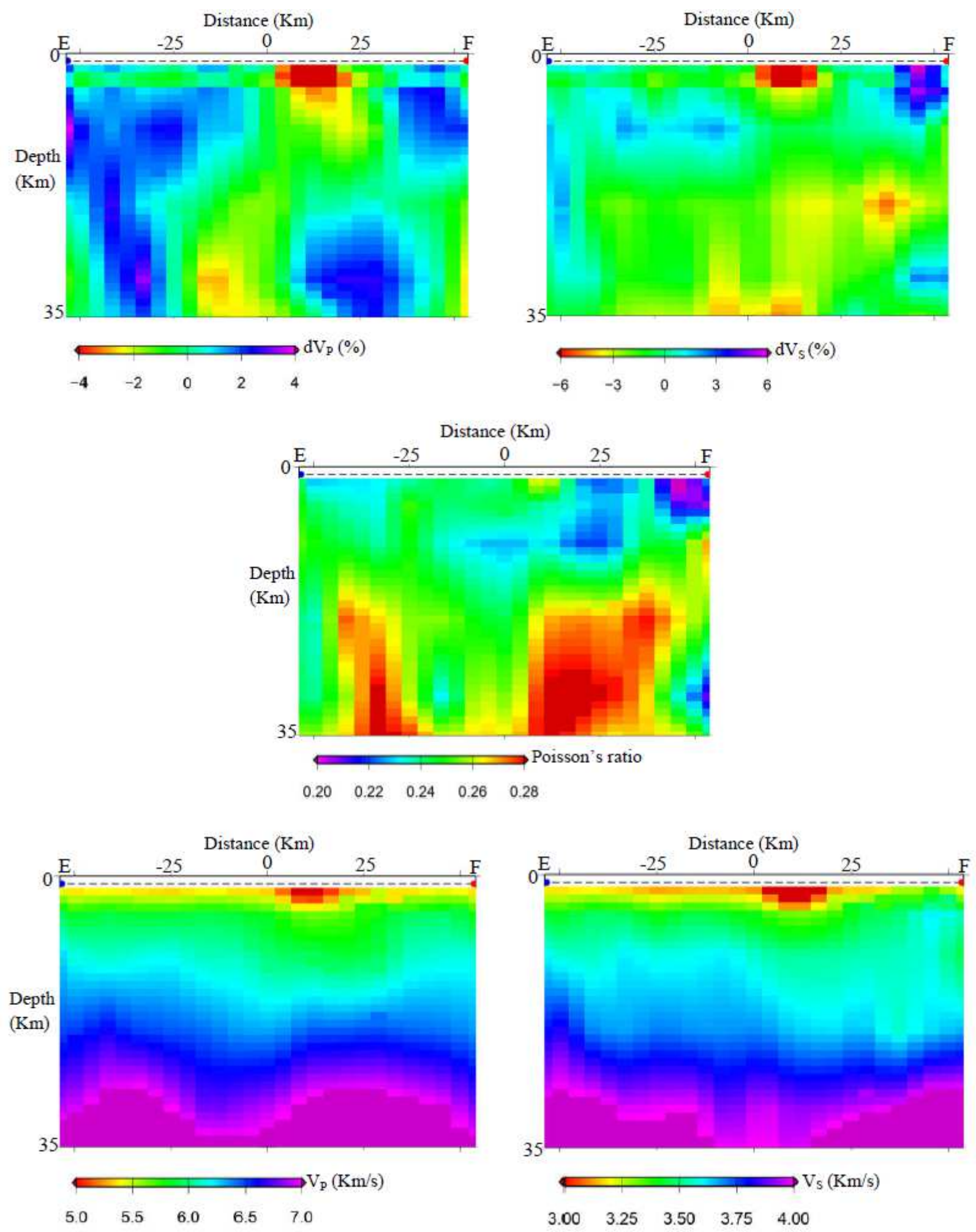

\section{Figure 7}

Subsurface tomography structures along profile EF in Akita-Iwate study area. 

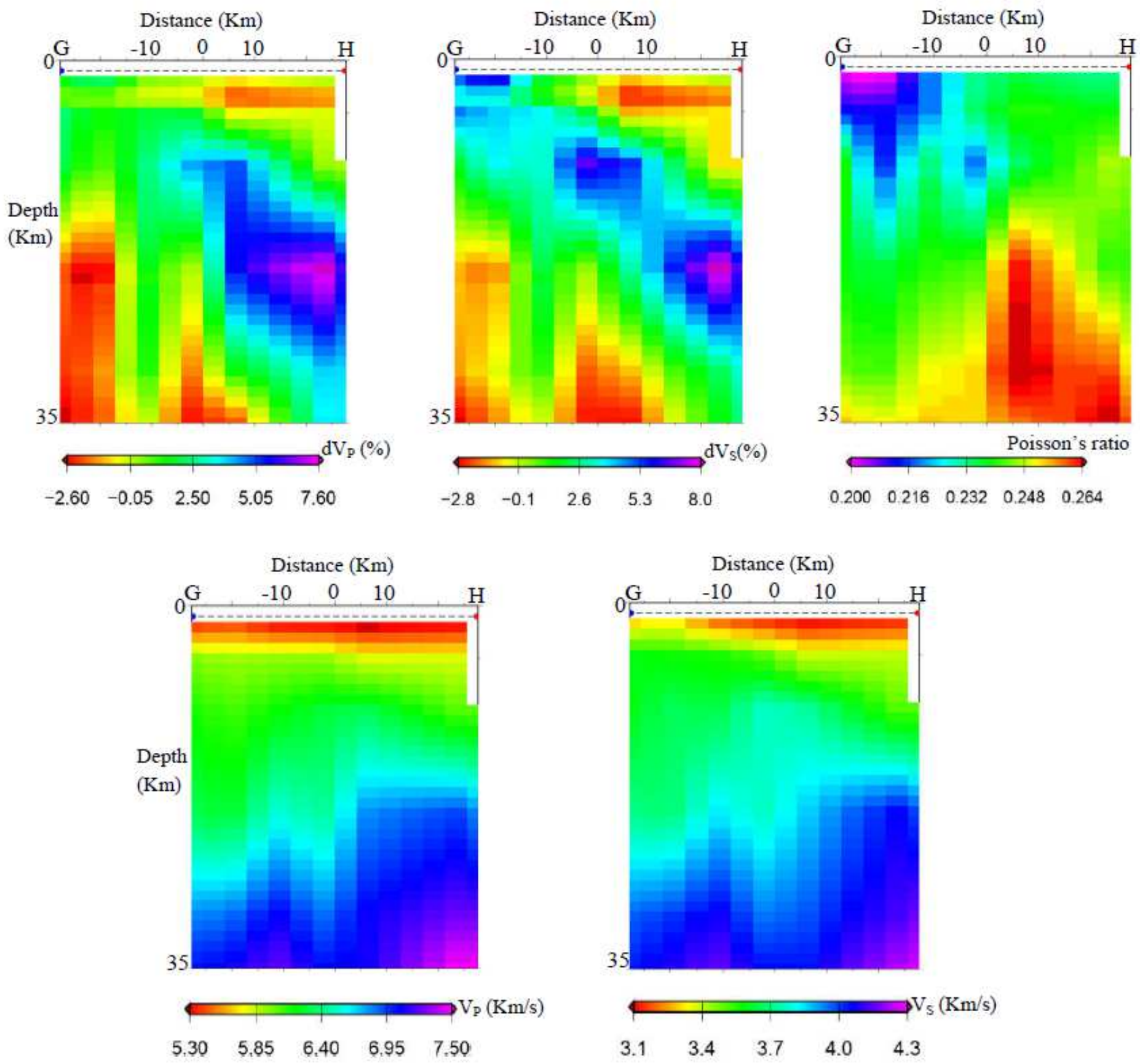

Figure 8

Subsurface tomography structures along profile GH in Fukushima study area based on calculation by Nakamura et al. (2008). 

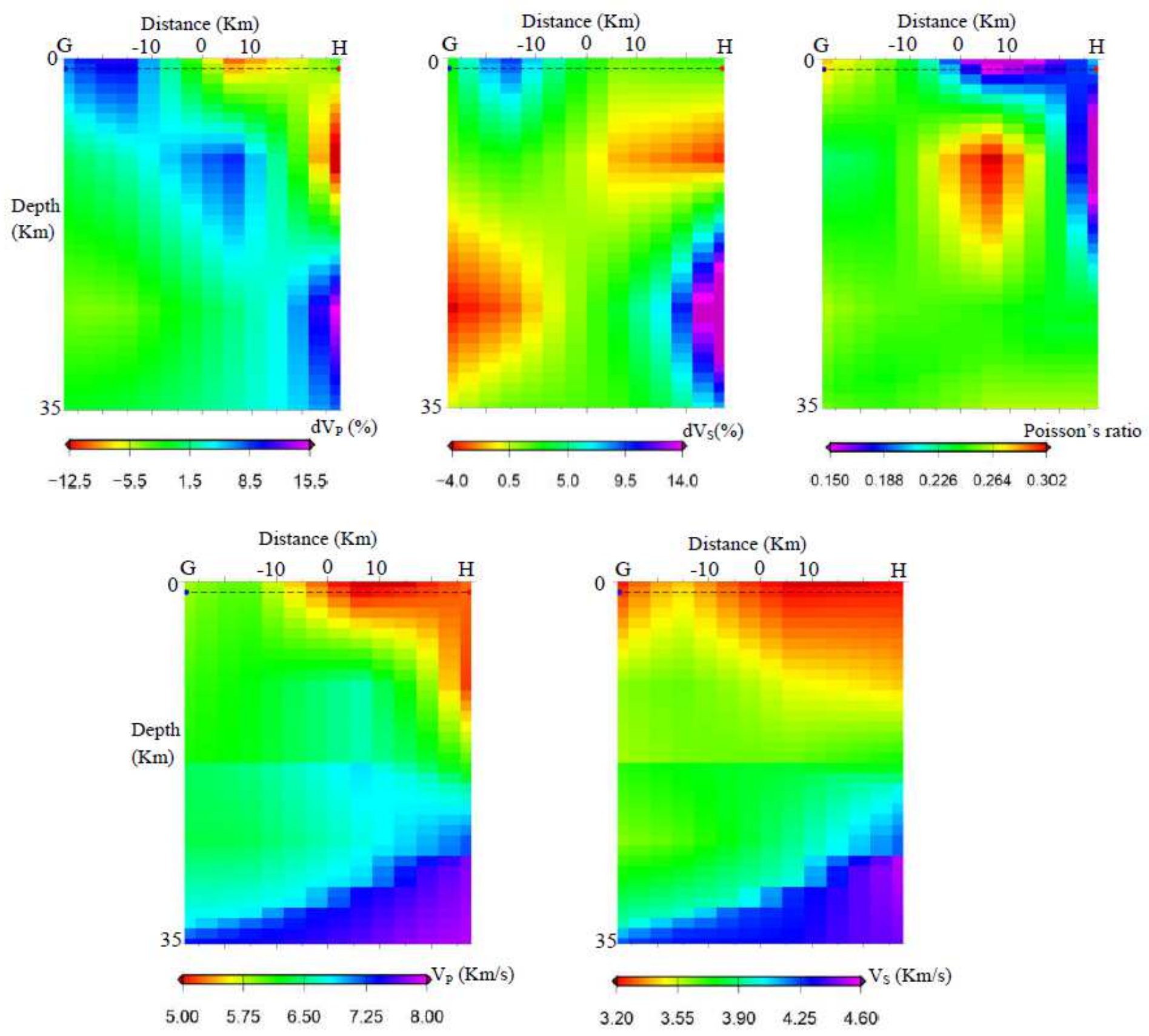

Figure 9

Subsurface tomography structures along profile GH in Fukushima study area based on calculation by Nakajima et al. (2001). 

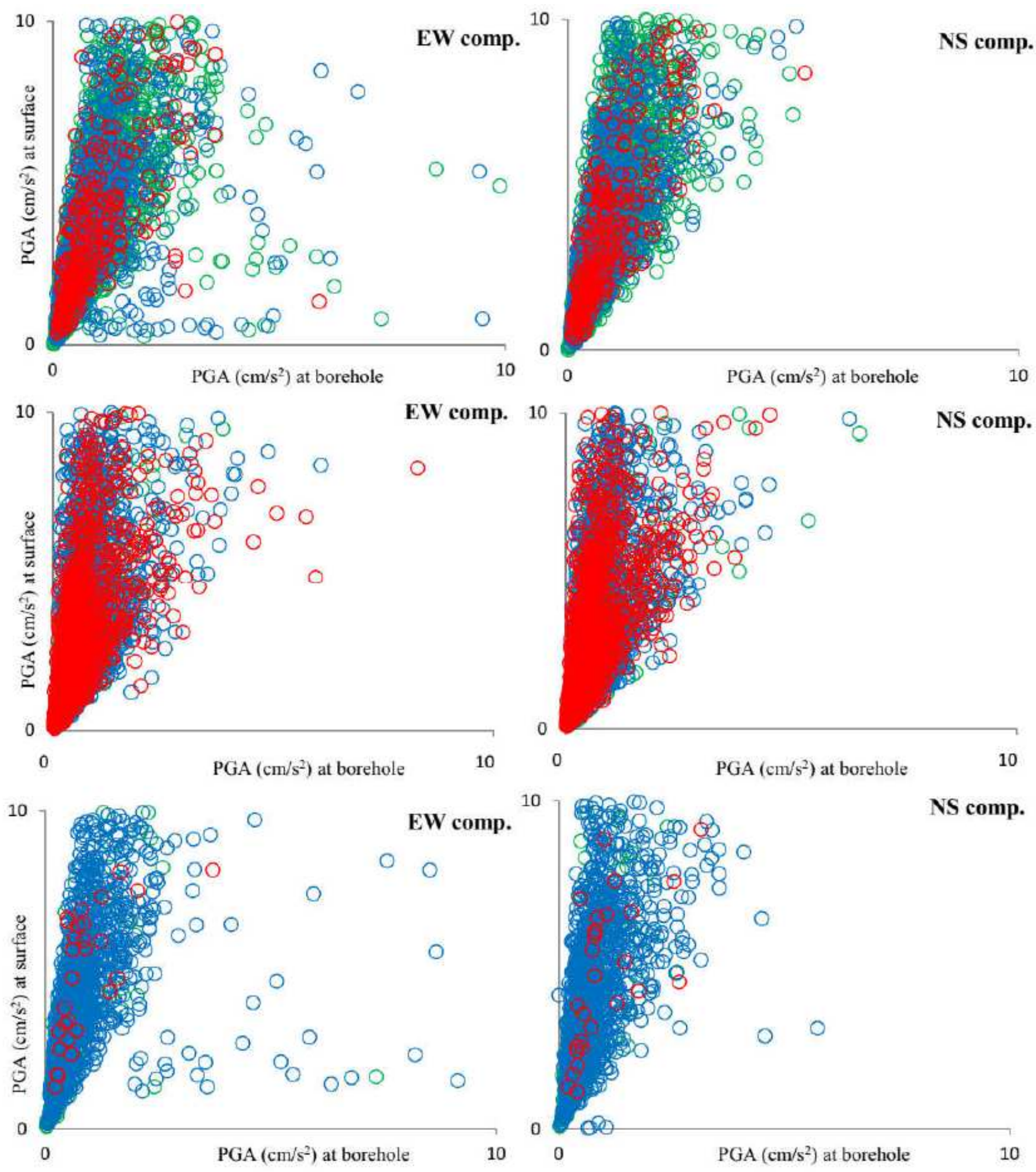

\section{Figure 10}

Correlation between PGAs of EW and NS components at surface and borehole obtained from KiK-net stations at the East Hokkaido (upper), Akita-Iwate (middle), and Fukushima (lower) study areas. (Note: colors of green, blue, and red are used to discriminate PGAs on HW (I.FW in the Akita-Iwate study rea), FW (r.FW in Akita-Iwate study area), and FZ (upthrown blocks in the Akita-Iwate study area), respectively) 

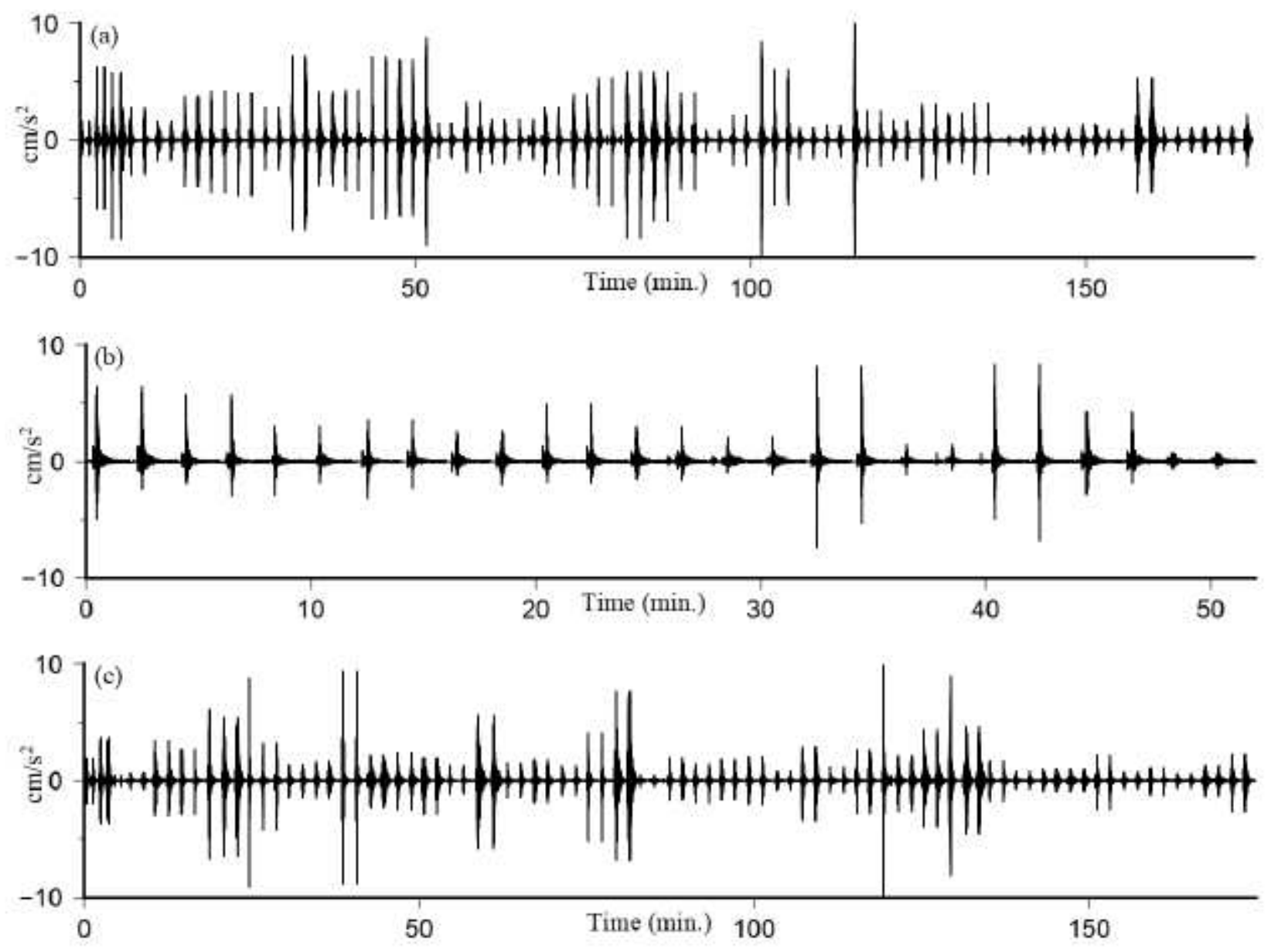

Figure 11

Example of continuous time series of EW components recorded at $\mathrm{TKCH} 05$ KiK-net station with their hypocenters located beneath FW (a), FZ (b), HW (c). 

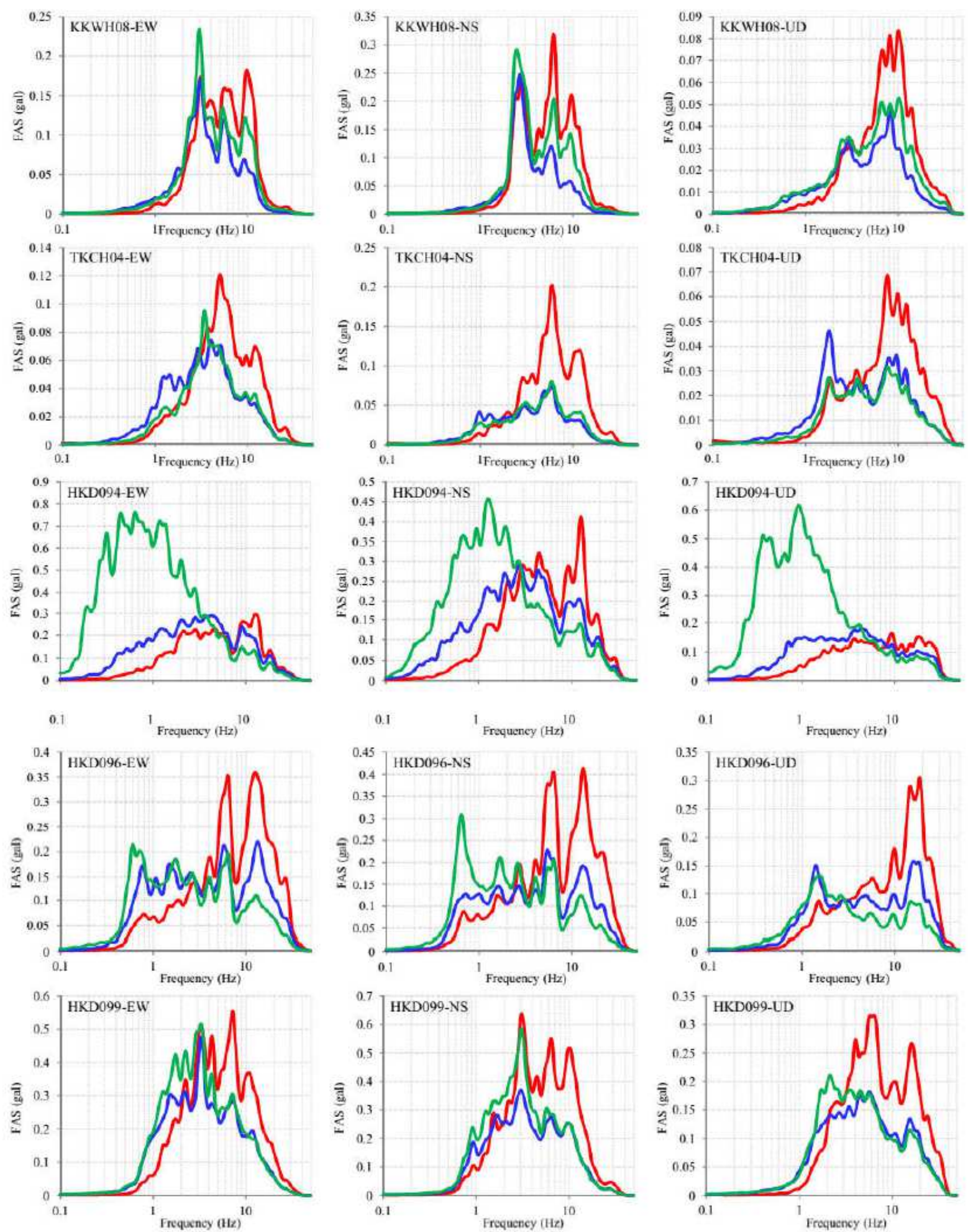

Figure 12

FASs at seismic stations located on FW block in the East Hokkaido study area due to recorded EFWs (blue), EFZs (red), and EHWs (green). 

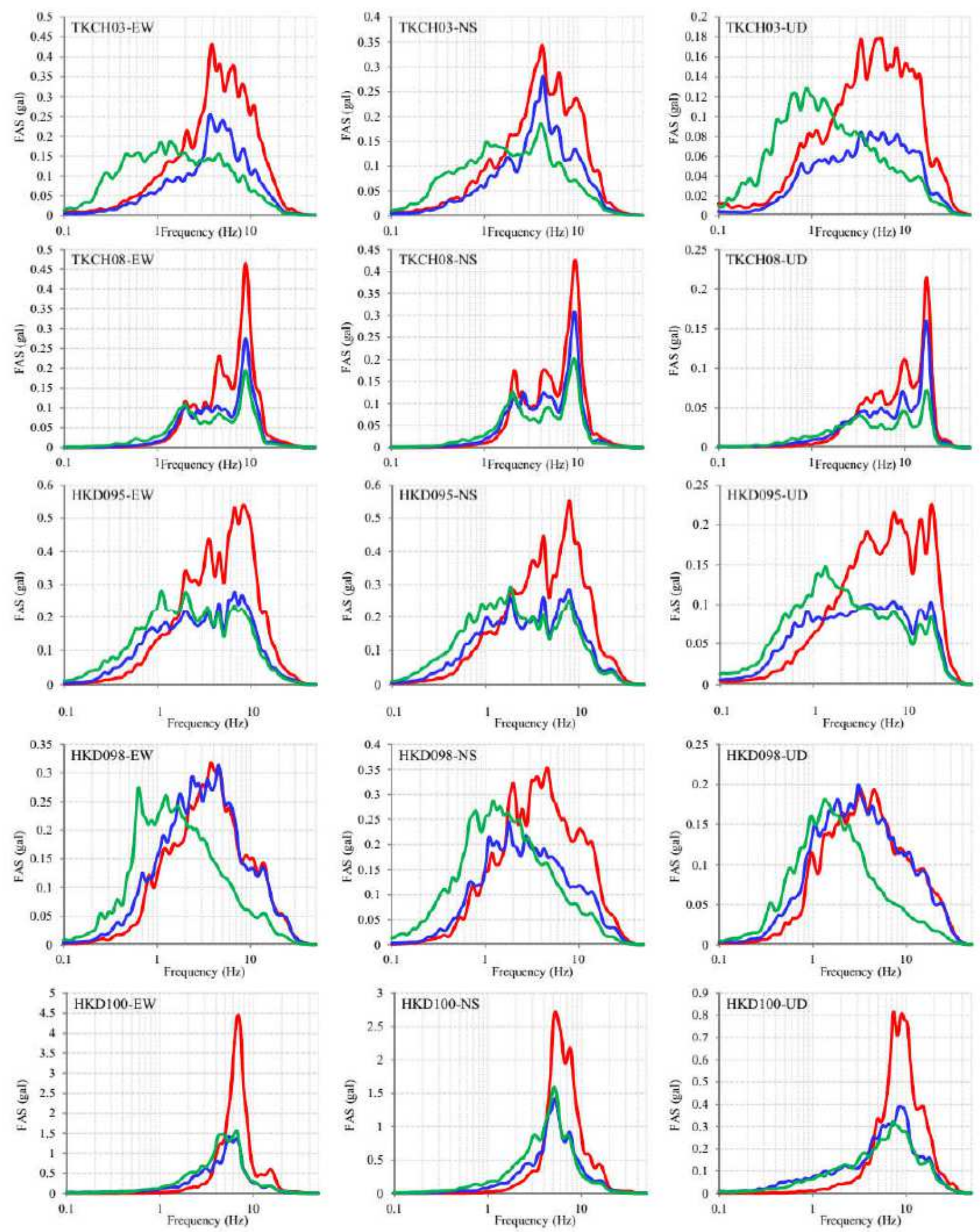

Figure 13

FASs at seismic stations located on FZ in the East Hokkaido study area due to recorded EFWs (blue), EFZs (red), and EHWs (green). 

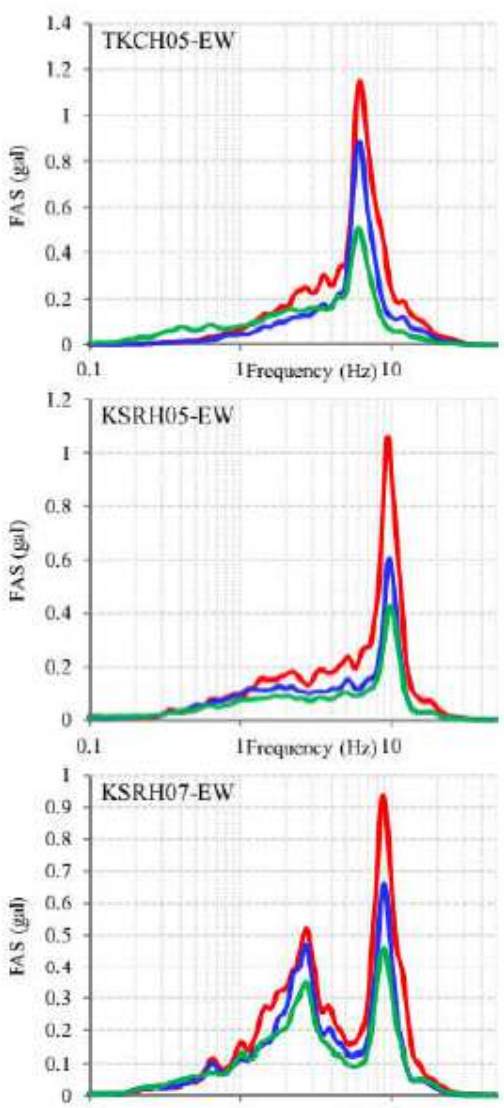

$0.1 \quad$ Itrequency $(\mathrm{Hz}) 10$
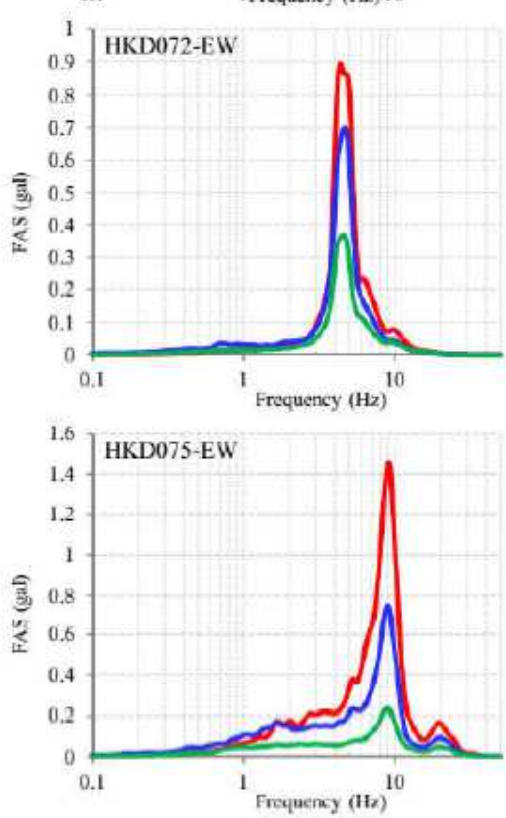
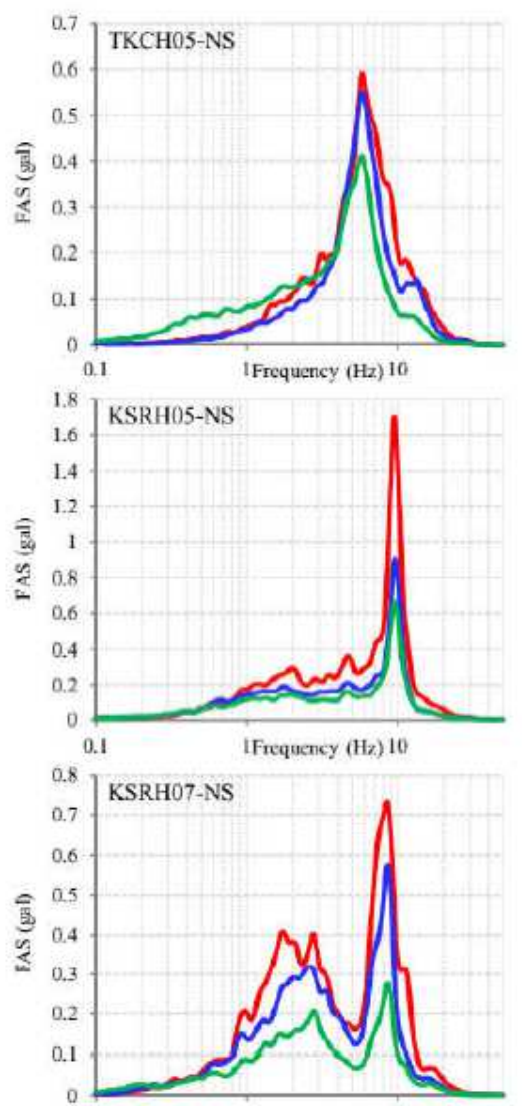

$0.1 \quad$ "1 requency $(\mathrm{Hz}) 10$
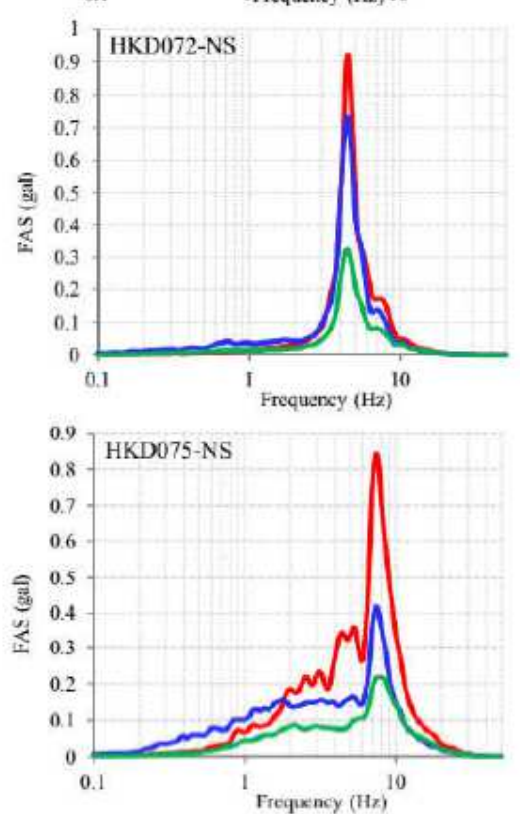
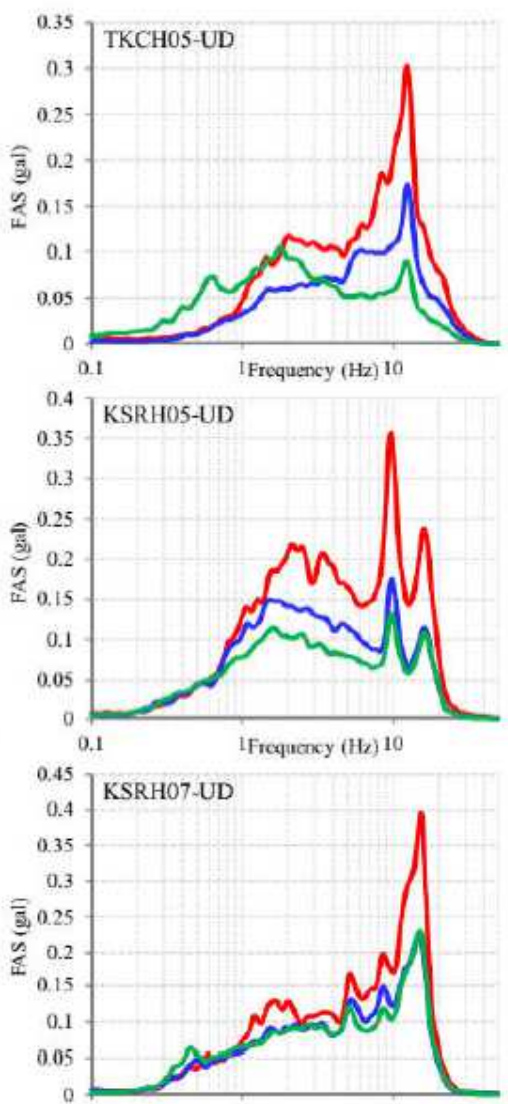

U.1 Ifrequency $(\mathrm{Hz})$ iv
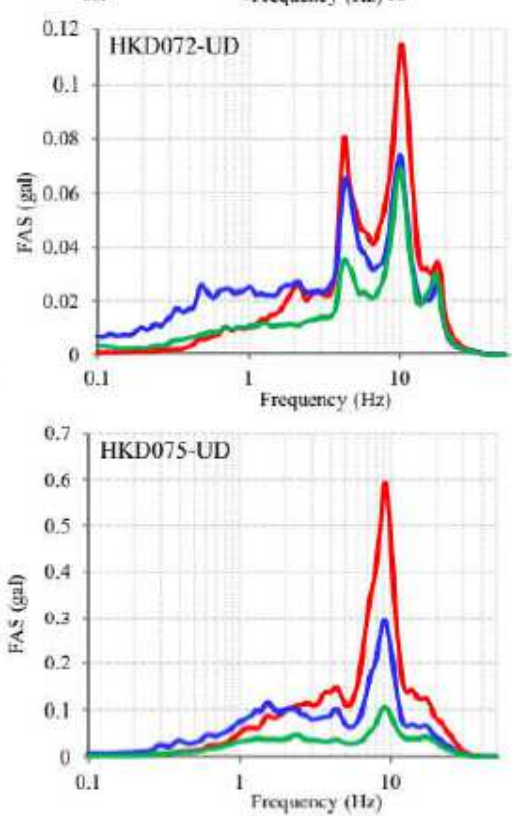

\section{Figure 14}

FASs at seismic stations located on HW block in the East Hokkaido study area due to recorded EFWs (blue), EFZs (red), and EHWs (green). 

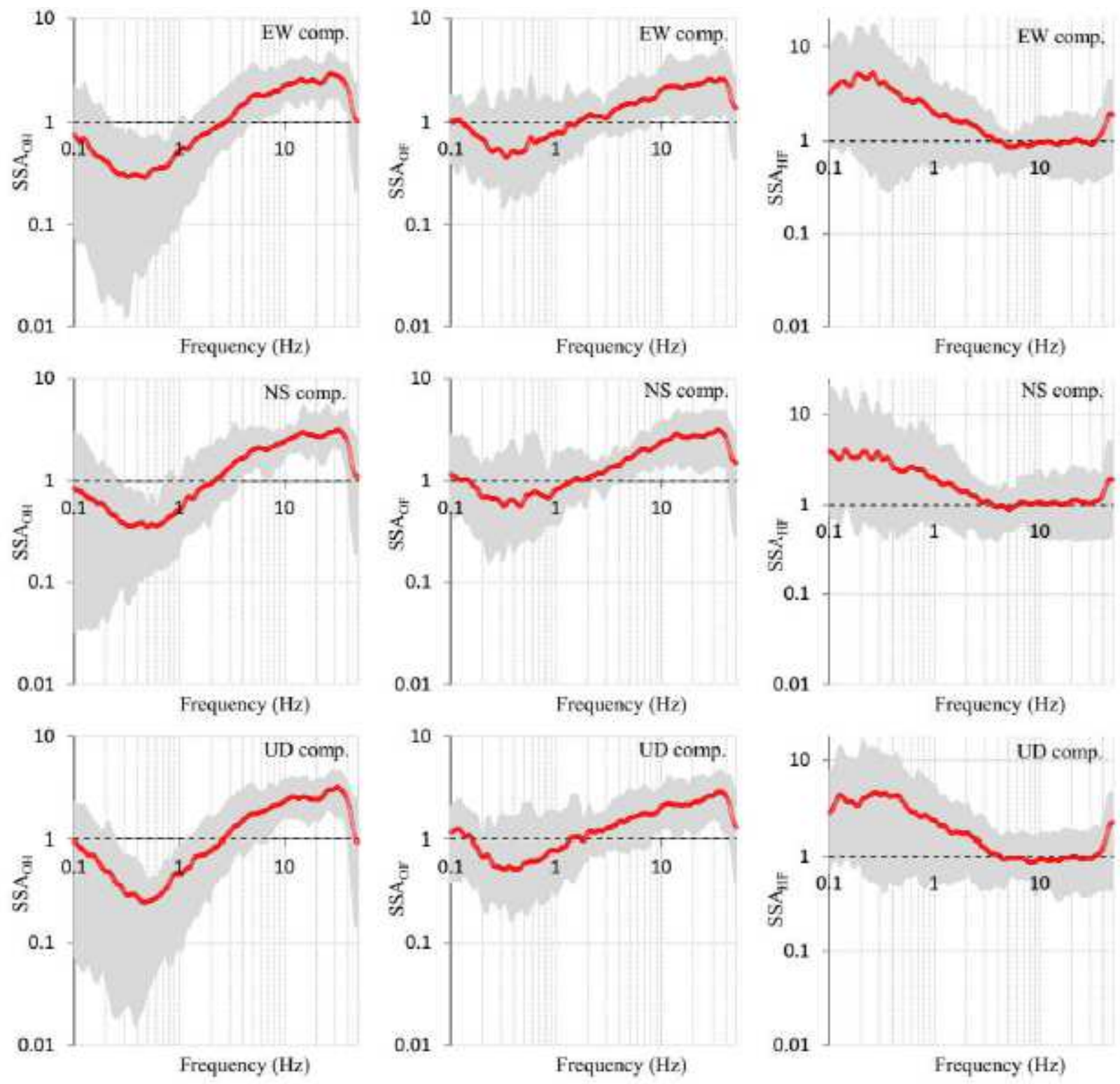

\section{Figure 15}

The estimated average SSAs (red) with their minimum and maximum (gray), which are calculated based on equations 1, 2, and 3 for the seismic stations located on the FW block in East Hokkaido study area. 

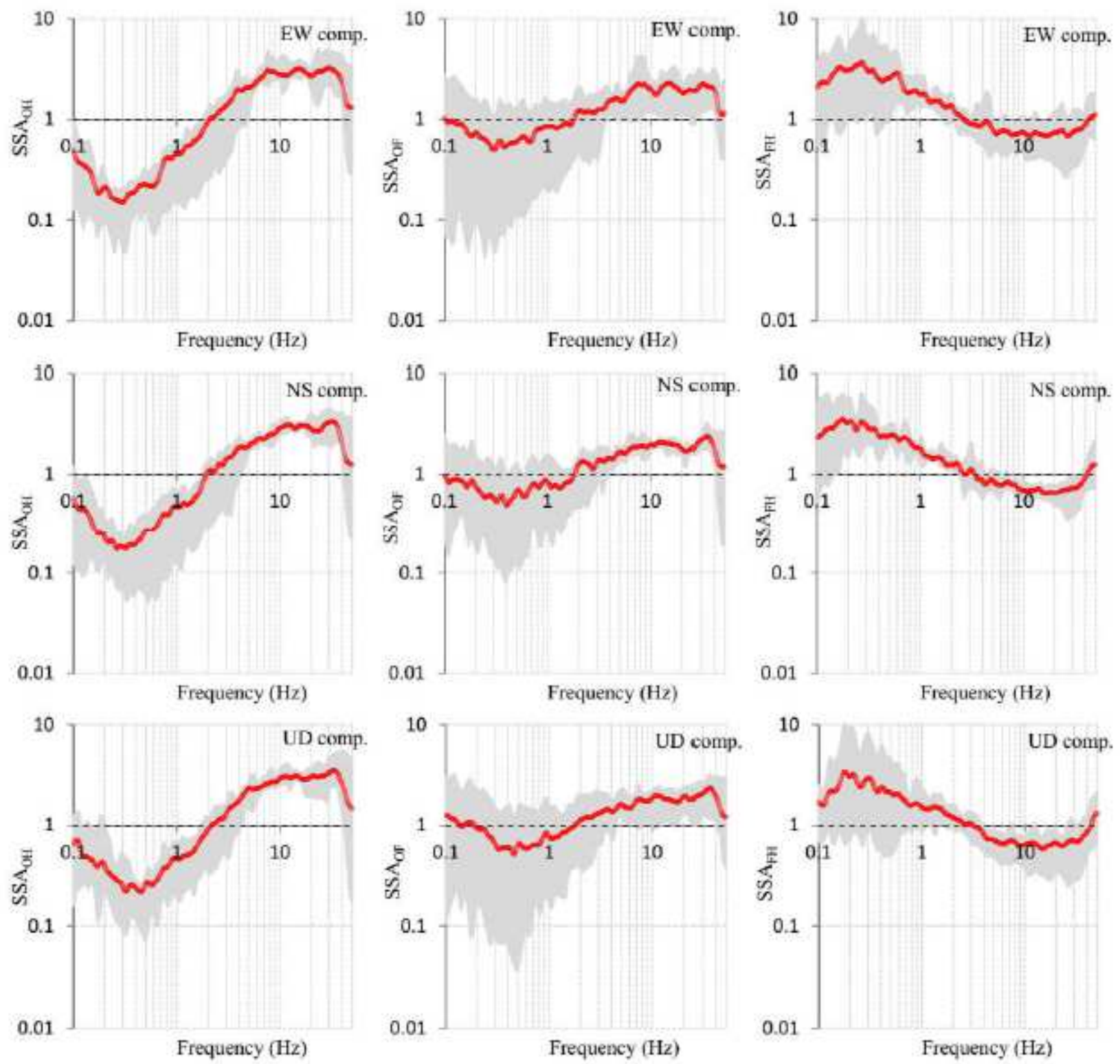

Figure 16

The estimated average SSAs (red) with their minimum and maximum (gray), which are calculated based on equations 1, 2, and 4 for the seismic stations located on the FZ in East Hokkaido study area. 

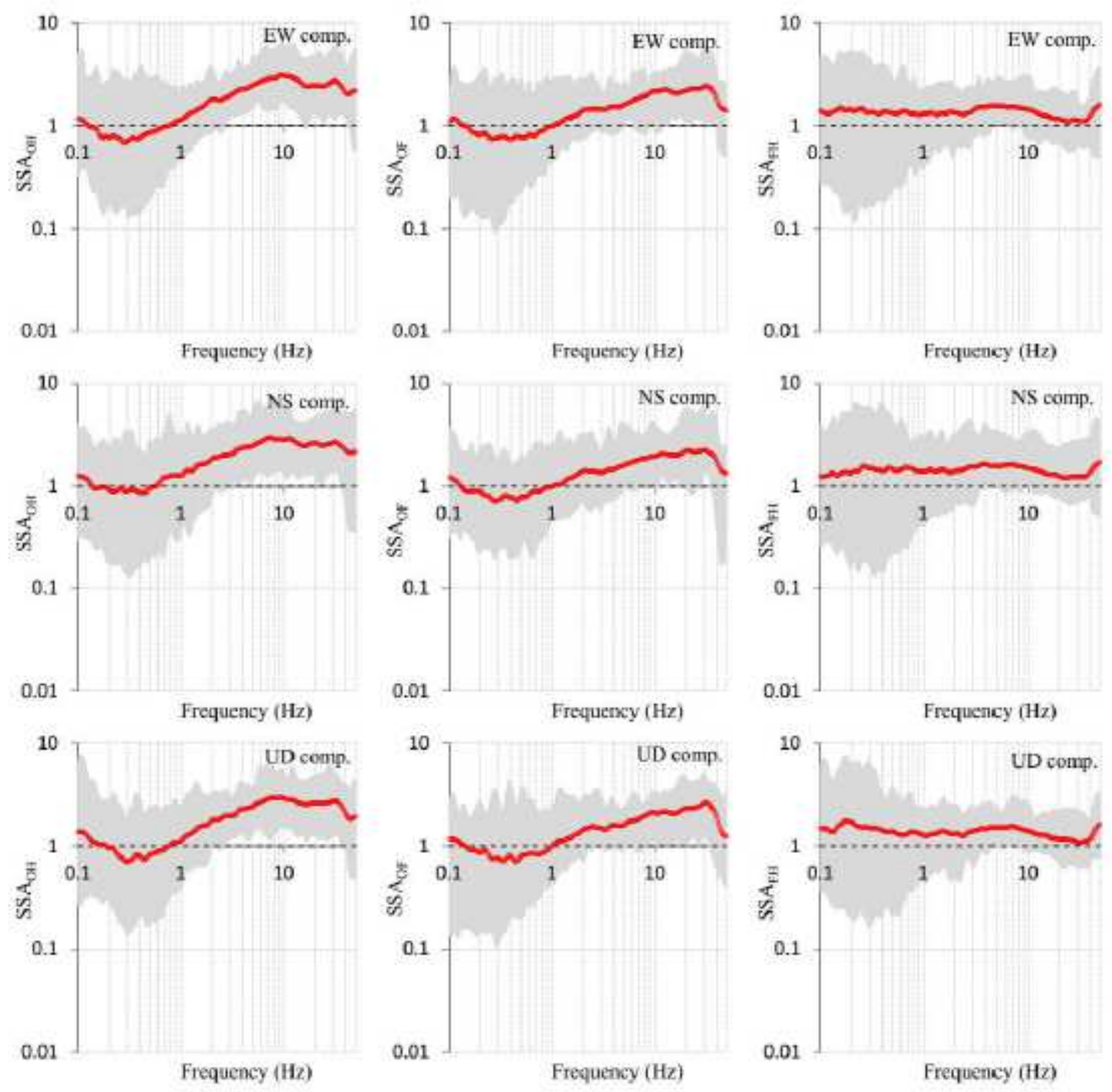

Figure 17

The estimated average SSAs (red) with their minimum and maximum (gray), which are calculated based on equations 1, 2, and 4 for the seismic stations located on the HW block in East Hokkaido study area. 

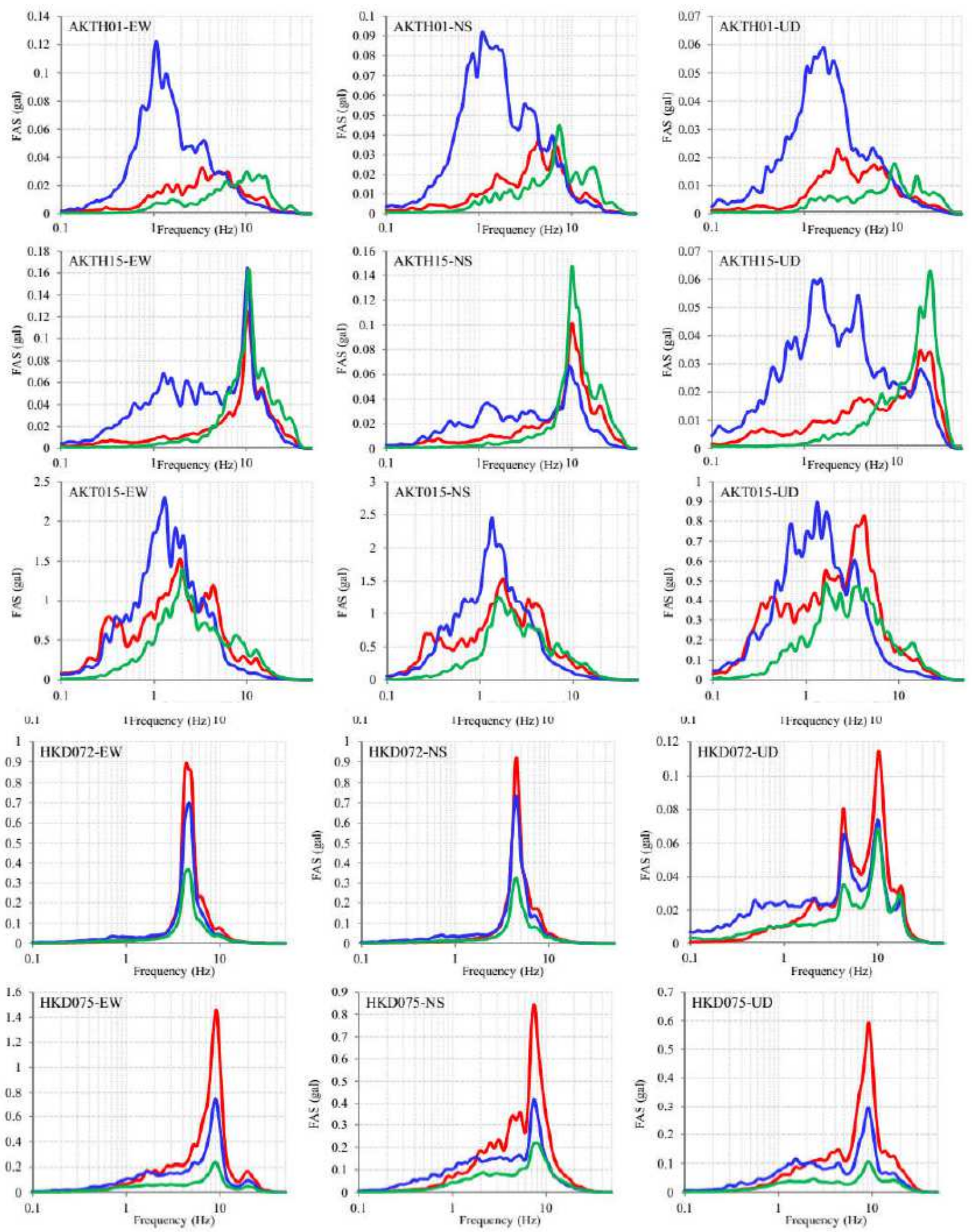

\section{Figure 18}

FASs at seismic stations located on I.FW block in Akita-Iwate study area due to recorded El.FWs (green), EFZs (red), and Er.FWs (blue). 

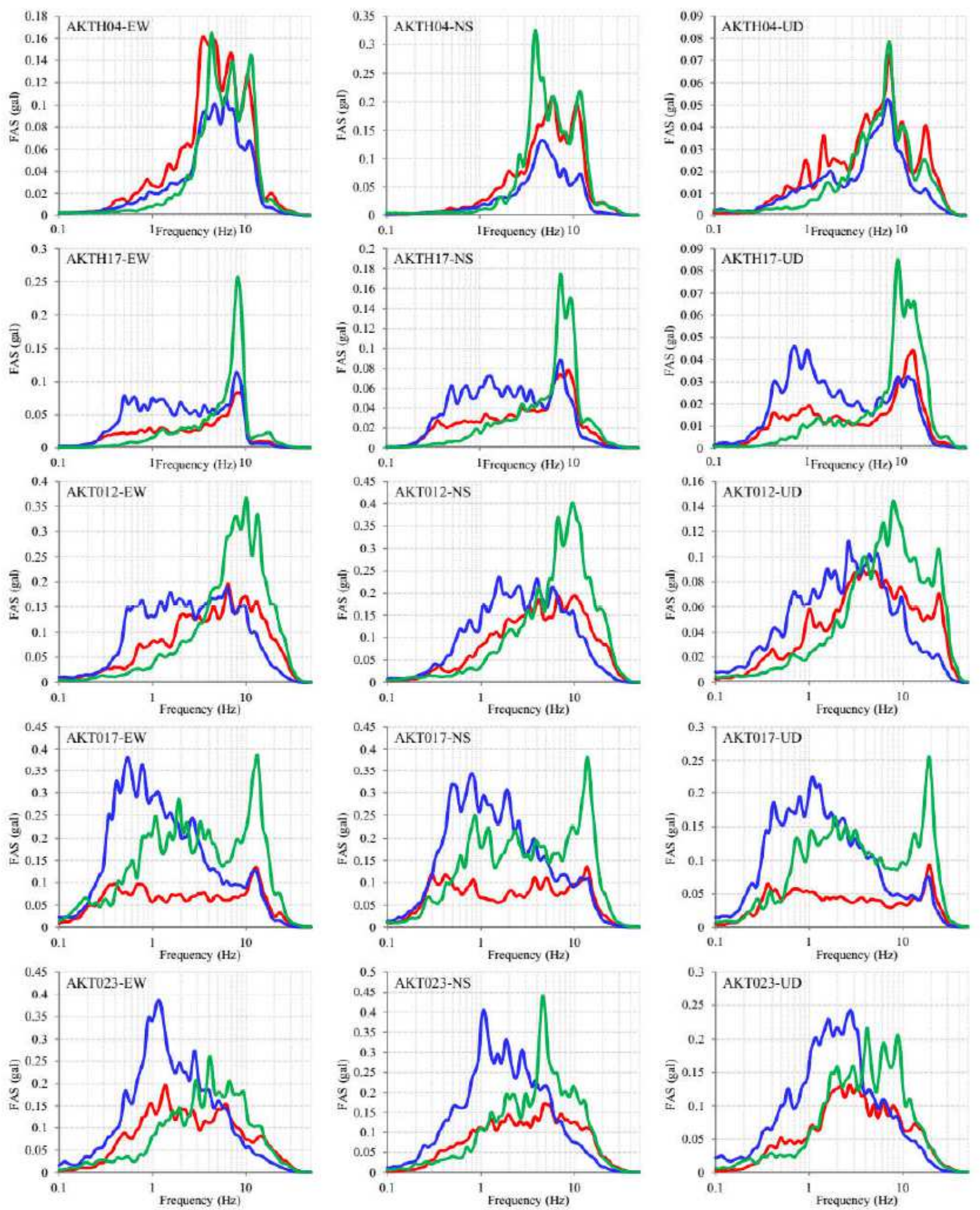

Figure 19

FASs at seismic stations located on FZ in Akita-Iwate study area due to recorded El.FWs (green), EFZs (red), and Er.FWs (blue). 

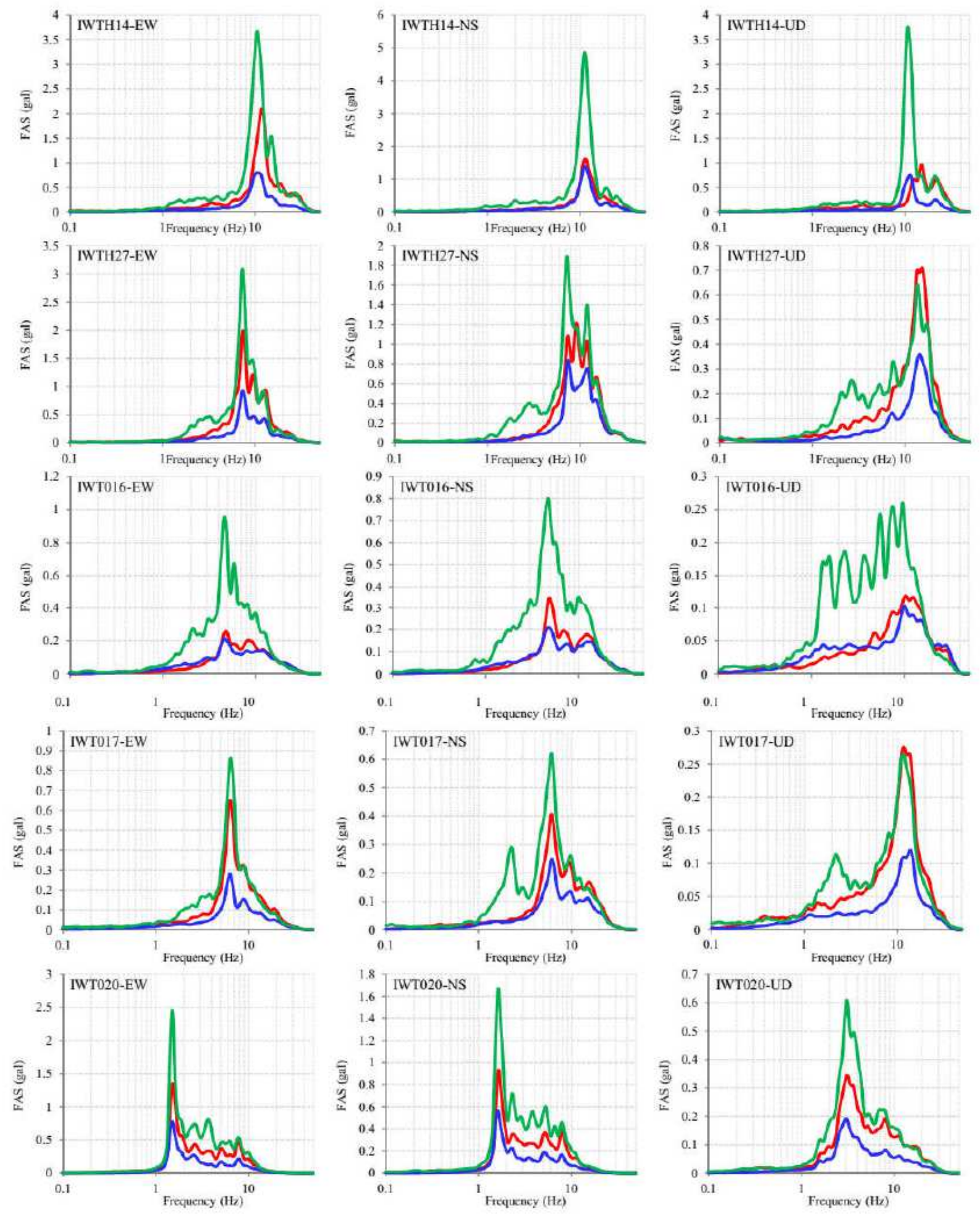

\section{Figure 20}

FASs at seismic stations located on r.FW block in Akita-Iwate study area due to recorded El.FWs (green), EFZs (red), and Er.FWs (blue). 

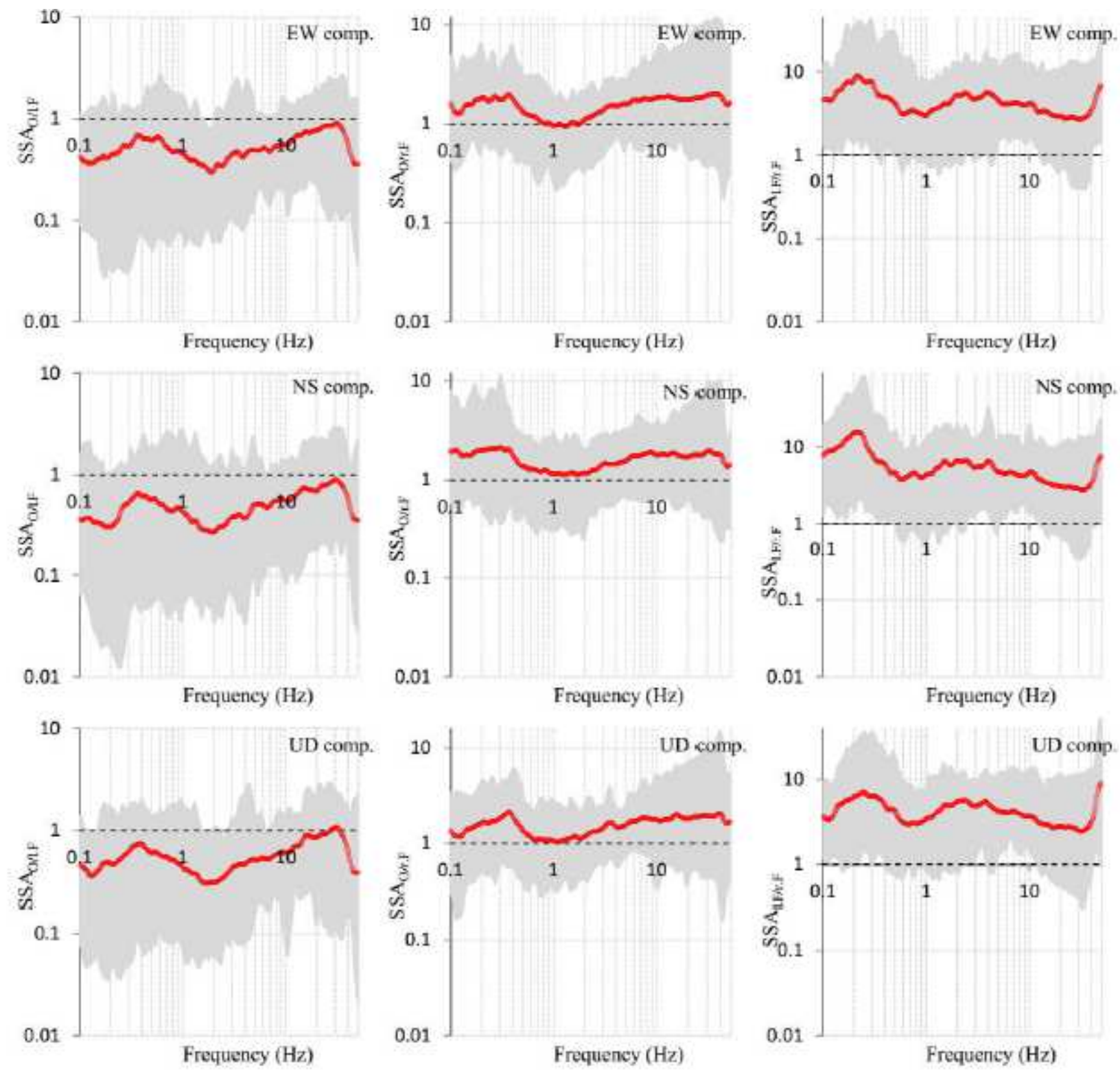

\section{Figure 21}

The estimated average SSAs (red) with their minimum and maximum (gray), which are calculated based on equations 1, 2, and 3 for the seismic stations located on the r.FW block in Akita-Iwate study area. 

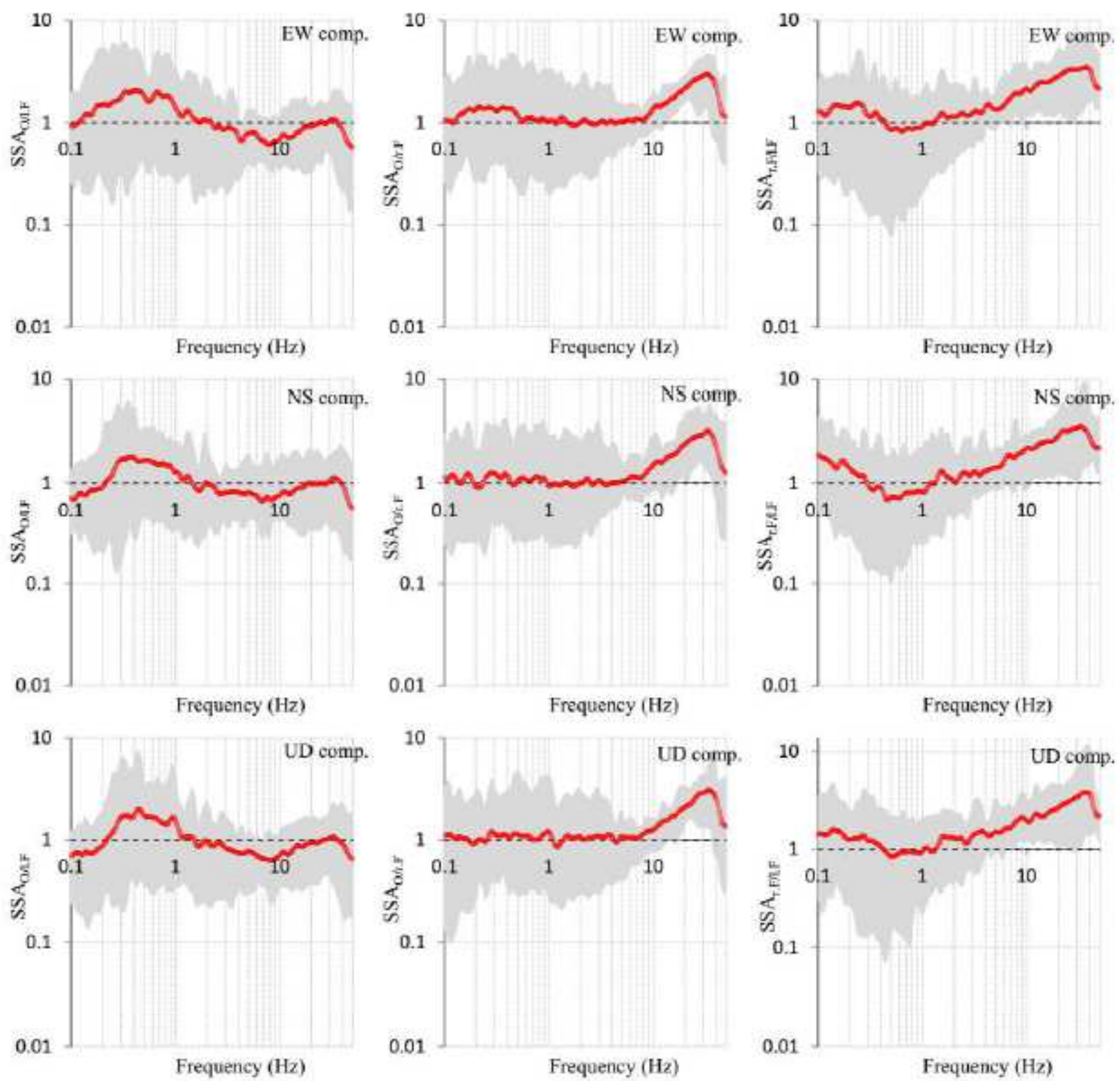

Figure 22

The estimated average SSAs (red) with their minimum and maximum (gray), which are calculated based on equations 1, 2, and 4 for the seismic stations located on the FZ in Akita-Iwate study area. 


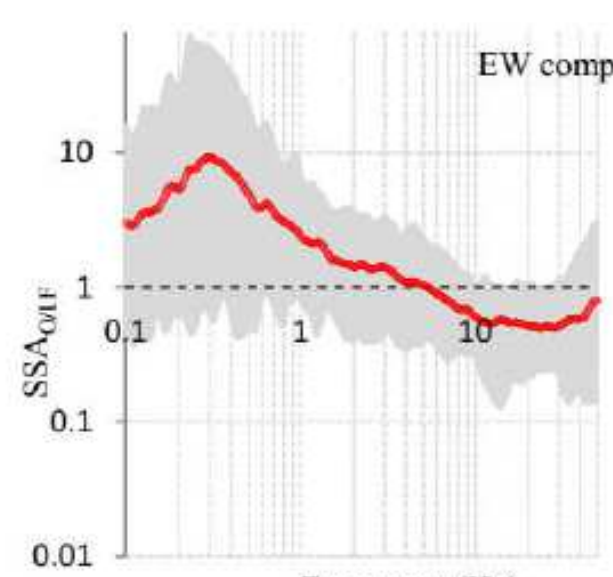

Frequency $(\mathrm{Hz})$

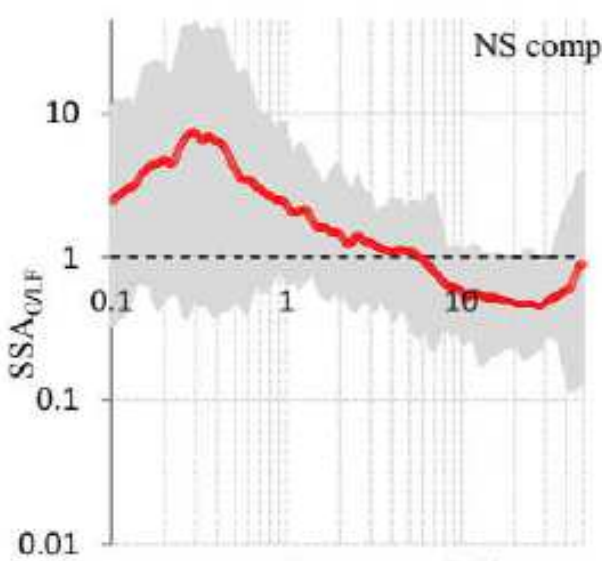

Frequency (Hz)

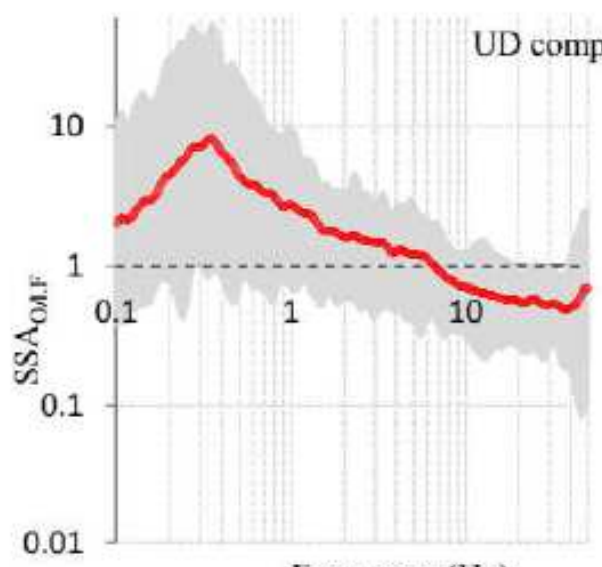

Frequency $(\mathrm{Hz})$

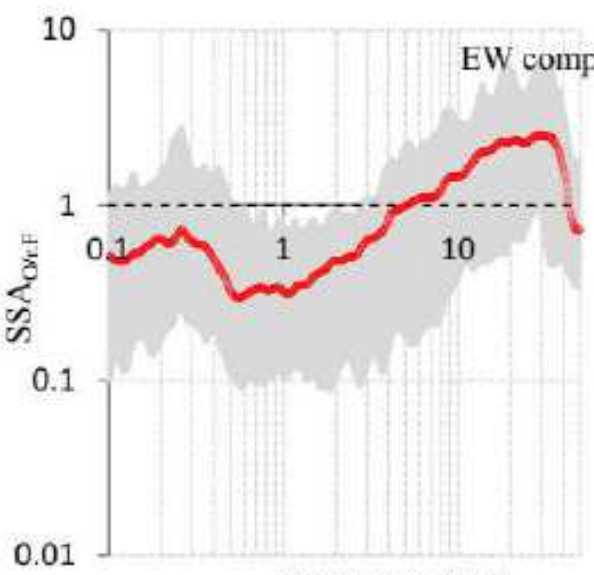

Frequency $(\mathrm{Hz})$

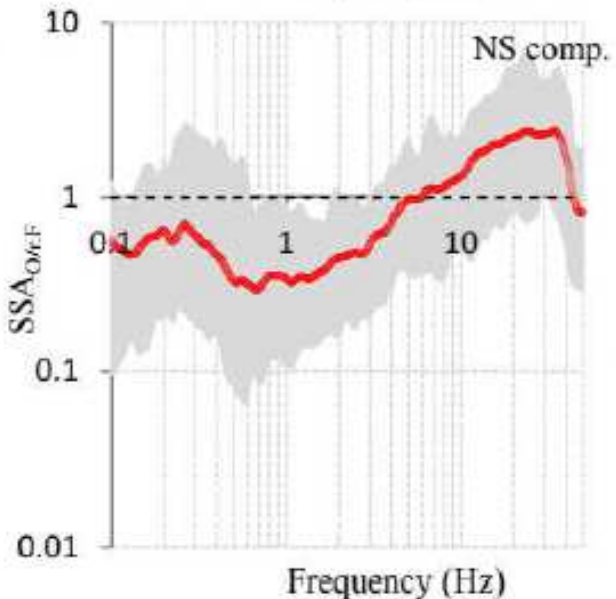

Frequency $(\mathrm{Hz})$

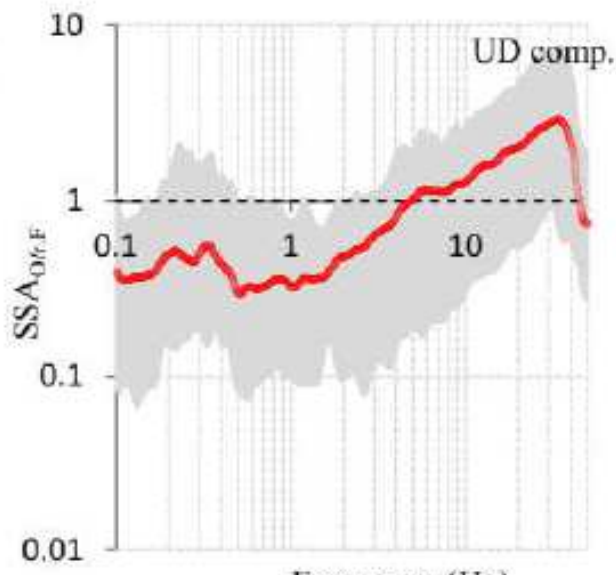

Frequency $(\mathrm{Hz})$

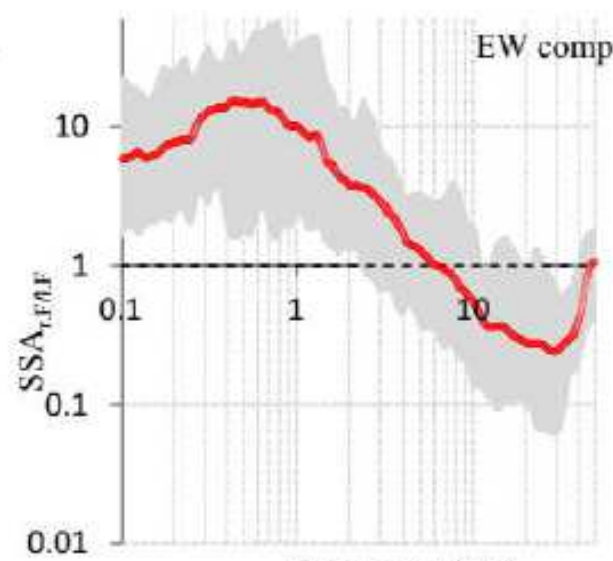

Frequency $(\mathrm{Hz})$

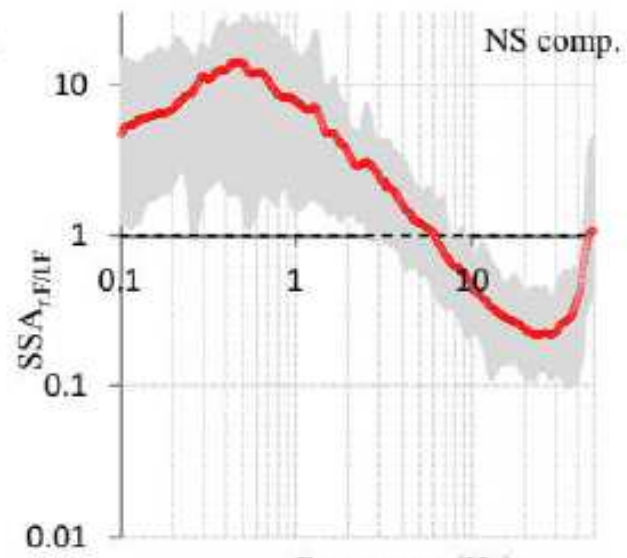

Frequency $(\mathrm{Hz})$

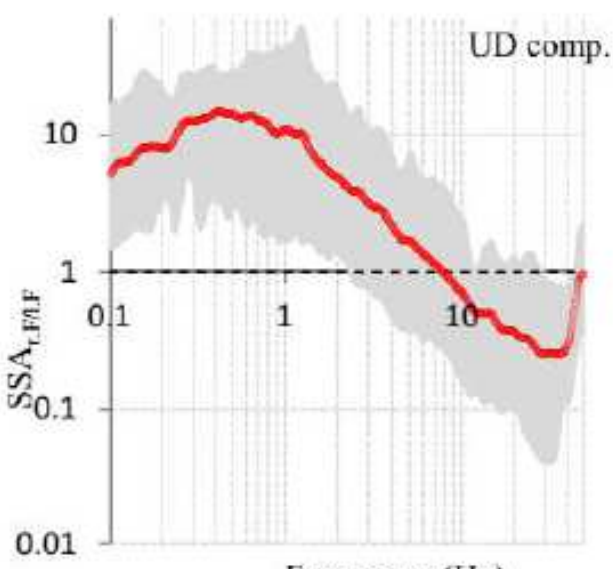

Frequency $(\mathrm{Hz})$

\section{Figure 23}

The estimated average SSAs (red) with their minimum and maximum (gray), which are calculated based on equations 1, 2, and 4 for the seismic stations located on the I.FW block in Akita-Iwate study area. 

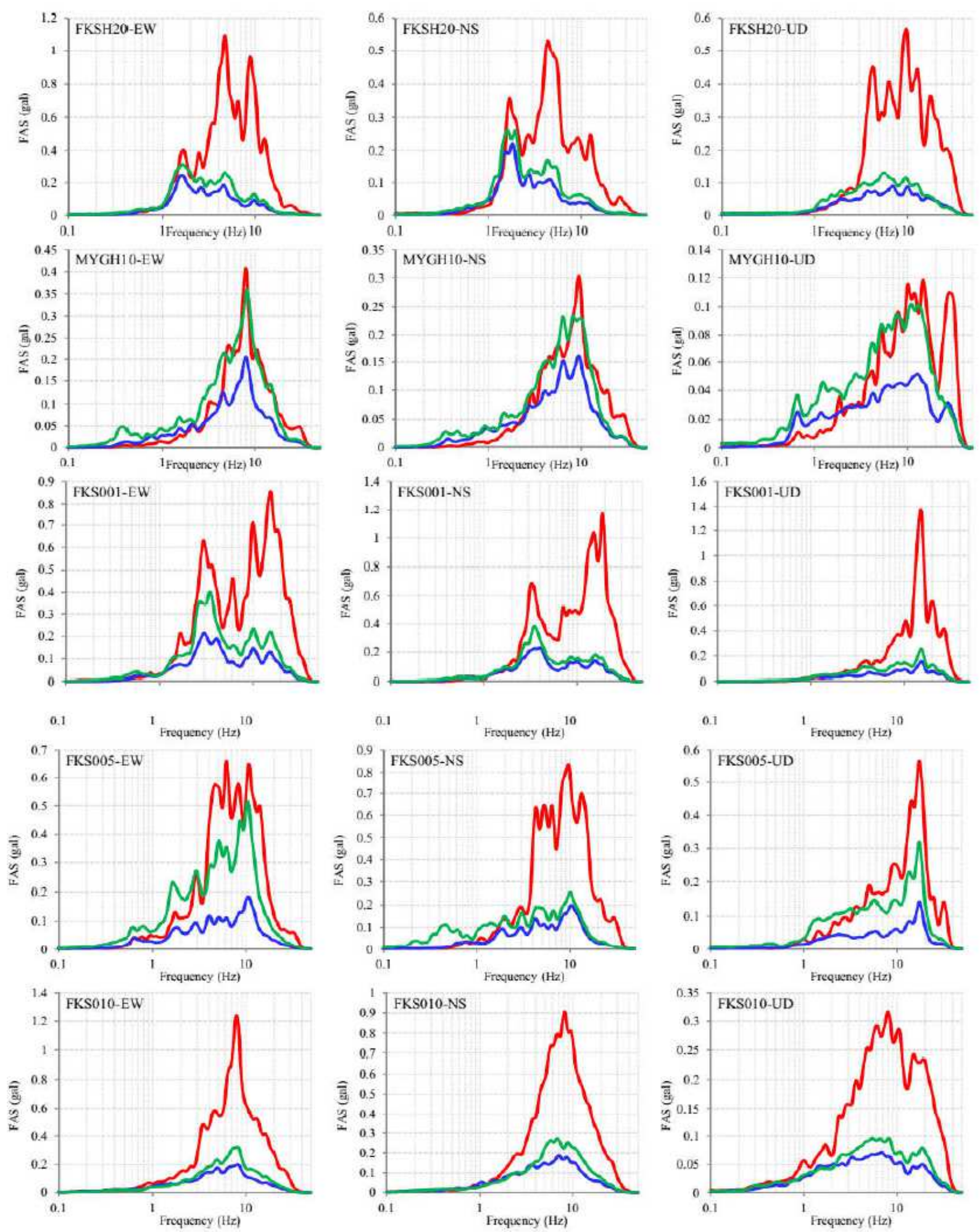

Figure 24

FASs at seismic stations located on FW block in Fukushima study area due to recorded EFWs (blue), EFZs (red), and EHWs (green). 

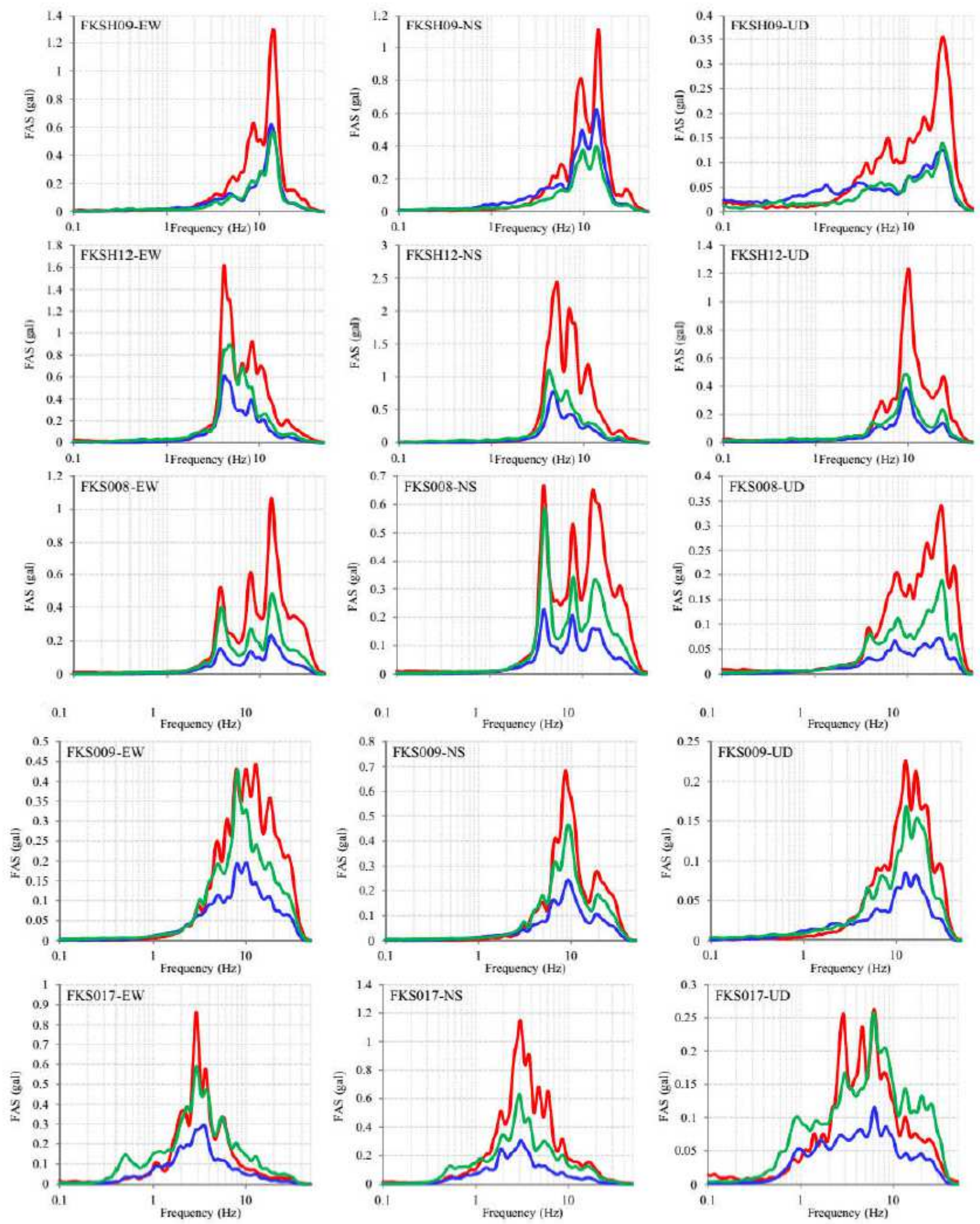

\section{Figure 25}

FASs at seismic stations located on HW block in Fukushima study area due to recorded EFWs (blue), EFZs (red), and EHWs (green). 

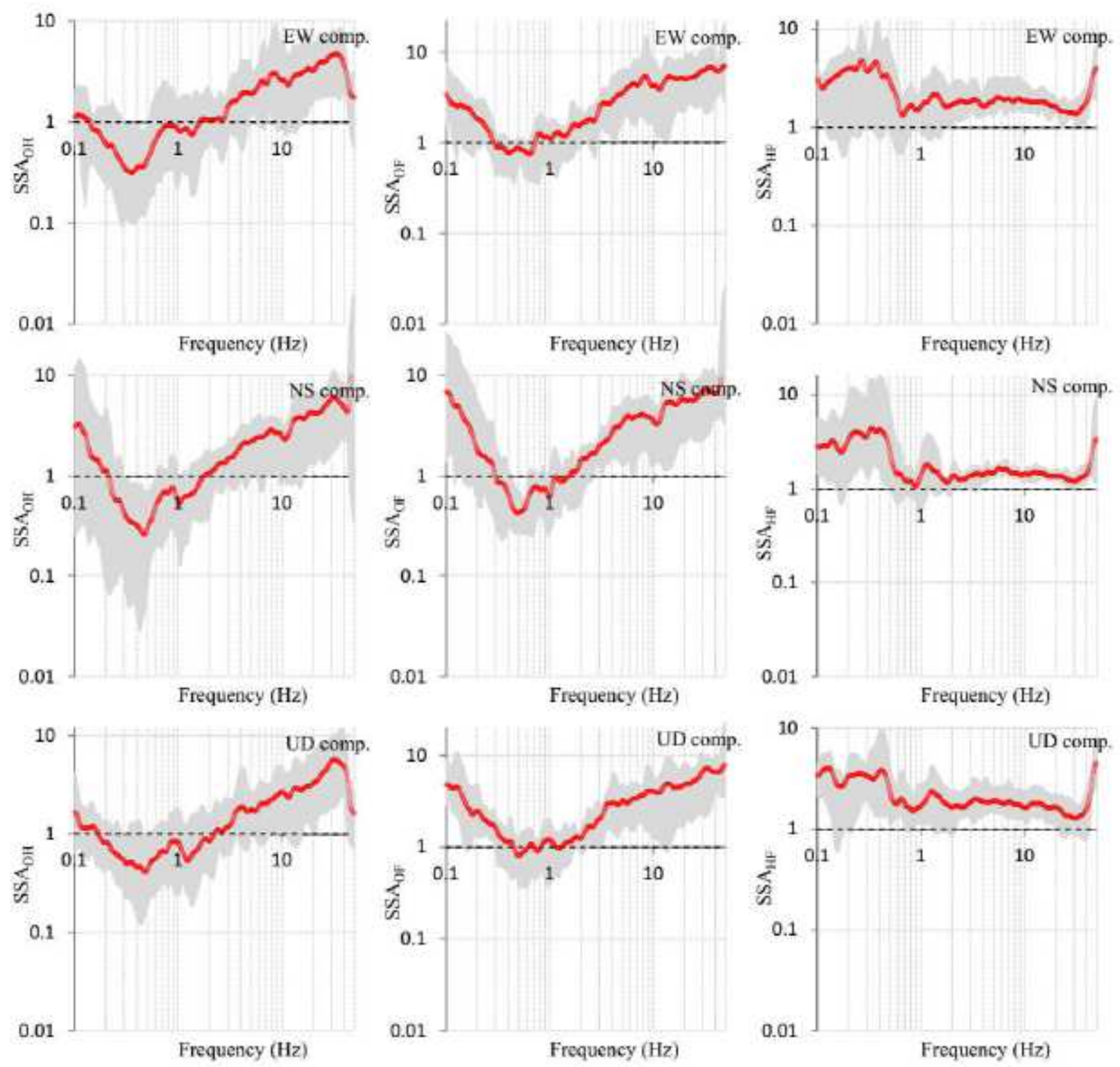

\section{Figure 26}

The estimated average SSAs (red) with their minimum and maximum (gray), which are calculated based on equations 1, 2, and 3 for the seismic stations located on the FW block in Fukushima study area. 

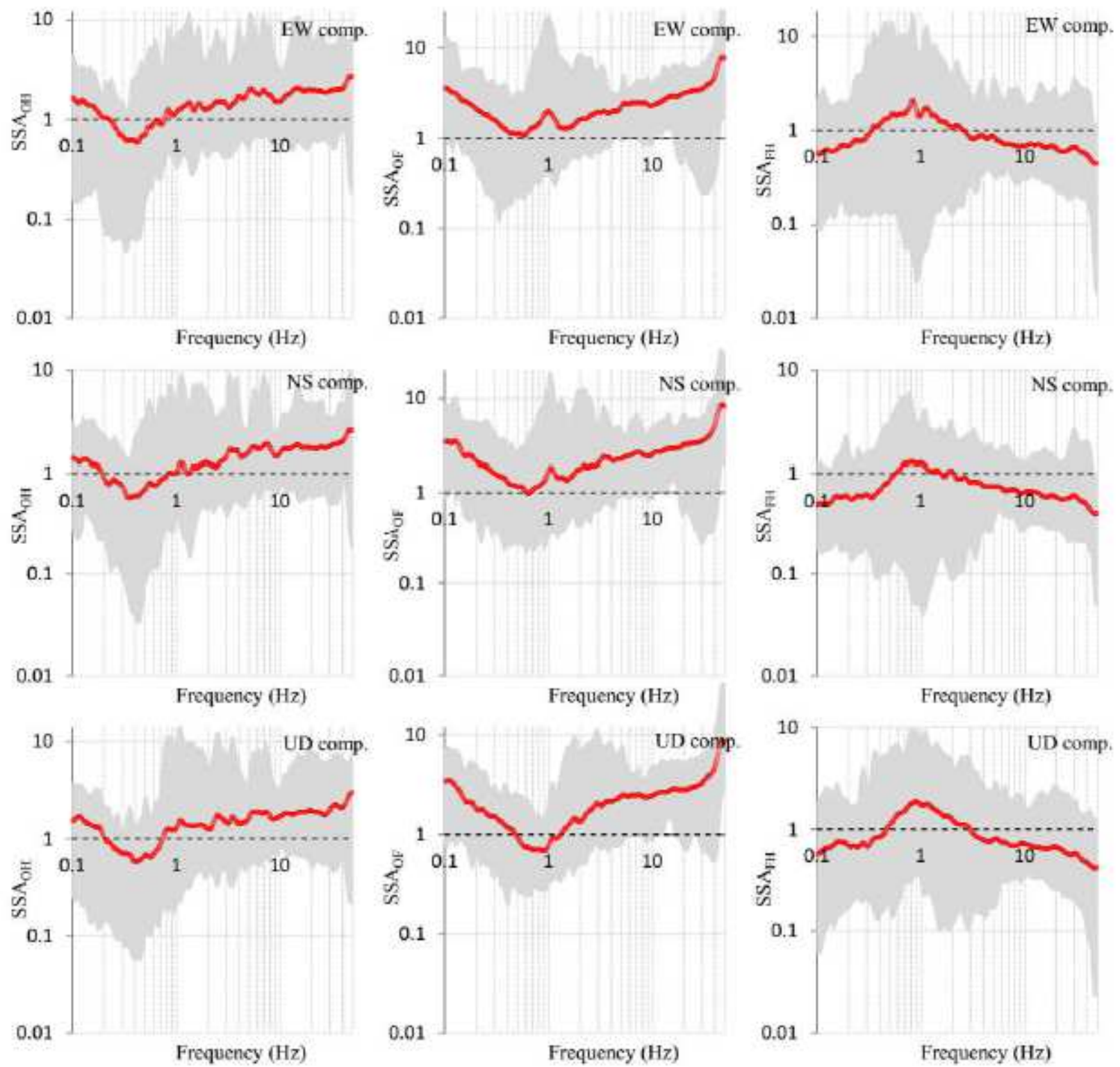

Figure 27

The estimated average SSAs (red) with their minimum and maximum (gray), which are calculated based on equations 1, 2, and 4 for the seismic stations located on the HW block in Fukushima study area. 

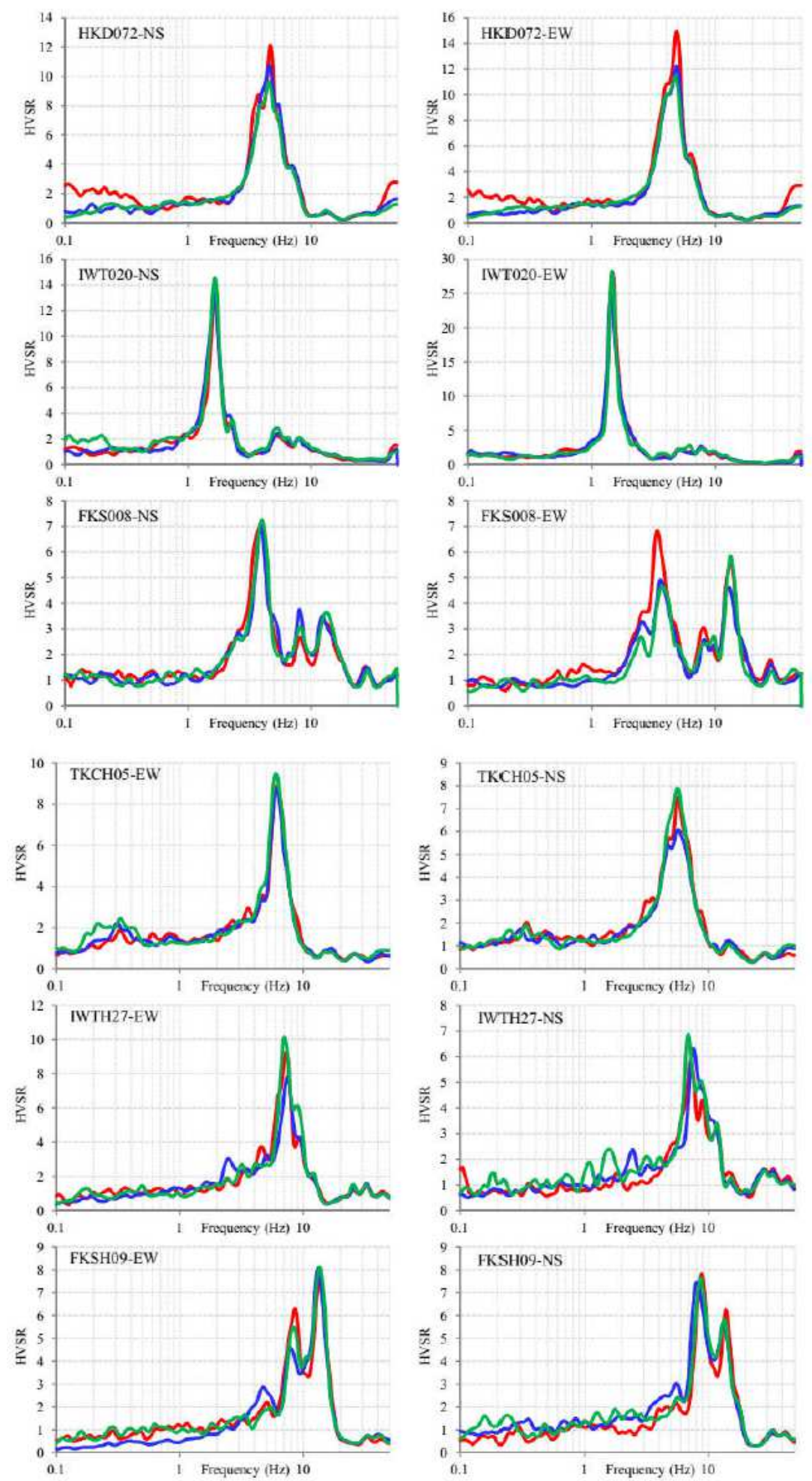

\section{Figure 28}

Examples of HVSRs at the three different study areas due to recorded EFWs or Er.FWs in Akita-Iwate area (blue), EFZs (red), EHWs or El.FWs in Akita-Iwate area (green). 

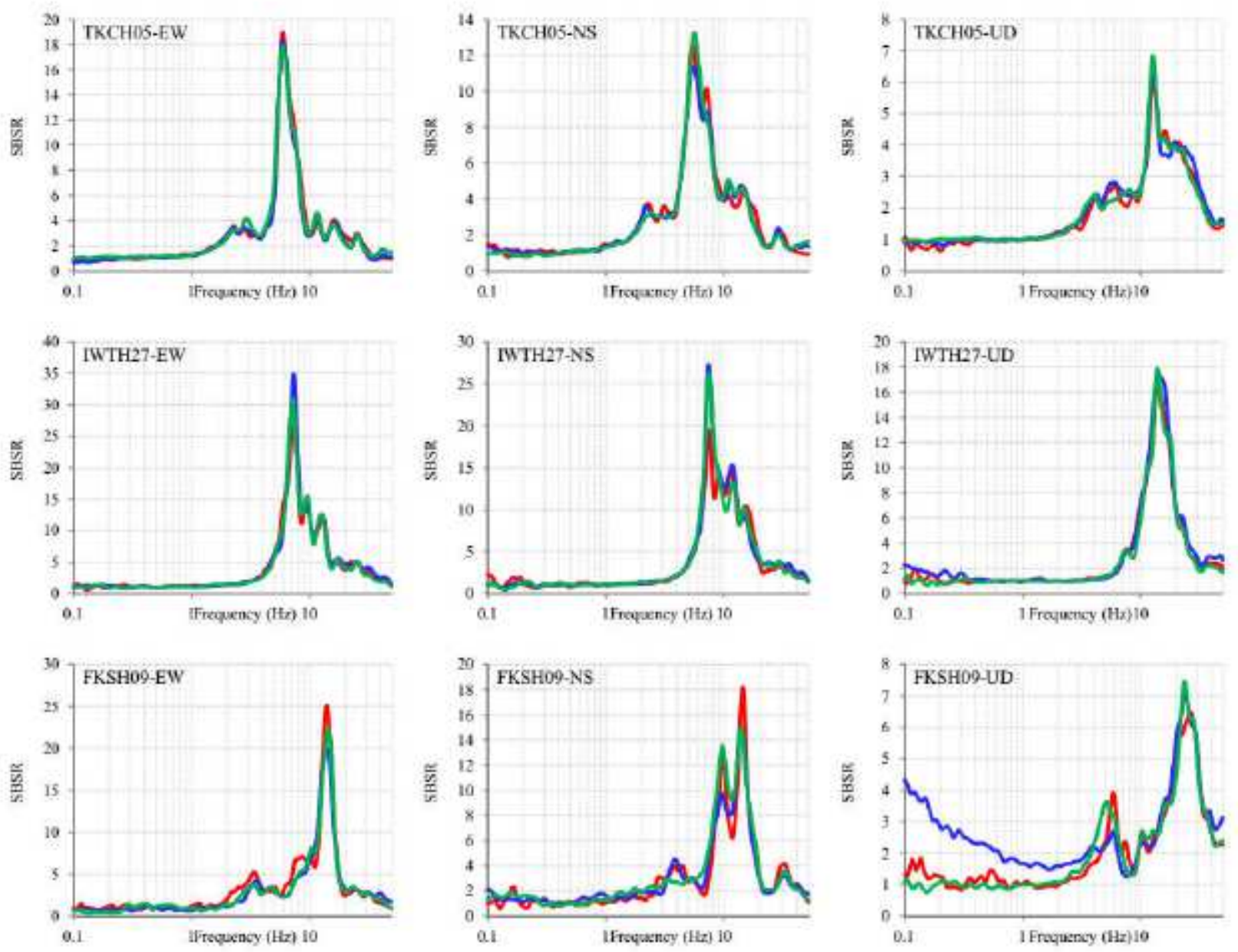

Figure 29

Examples of SBSRs at the three different study areas due to recorded EFWs or Er.FWs in Akita-Iwate area (blue), EFZs (red), EHWs or El.FWs in Akita-Iwate area (green). 


\section{(a)}

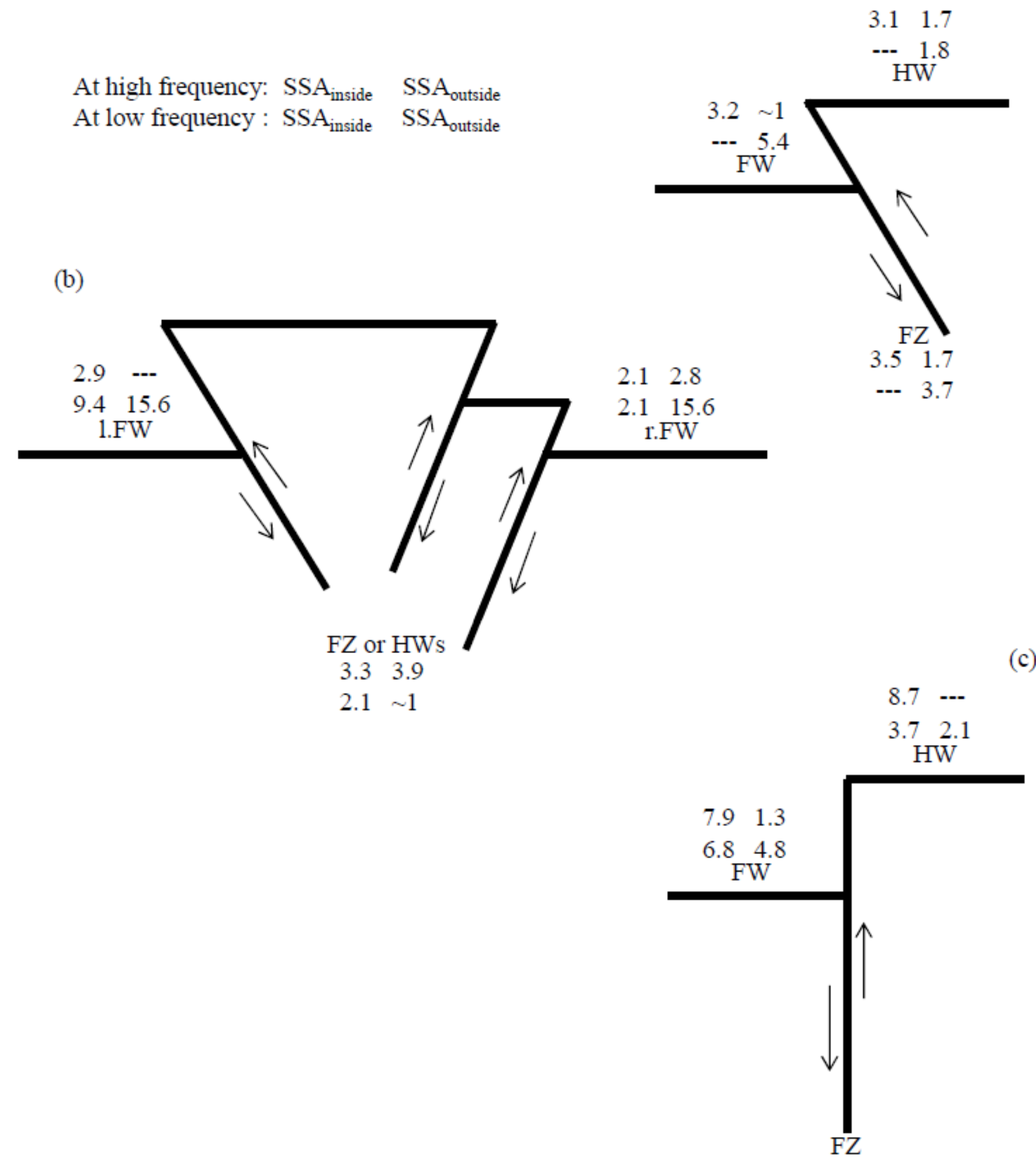

\section{Figure 30}

Schematic representations of active fault zones for the three present case studies. (a) East Hokkaido area, (b) Akita-Iwate area, and (c) Fukushima area. (SSAinside and SSAoutside are the maximum of averages of SSA (refer to Tables 5,6 , and 7) due to sources inside and outside the active fault zones, respectively.) 

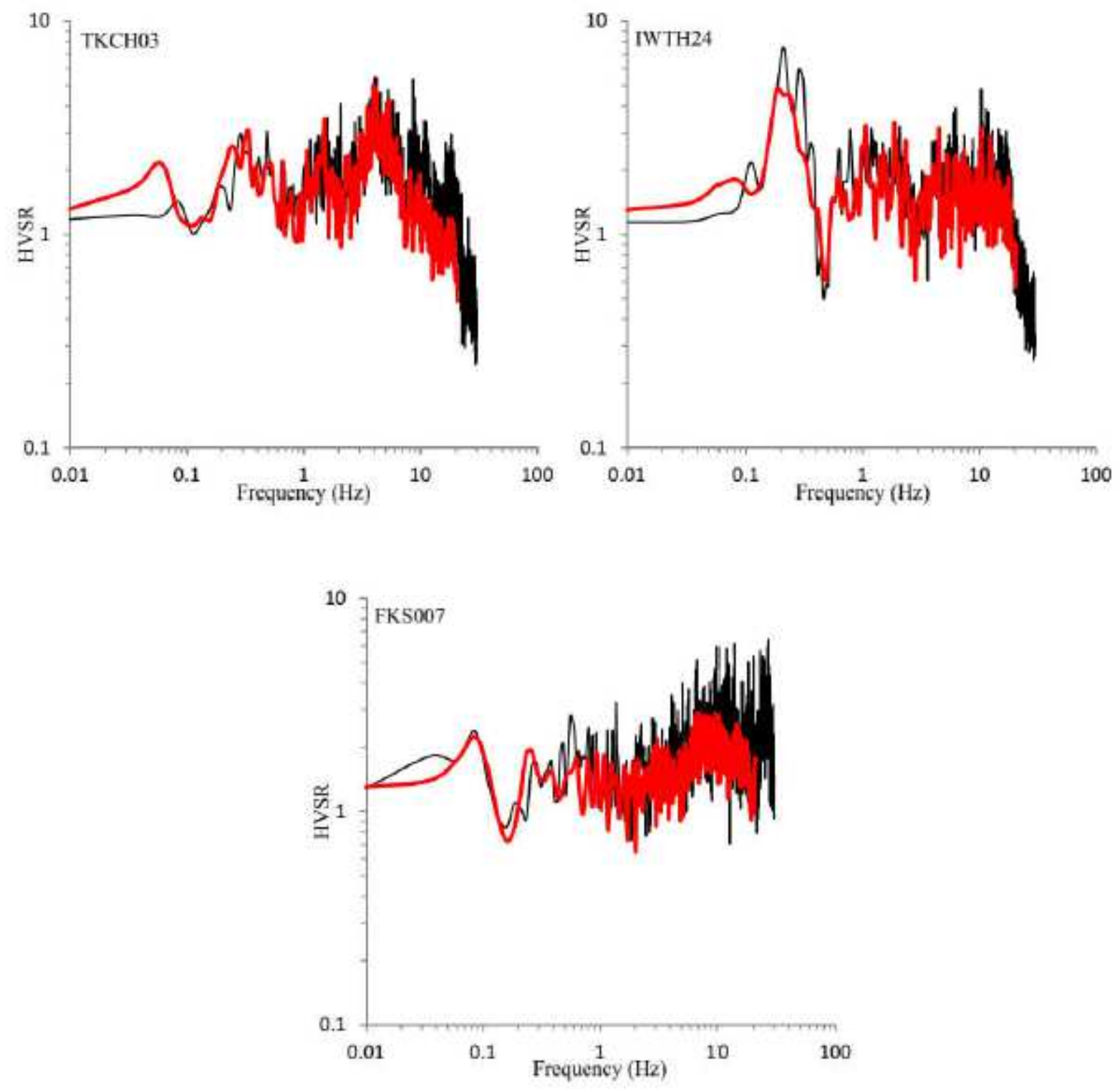

Figure 31

Examples of inverted EHVSRs (red) superimposed with observed HVSRs (black) at three seismic stations on fault zones of the present study. 

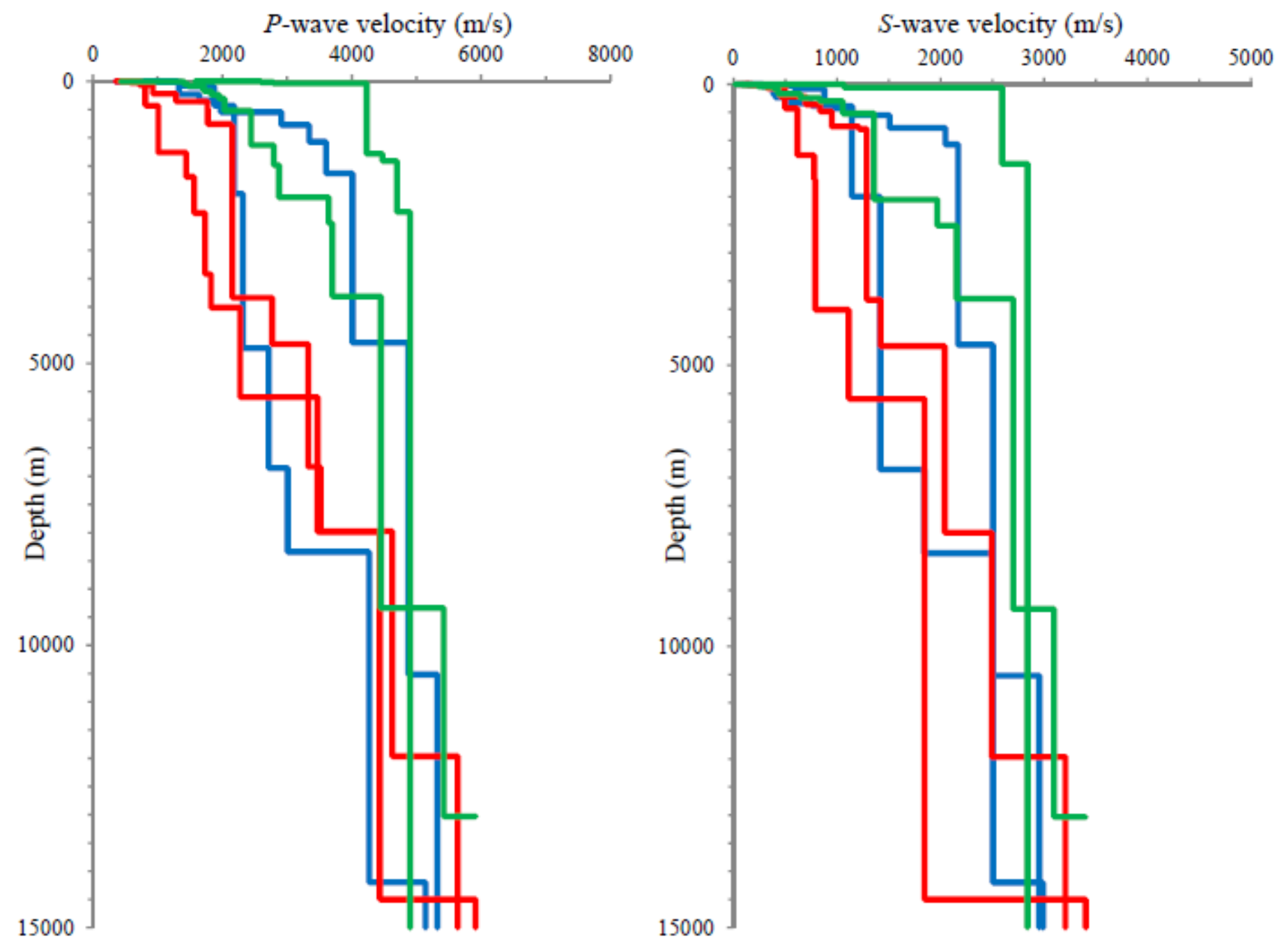

Figure 32

Inverted velocity structures in the East Hokkaido study area beneath stations on FW (blue), FZ (red), and HW (green). 


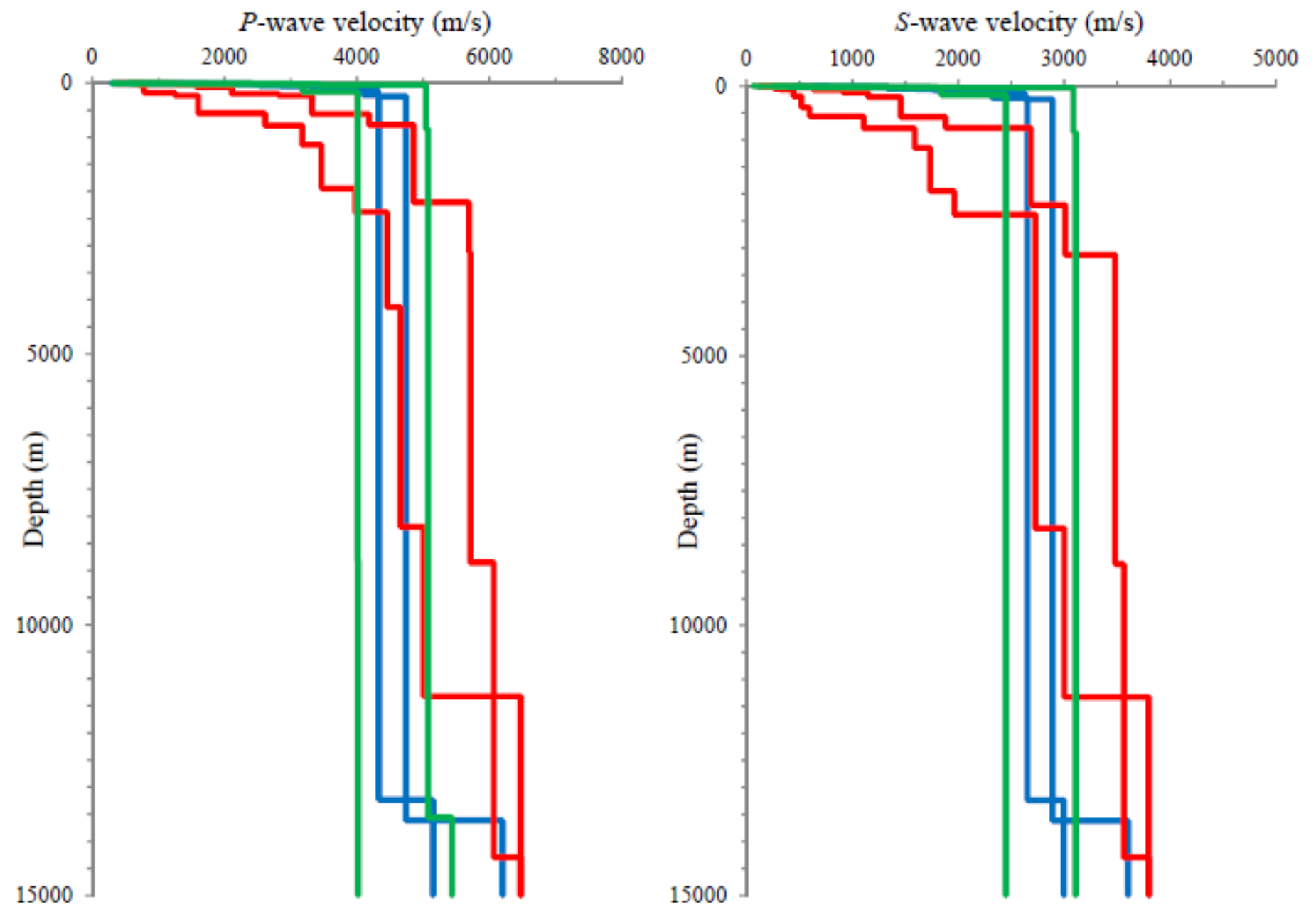

Figure 33

Inverted velocity structures in the Akita-Iwate study area beneath stations on r.FW (blue), FZ (red), and I.FW (green). 


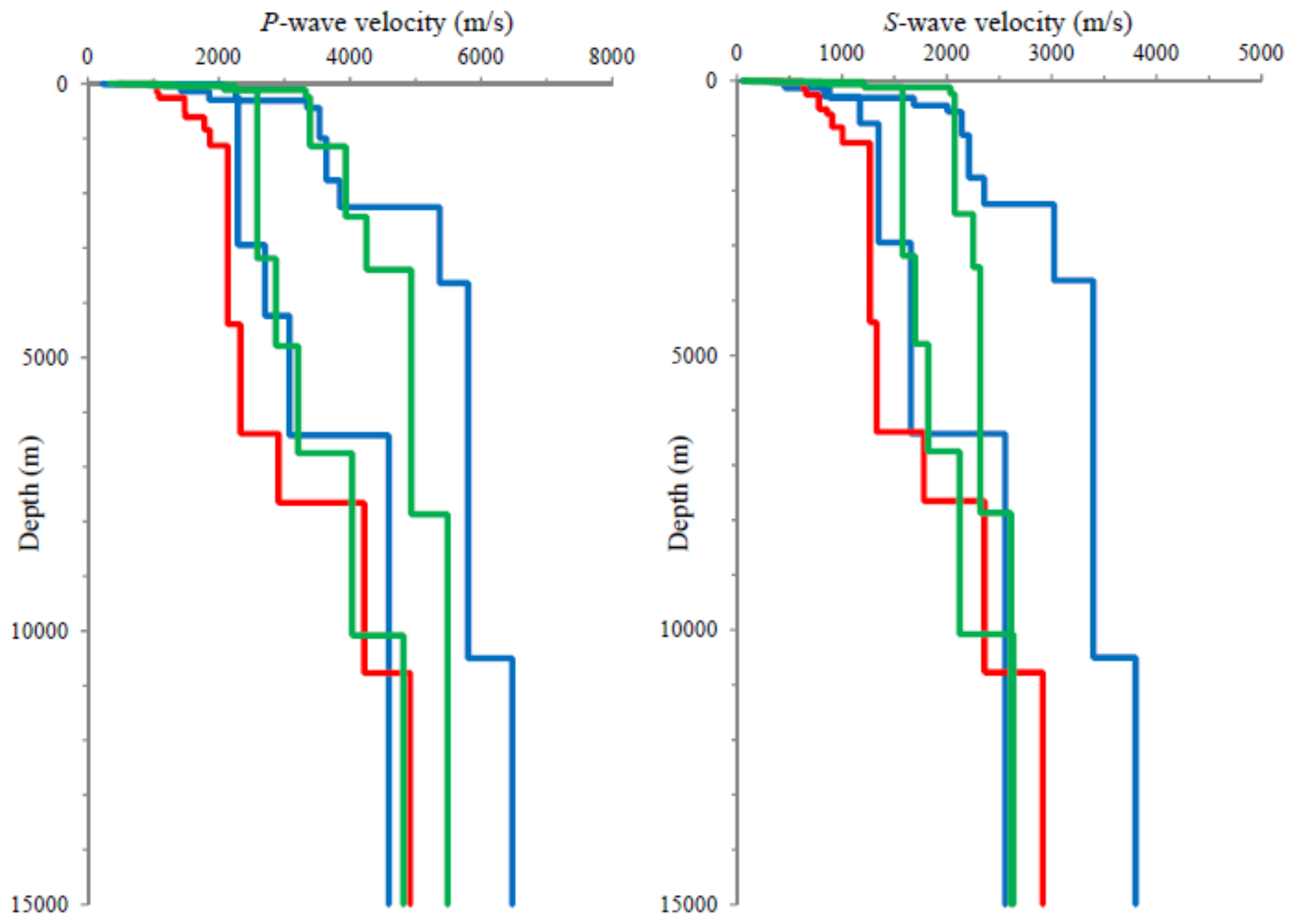

Figure 34

Inverted velocity structures in the Fukushima study area beneath stations on FW (blue), the closest to FZ (red), and HW (green). 